The Las Vegas Valley Seismic Response Project: Ground Motions in Las Vegas Valley from Nuclear Explosions at the Nevada Test Site

A. Rodgers, H. Tkalcic, D. McCallen

March 23, 2005 
This document was prepared as an account of work sponsored by an agency of the United States Government. Neither the United States Government nor the University of California nor any of their employees, makes any warranty, express or implied, or assumes any legal liability or responsibility for the accuracy, completeness, or usefulness of any information, apparatus, product, or process disclosed, or represents that its use would not infringe privately owned rights. Reference herein to any specific commercial product, process, or service by trade name, trademark, manufacturer, or otherwise, does not necessarily constitute or imply its endorsement, recommendation, or favoring by the United States Government or the University of California. The views and opinions of authors expressed herein do not necessarily state or reflect those of the United States Government or the University of California, and shall not be used for advertising or product endorsement purposes.

This work was performed under the auspices of the U.S. Department of Energy by University of California, Lawrence Livermore National Laboratory under Contract W-7405-Eng-48. 


\title{
The Las Vegas Valley Seismic Response Project: \\ Ground Motions in Las Vegas Valley From \\ Nuclear Explosions at the Nevada Test Site
}

\author{
Arthur Rodgers, Hrvoje Tkalcic \\ Earth Sciences Division \\ Energy and Environment Directorate \\ Lawrence Livermore National Laboratory \\ and \\ David McCallen \\ Yucca Mountain and Repository Science Program \\ Energy and Environment Directorate \\ Lawrence Livermore National Laboratory
}

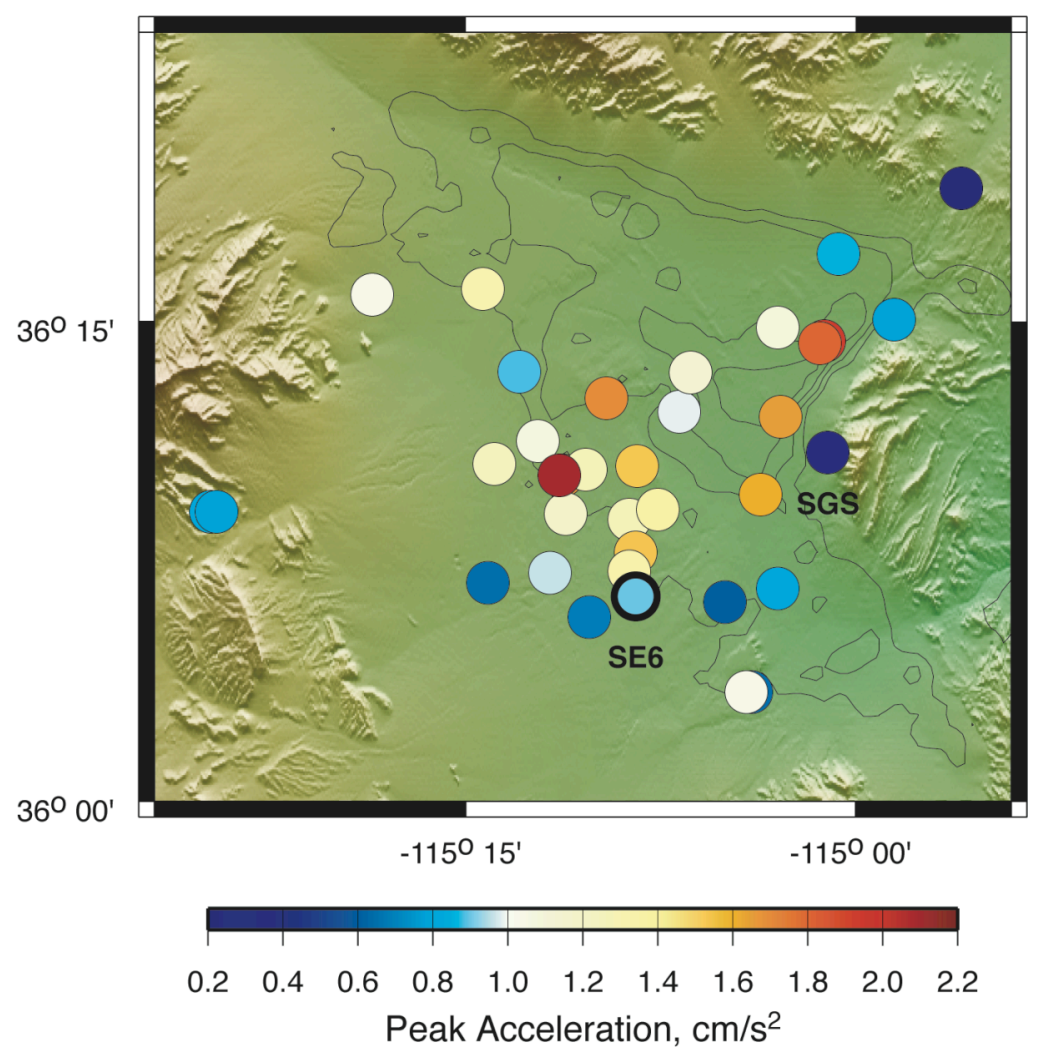

Final Report for Enhanced Test Site Readiness Program

March 2005 


\section{Summary}

Between 2001-2004 the Las Vegas Seismic Response Project has sought to understand the response of Las Vegas Valley (LVV) to seismic excitation. In this study, we report the findings of this project with an emphasis on ground motions in LVV from nuclear explosions at the Nevada Test Site (NTS). These ground motions are used to understand building structural response and damage as well as human perception (described in companion reports by McCallen et al. (2004) and Gerhard et al. (2004). Historical nuclear explosion observations are augmented with earthquake recordings from a temporary deployment of seismometers to improve spatial coverage of LVV. The nuclear explosions were conducted between 1968 and 1989 and were recorded at various sites within Las Vegas. The data from past nuclear tests were used to constrain ground motions in LVV and to gain a predictive capability of ground motions for possible future nuclear tests at NTS. Analysis of ground motion data includes peak ground motions (accelerations and velocities) and amplification of basin sites relative to hard rock sites (site response). Site response was measured with the Standard Spectral Ratios (SSR) technique relative to hard rock reference sites on the periphery of LVV. The site response curves indicate a strong basin amplification of up to a factor of ten at frequencies between 0.5-2 Hz. Amplifications are strongest in the central and northern portions of LVV, where the basin is deeper than $1 \mathrm{~km}$ based on the reported basin depths of Langenheim et al (2001a). We found a strong correlation between amplification and basin depth and shallow shear wave velocities. Amplification below $1 \mathrm{~Hz}$ is strongly controlled by slowness-averaged shear velocities to depths of 30 and 100 meters. Depth averaged shear velocities to 10 meters has modest control of amplifications between 1-3 Hz. Modeling reveals that low velocity material in the shallow layers $(<200 \mathrm{~m})$ effectively controls amplification. We developed a method to scale nuclear explosion ground motion time series to sites around LVV that have no historical record of explosions. The method is also used to scale nuclear explosion ground motions to different yields. We also present a range of studies to understand basin structure and response performed on data from our temporary deployment. 


\section{Table of Contents}

1. Introduction 1

1.1 Geographic Background 1

1.2 Previous Ground Motion Studies $\quad 4$

$\begin{array}{ll}1.3 \text { Outline For This Report } & 6\end{array}$

2. Ground Motion Data 7

2.1 Historical Explosion Data $\quad 7$

2.2 The Little Skull Mountain Earthquake $\quad 10$

$\begin{array}{ll}2.3 \text { Las Vegas Broadband Deployment } & 11\end{array}$

$\begin{array}{ll}2.4 \text { NTS Explosions at the BLUME Sites } & 13\end{array}$

3. Peak Ground Motion 22

4. Site Response and Basin Amplification 27

4.1 Site Response Methodology 27

4.2 Site Response Results $\quad 30$

4.3 Understanding Site Response Amplification 34

4.4 Site Response Conclusions 41

5. Two-Dimensional Elastic Finite Difference Modeling 43

5.1 Finite Difference Modeling 43

5.2 Modeling Experiments 43

5.3 Site Response Modeling Conclusions 48

6. Empirical Transfer Functions to Predict Ground Motion Time-Series $\quad 50$

6.1 Background on Ground Motion Scaling $\quad 50$

$\begin{array}{ll}\text { 6.2 Data } & 50\end{array}$

6.3 Empirical Transfer Function Methodology 51

6.4 Validation of the Method 54

6.5 Site Scaling Ground Motion Prediction in Las Vegas 57

6.6 Site Scaling Ground Motion Prediction in Las Vegas 59

7. Analysis of Las Vegas Valley Broadband Deployment Data 62

7.1 Teleseismic P-wave Travel Time Residuals 62

$\begin{array}{ll}\text { 7.2 Teleseismic Receiver Functions } & 68\end{array}$ 
7.3 Teleseismic S-Wave Site Response

7.4 Microtremor Site Response Analysis

8. Summary of UNLV and UNR Sub-Contracts 73

$\begin{array}{ll}8.1 \text { Basin Structure } & 73\end{array}$

8.2 Geotechnical Shear Wave Velocities 73

8.3 Modeling Amplification by Geotechnical Layers 74

$\begin{array}{ll}8.4 \text { Geologic Modeling } & 75\end{array}$

8.5 ModelAssembler $\quad 75$

8.6 Two-Dimensional Sensitivity Tests 75

$\begin{array}{ll}\text { 9. References } & 77\end{array}$

10. Acknowledgments 84 


\section{Introduction}

As part of a multidisciplinary program for Enhanced Test Site Readiness, this report summarizes our efforts to predict ground motions in Las Vegas Valley (LVV) for possible future nuclear explosions at the Nevada Test Site (NTS). This effort provides ground motion time series to engineers for the evaluation of structural response and human perception. Our approach relies heavily on historical recordings made in Las Vegas of nuclear explosions at NTS. LVV lies about $110-180 \mathrm{~km}$ to the southeast of NTS.

\subsection{Geographic Background}

The city of Las Vegas, Nevada is situated in the Las Vegas Valley (LVV), a broad northwest-southeast trending sedimentary basin within the central Basin and Range province. Figure 1.1 shows a map of southern Nevada, including NTS, LVV and the surrounding regions. The basin was formed by extensional tectonics (Wernicke et al., 1988) and is filled with Tertiary sediments in the deeper sections and Quaternary alluvial and lakebed sediments at the surface (Tabor, 1982). The basin is bounded on the north by the Las Vegas Valley Shear Zone (LVVSZ) and the Las Vegas Range, on the east by Frenchman Mountain and on the west by the Spring Mountains. Under the Las Vegas Seismic Response Project, Taylor (2004) reviewed the available geologic studies on the Las Vegas Basin and describes a model of the lithology in the basin.

The geographic orientation, major roads and seismic stations used in this report are shown in Figure 1.2. The City of Las Vegas is among the fastest growing urban centers in the United States. The population has steadily increased since the beginning of nuclear testing at the NTS, growing outward from the center near the intersection of the major thoroughfares, I-95 and US95. Major hotels and casinos are concentrated along Las Vegas Boulevard south of downtown ("The Strip"). Nellis Air Force Base occupies a large area in the northeastern portion of the valley. Extensive residential housing surrounds a densely urbanized central region of the valley. 


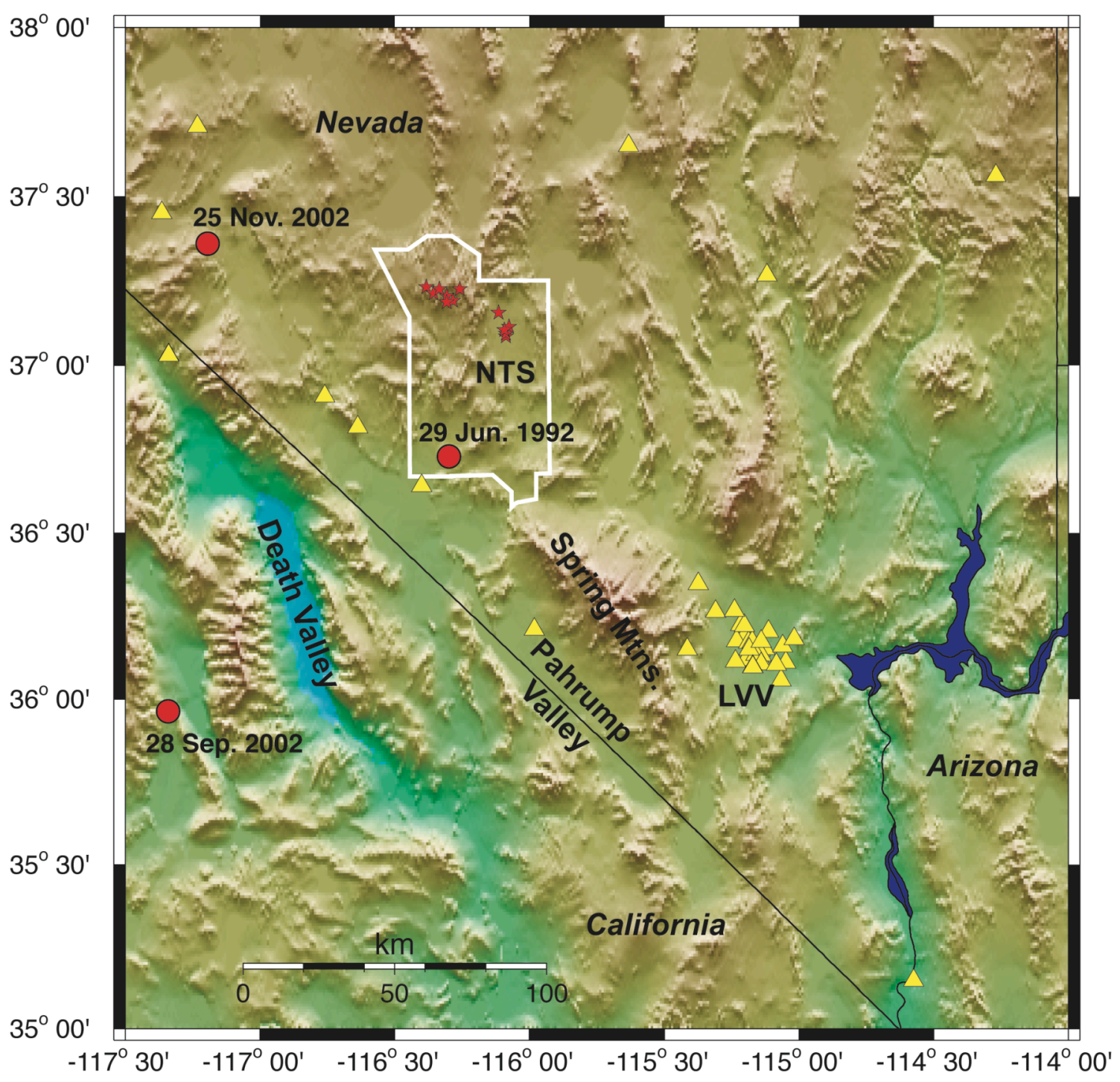

Figure 1.1 Map of Las Vegas Valley (LVV), the Nevada Test Site (NTS), southern Nevada and the surrounding regions. Seismic stations of the Blume and Associates network (yellow triangles), NTS nuclear explosions (red stars) and regional earthquakes (red circles) are shown.

Recently Langenheim et al. (2001a, 2001b) reported the geometry of the basin and the LVVSZ using gravity and seismic reflection data. Their model of basin depth, shown in Figure 1.3, estimated the maximum depth to bedrock to be nearly $5 \mathrm{~km}$, although the definitions of geologic units and the ages of sedimentary sequences are poorly known. Significant seismic hazard in Las Vegas is indicated by its location in a deep sedimentary 
basin, surface sedimentary deposits, the proximity of major earthquake faults and high population. These factors indicate that the response of LVV to seismic ground motion deserves thorough investigation.

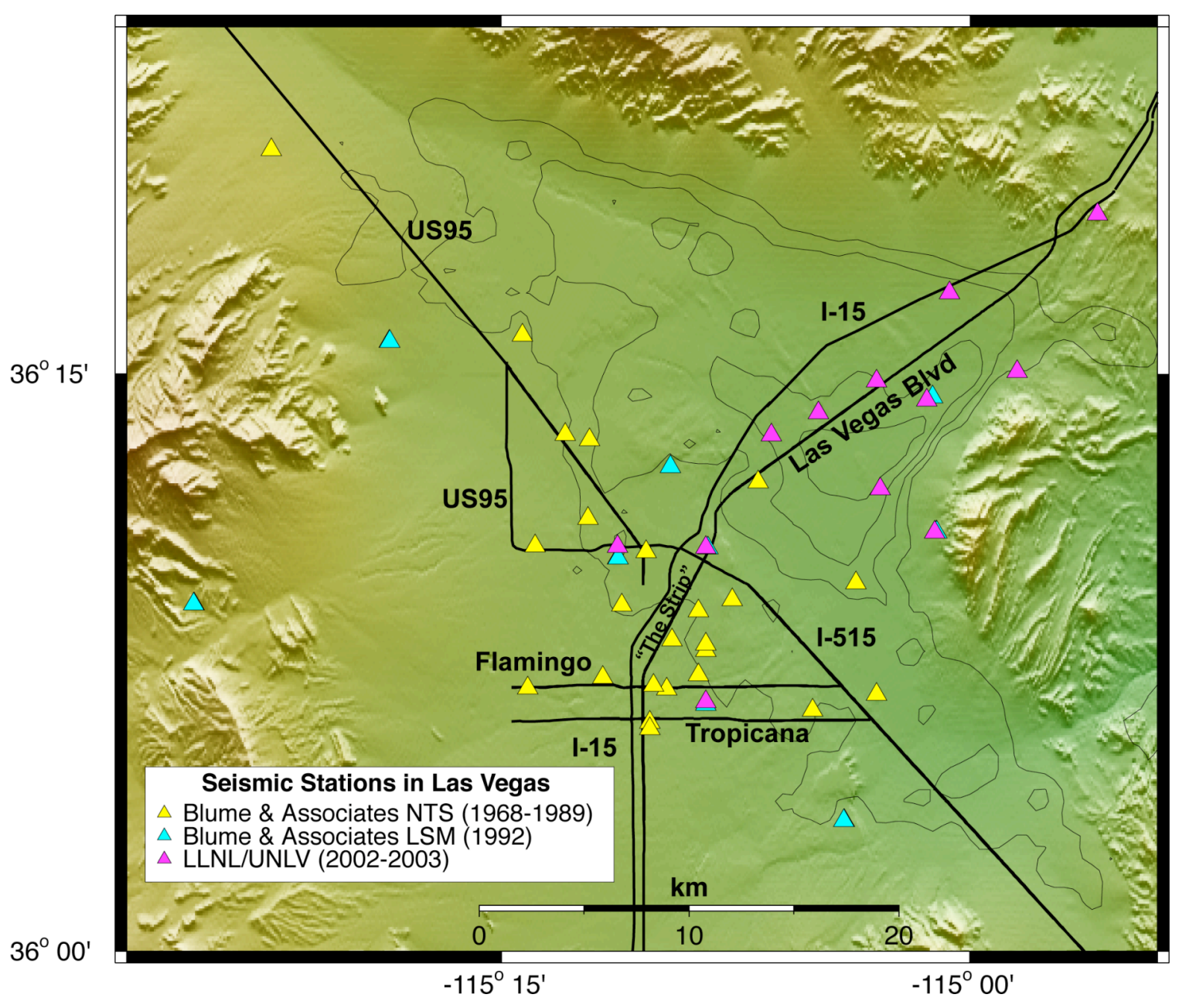

Figure 1.2 Map of Las Vegas Valley showing the major roads and seismic stations used in this study. Basin depth from Langenheim et al. (2000) is shown with the contours (interval $1 \mathrm{~km}$ ). 


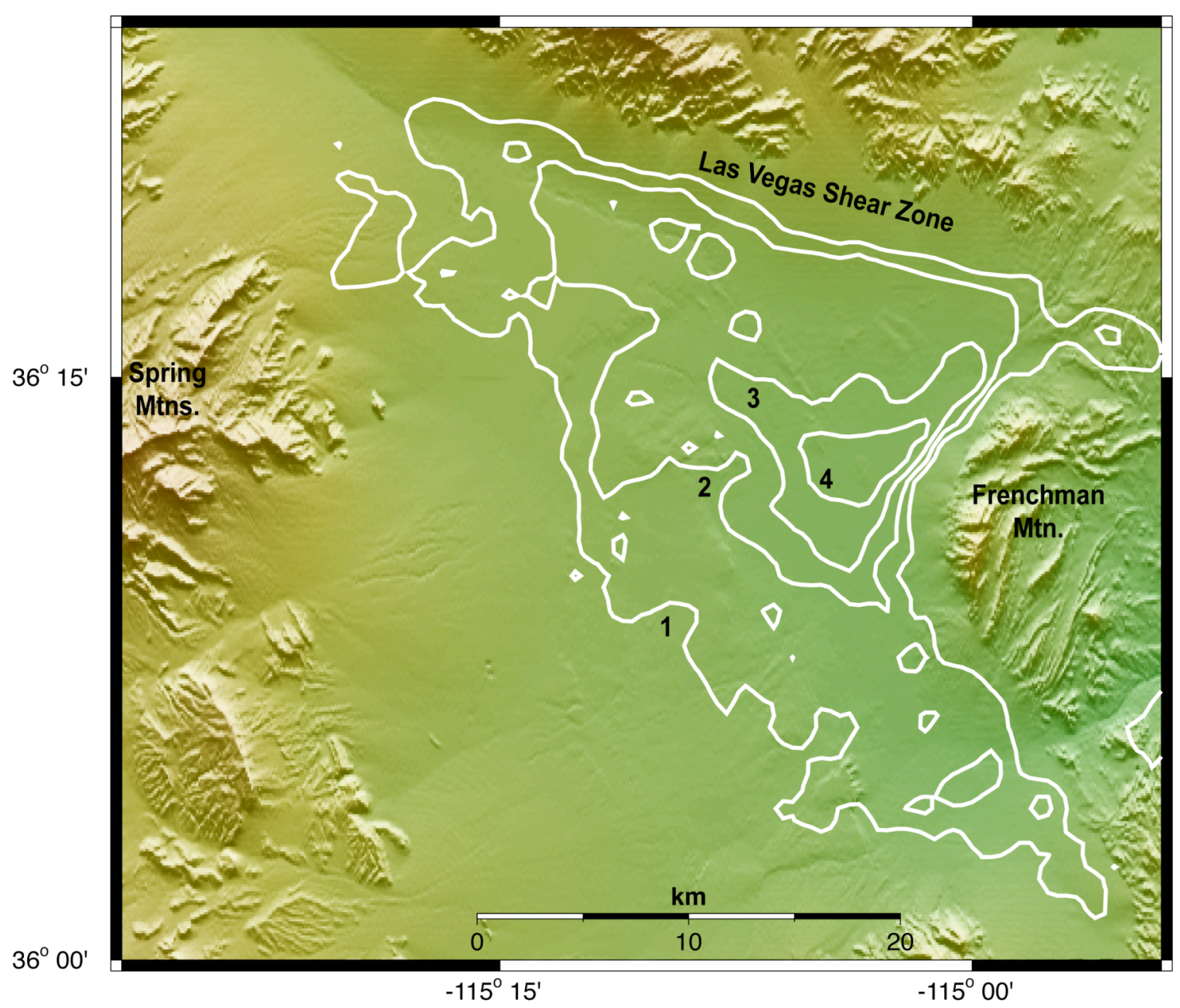

Figure 1.3 Map of Las Vegas Valley showing the major geographic features. Basin depth from Langenheim et al. (2000) is shown with the white contours (in km).

\subsection{Previous Ground Motion Studies}

An early report by Davis and Lynch (1970) studied the seismic response of Las Vegas to underground nuclear explosions at the Nevada Test Site (NTS). A network of sensors was operated by Blume and Associates for the Atomic Energy Commission (AEC) and later the Department of Energy (DOE). Early studies of ground motion in Las Vegas used data from the Blume and Associates network. Davis and Lynch (1970) reported variable seismic response within the central section of present day Las Vegas (near Las Vegas Boulevard or "The Strip"), with amplifications of up to a factor of four in peak ground motion. However, due to limited data at the time, emphasis was placed on just two sites (SQPK and SE6). Numerous reports were published by Blume and Associates 
and other contractors on ground motions in Las Vegas as nuclear testing continued in the 1970’s and 1980's.

Two published studies investigated seismic ground motion in LVV. Murphy and Hewlett (1975) used recordings from six NTS nuclear explosions to determine ground motion amplification within Las Vegas at 26 sites, concentrated within present-day central Las Vegas (Las Vegas Boulevard). Their data set was comprised of different explosions and sites than ours, but we have some sites in common. They reported a correlation between low-frequency site response and inferred alluvium thickness, based on Rayleigh wave ellipticity. The greatest amplification was observed at frequencies $0.33-0.22 \mathrm{~Hz}$ (3.3-4.5 s periods) where the amplification was nearly a factor of 8 . However, they used a reference site within the basin on the western side of downtown (Site 801, Figure 1, Murphy and Hewlett, 1975). Ideally a reference site should be located on hard rock with little or no site response in order to obtain accurate estimates of basin site amplification (e.g., Steidl et al., 1996). Therefore the reported amplifications could be greater depending on the frequency dependent site response at Site 801. Without the access to their data set we cannot assess possible biases in their results relative to our data set. Murphy and Hewlett (1975) performed some two-dimensional modeling of surface waves and showed that variable alluvium thickness in the upper $1 \mathrm{~km}$ of the basin can account for some of the observed variability between sites in LVV. However, reflections and conversions from the basin edge were not considered in their analysis.

Su et al. (1998) reported ground motion and site response at nine sites in a broader area of LVV from the $\mathrm{M}_{\mathrm{W}}$ 5.6 June 291992 Little Skull Mountain (LSM) earthquake (Figure 1.2 shows the sites considered as cyan triangles). That event was located on the southwestern corner of NTS with similar although slightly shorter paths compared to NTS explosions (Figure 1.1). They reported amplifications greater than a factor of ten at sedimentary sites in the Valley relative to the average spectral amplitude at two reference sites (ST6 and ST17) on the Valley's periphery. They also reported that maximum amplification generally occurred for periods below $1 \mathrm{~Hz}$ (Su et al., 1998, Figure 8). By using data from co-located sites, Su et al. (1998, Figure 10) showed that the analysis of 
Murphy and Hewlett (1975) underpredicts the site response in Las Vegas relative to a reference site on the Valley's periphery. The amplification at sites within LVV relative to a reference site outside the basin is as much as ten for frequencies below $1 \mathrm{~Hz}$. Su et al. (1998) used site response to predict ground motion in LVV from large scenario earthquakes on the Death Valley Fault system.

\subsection{Outline For This Report}

In the following sections, this report describes the results of a three year effort to understand and predict ground motions in Las Vegas Valley (LVV) from nuclear explosions at the Nevada Test Site (NTS). This project is motivated by the tremendous urban growth in Las Vegas and the need to prepare for possible future nuclear testing at NTS (see the companion report by McCallen et al., 2004). In this report, we describe several aspects of our program: the data used in the analysis, including seismic waveform data; peak ground motions; site response; a scaling technique for predicting time-series of possible future nuclear tests in Las Vegas; and analysis of a new unique data set we collected in LVV. Finally, we conclude with a summary of the results from external subcontracts to University of Nevada, Las Vegas (UNLV) and University of Nevada, Reno (UNR). 


\section{Ground Motion Data}

In this section we describe the data sets used in the ground motion analysis. This includes 13 nuclear explosions recorded at the Blume and Associates network, the Little Skull Mountain earthquake and our temporary Las Vegas Broadband Deployment.

\subsection{Historical Explosion Data}

The engineering firm Blume and Associates operated the Seismic Safety Program to measure ground motion throughout the western U.S. from nuclear explosions at NTS. A seismic station network was installed in the early 1960's and operated until the end of nuclear testing in 1992. Data were used to understand the response of Las Vegas Basin to ground motion from nuclear explosions at NTS and the impact on buildings and structures. The network configuration and instrumentation varied through time. We obtained data recorded on three component analog strong motion accelerographs. The ground motions were digitized at 200 samples per second. We found these records to be useful in the pass band $0.2-5 \mathrm{~Hz}$ (details provide below). The instrument corrected ground motion time series from legacy NTS shots were read from their archival ASCII format and converted to Seismic Analysis Code (SAC2000) format (Goldstein et al., 2003). We did not have absolute time information for the seismograms, so we could not analyze travel times or surface wave dispersion.

All seismograms for NTS explosions recorded in LVV were previewed and P- and Swaves were picked. We collected records for thirteen nuclear test explosions recorded at 29 sites in LVV, however only four explosions (BARNWELL, BODIE, COTTAGE and GASCON) were recorded at our best hard rock reference site, SGS located on the flank of Frenchman Mountain. Table 2.1 compiles details about the nuclear explosions taken from Springer et al. (2002). None of the explosions we collected were included in the analysis of Murphy and Hewlett (1975). 
Table 2.1. Event information for the NTS nuclear explosions (Springer et al., 2002) and earthquakes used in this study. Body-wave magnitudes, $\mathrm{m}_{\mathrm{b}}$, are taken from the International Seismological Centre (ISC) catalog.

\begin{tabular}{|l|l|l|l|l|l|l|l|l|}
\hline Name & Date & $\begin{array}{l}\text { Time } \\
\text { (UTC) }\end{array}$ & Region & Latitude & Longitude & $\begin{array}{l}\text { Depth } \\
\text { (meters) }\end{array}$ & $\begin{array}{l}\mathbf{m}_{\mathbf{b}} \\
\text { Yield } \\
\text { (kiloton) }\end{array}$ \\
\hline BOXCAR & 1968 Apr 26 & $15: 00: 00.07$ & Pahute & 37.295 & -116.457 & 1158 & - & 1300 \\
\hline HANDLEY & 1970 Mar 26 & $19: 00: 00.20$ & Pahute & 37.300 & -116.535 & 1209 & - & $>1000$ \\
\hline MUENSTER & 1976 Jan 03 & $19: 15: 00.16$ & Pahute & 37.297 & -116.334 & 1452 & - & $200-1000$ \\
\hline FONTINA & 1976 Feb 12 & $14: 45: 00.16$ & Pahute & 37.271 & -116.489 & 1219 & - & $200-1000$ \\
\hline JORNADA & 1982 Jan 28 & $16: 00: 00.10$ & Yucca & 37.091 & -116.052 & 639 & 5.9 & 139 \\
\hline NEBBIOLO & 1982 Jun 24 & $14: 15: 00.09$ & Pahute & 37.236 & -116.371 & 640 & 5.6 & $20-150$ \\
\hline TURQUOISE & 1983 Apr 14 & $19: 05: 00.12$ & Yucca & 37.073 & -116.047 & 533 & 5.7 & $<150$ \\
\hline MUNDO & 1984 May 01 & $19: 05: 00.09$ & Yucca & 37.106 & -116.023 & 566 & 5.3 & $20-150$ \\
\hline COTTAGE* & 1985 Mar 23 & $18: 30: 00.08$ & Yucca & 37.180 & -116.090 & 515 & 5.3 & $20-150$ \\
\hline GASCON* & 1986 Nov 14 & $16: 00: 00.07$ & Yucca & 37.100 & -116.049 & 593 & 5.8 & $20-150$ \\
\hline BODIE* & 1986 Dec 13 & $17: 50: 05.08$ & Pahute & 37.263 & -116.413 & 635 & 5.5 & $20-150$ \\
\hline TAHOKA & 1987 Aug 13 & $14: 00: 00.09$ & Yucca & 37.061 & -116.046 & 639 & 5.9 & $20-150$ \\
\hline BARNWELL* & 1989 Dec 08 & $15: 00: 00.09$ & Pahute & 37.231 & -116.410 & 601 & 5.5 & $20-150$ \\
\hline & & & & & & & & \\
\hline LSM* & 1992 Jun 29 & $10: 14: 00.00$ & LSM & 36.72 & -116.30 & 11,000 & 5.4 & - \\
\hline LVVBB1* & 2002 Sep 28 & $10: 34: 46.00$ & Coso & 35.95 & -117.31 & 15,000 & 4.1 & - \\
\hline LVVBB2* & 2002 Nov 25 & $00: 03: 10.05$ & Goldfield & 37.38 & -117.19 & 7,000 & 3.9 & - \\
\hline
\end{tabular}

* indicates events recorded at reference site SGS/ST17

Explosion events were located in the Pahute Mesa and Yucca Flat areas of NTS (Figure 1.1). Both source regions have very similar paths from NTS to LVV, however the emplacement geologies are very different leading to differences in S-wave generation at the source (Mayeda and Walter, 1996). The events tend to have large teleseismic bodywave magnitudes, $\mathrm{m}_{\mathrm{b}}$, between 5.3 and 5.9. Figure 2.1 shows a map of the Blume and Associates sites in LVV that recorded at least one explosion. The explosion locations on the NTS are shown in Figure 2.2. 


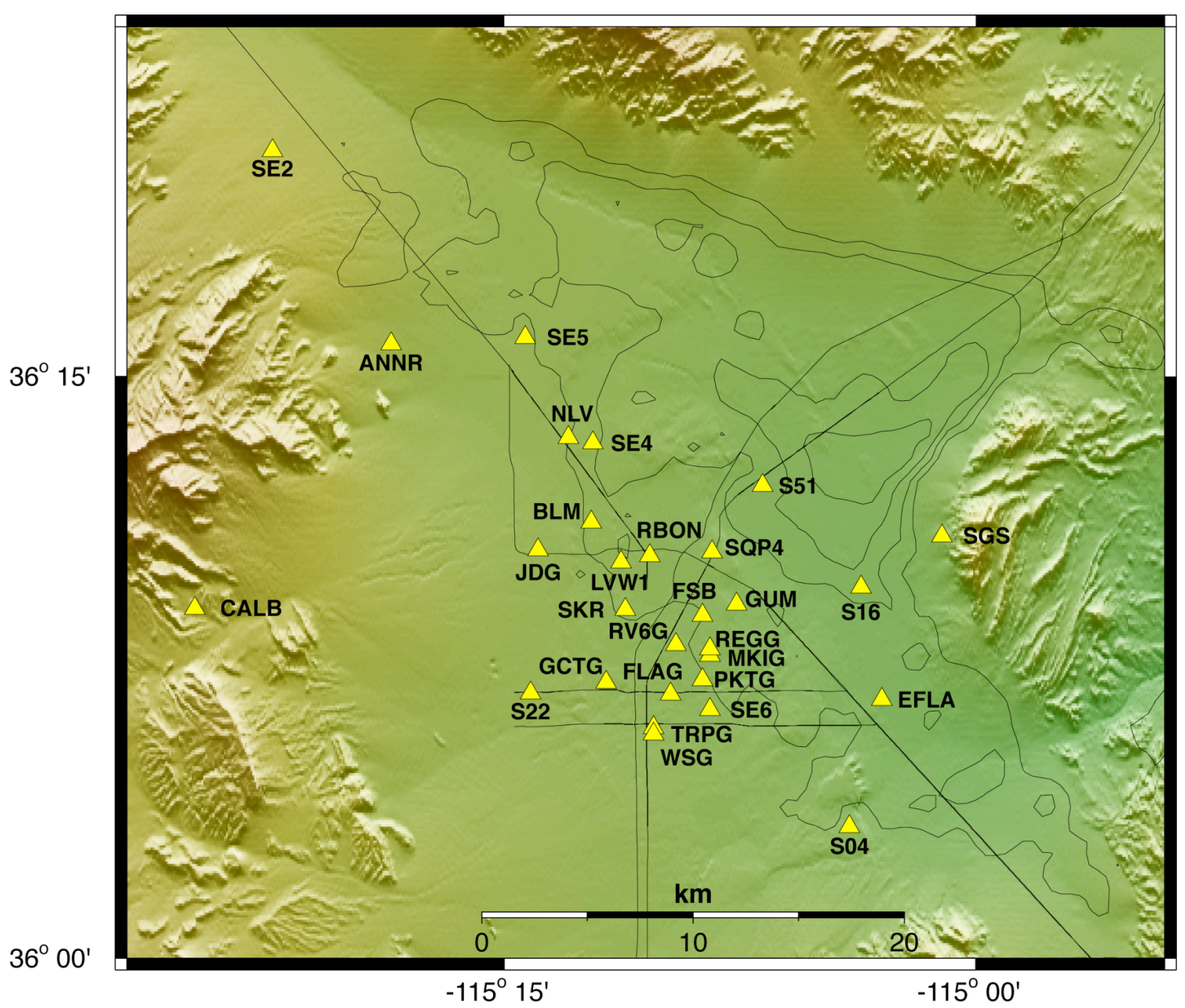

Figure 2.1 Seismic stations from the BLUME network that recorded the historical nuclear explosions at NTS (yellow triangles). 


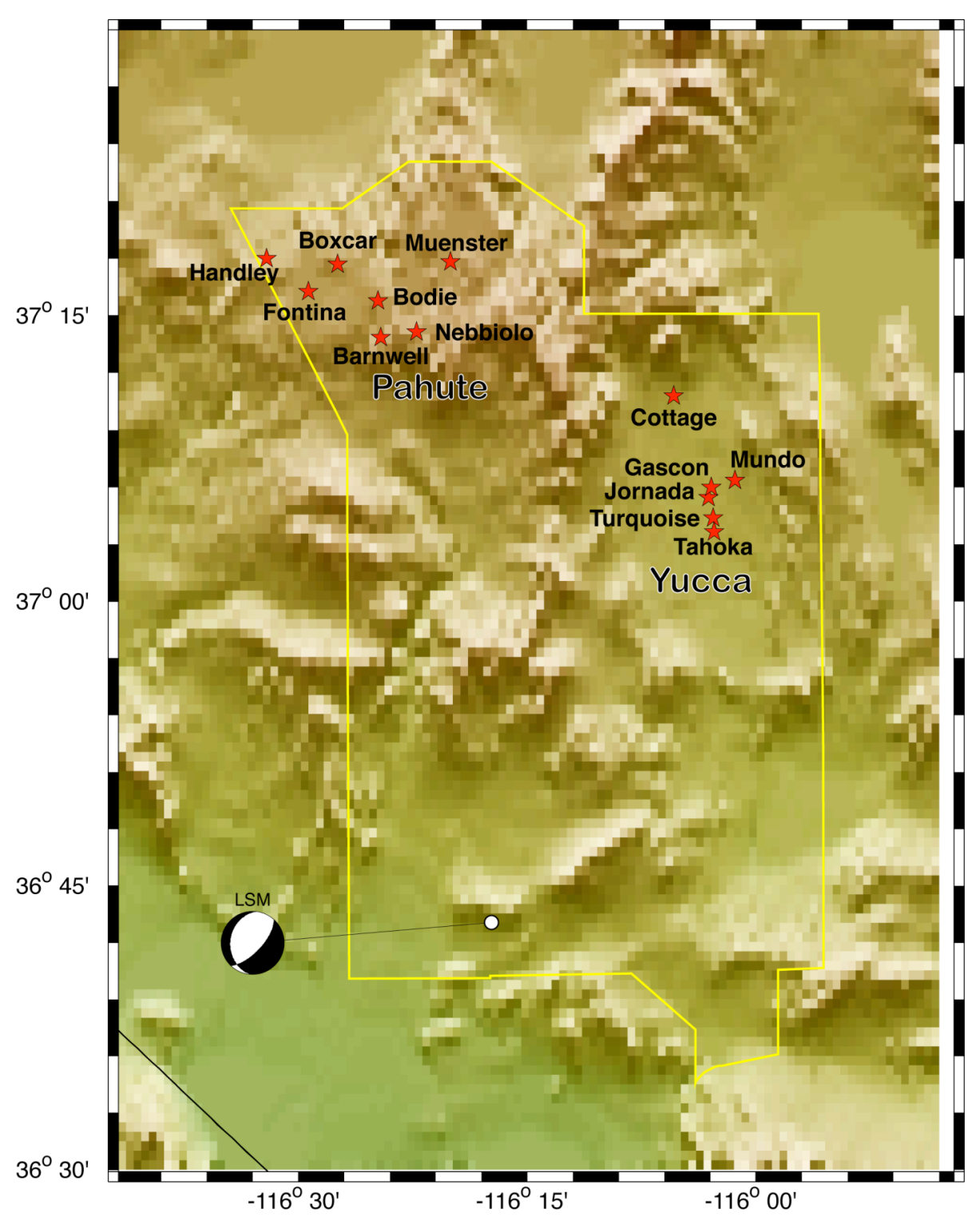

Figure 2.2 Map of nuclear explosions recorded by the BLUME network. The June 29, 1992 Little Skull Mountain earthquake on NTS is also shown.

2.2 The Little Skull Mountain Earthquake

We also obtained data for the 29 June 1992 Little Skull Mountain earthquake on NTS recorded by the Blume \& Associates network and analyzed by Su et al. (1998). These sites (LSM) are shown in Figure 2.3. Station ST17 is essentially co-located with the BLUME station SGS. 


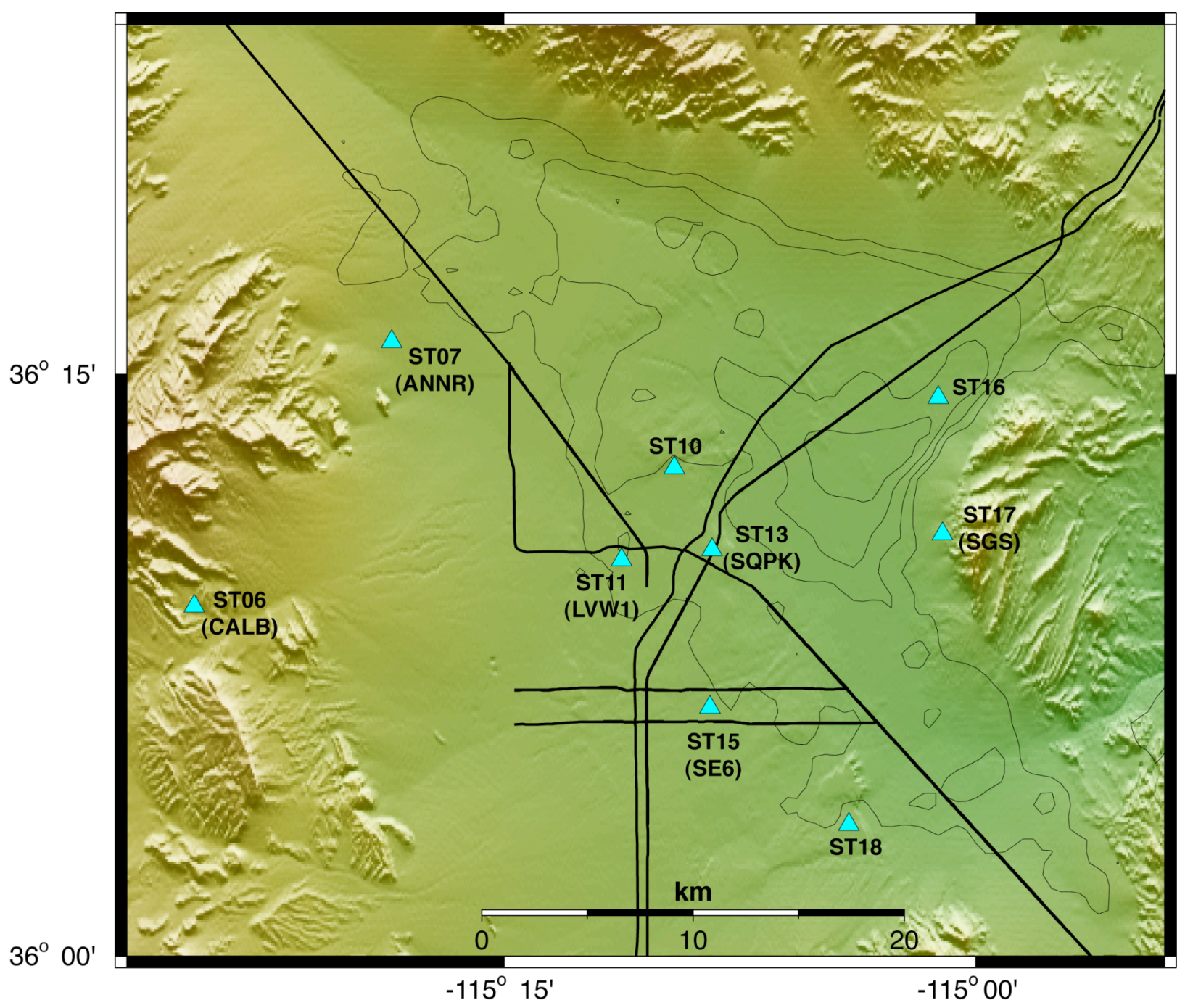

Figure 2.3 Seismic stations from the BLUME network that recorded the Little Skull Mountain earthquake (cyan triangles).

\subsection{Las Vegas Broadband Deployment}

The available sites from the BLUME and LSM networks sample the densely populated central portion of LVV, but not the northern portion of the valley. Thicker sedimentary cover underlies the northern portion of the valley (Langenheim et al., 2001a). In order to improve the spatial coverage of LVV with seismic sensors, and investigate the response of the deeper sediments in the northern valley, we deployed a temporary network of seismometers. The Las Vegas Valley Broadband Deployment (LVVBB) recorded continuous weak motions from local, regional and teleseismic events between September 


\section{Ground Motion Data}

2002 and January 2003. The eleven stations, shown in Figure 2.4, were configured to sample the northern parts of LVV along densely populated the Las Vegas Boulevard/I-15 corridor as well as to overlap sites from the BLUME and LSM data sets.

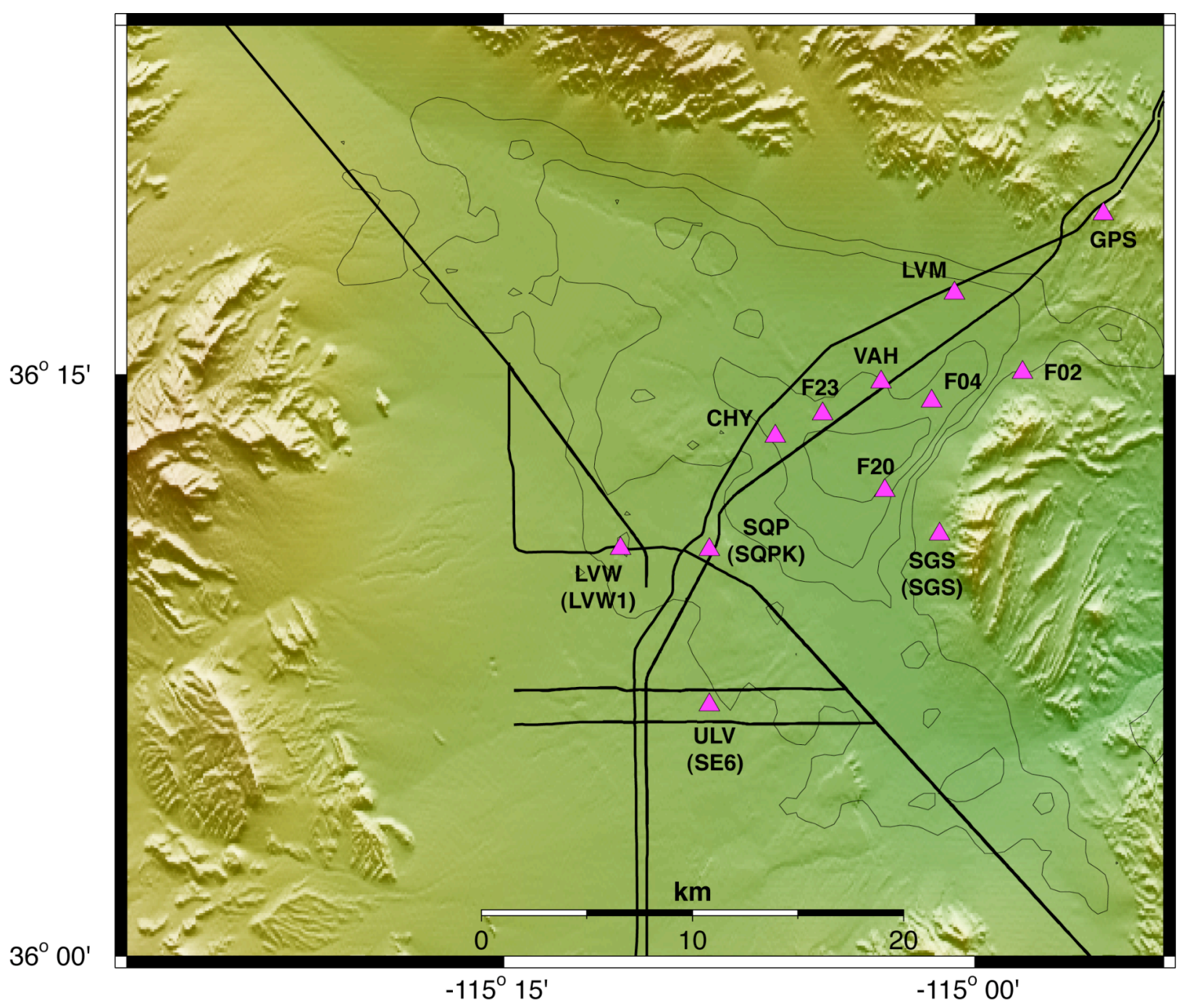

Figure 2.4 Seismic stations from the Las Vegas Valley Broadband Deployment network (magenta triangles).

We deployed one station on the foot of Frenchman Mountain near the BLUME station SGS, although the area near SGS has been urbanized since the time of the BLUME network. The LVVBB stations featured various instruments including Guralp CMG3ESP, Guralp 40T and Geotech S-13 sensors. Reftek 72A-08 24-bit data loggers 
recorded data with GPS time at 40 samples per second. Two regional earthquakes were used for site response measurements (Figure 1.1 and Table 1.1).

\subsection{NTS Explosions at the BLUME Sites}

This report relies heavily on the historical recordings of NTS nuclear explosions recorded by the Blume and Associates network. In this section we provide some details about the data. Some events were recorded by only a few sites in Las Vegas. This can be seen in Figures 2.5-2.17, which show the specific sites that recorded each of the 13 explosions along with the entire Blume, LSM and LVVBB networks. Because the sampling of the explosions in Las Vegas was so geographically heterogeneous, a major objective of our project was to obtain sampling of the amplifications in the northern parts of Las Vegas, for which we have no explosion recordings.

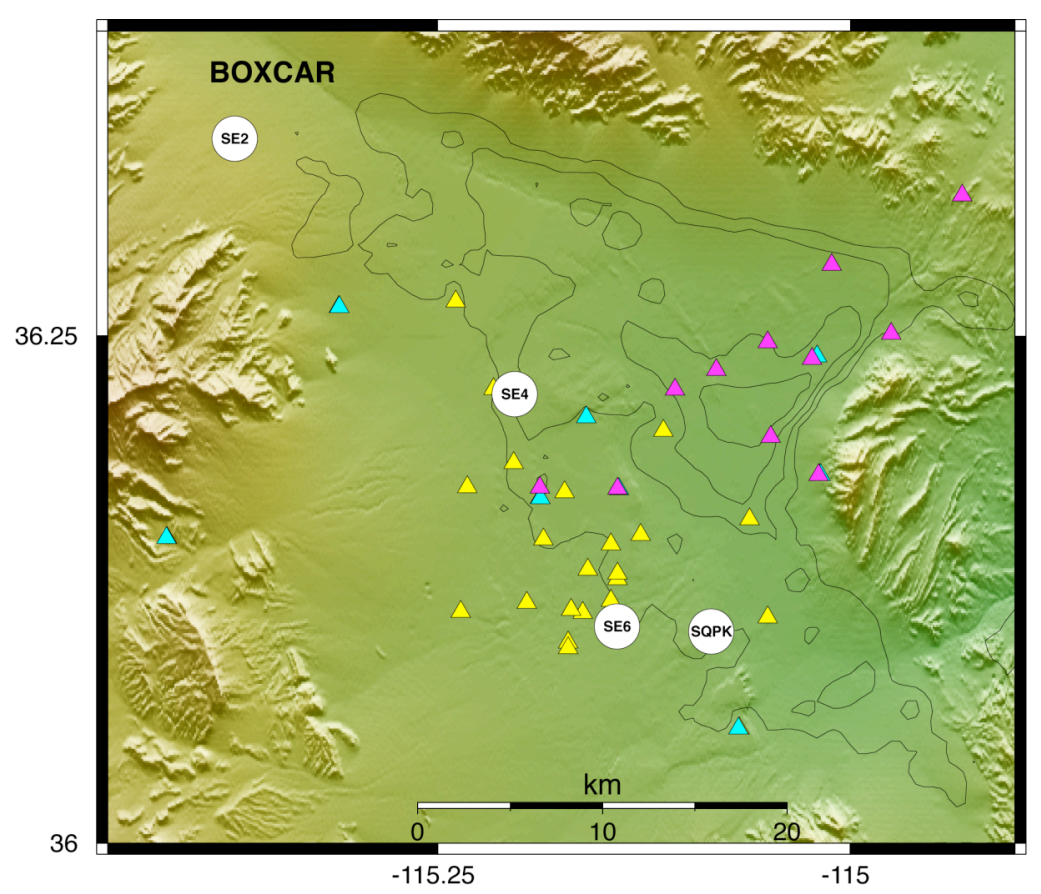

Figure 2.5 BLUME network stations (circles) in Las Vegas with good recordings of the BOXCAR explosion. Stations from the BLUME, LSM and LVVBB data sets and basin depths from Langenheim et al. (2000) are shown as in Figure 1.3 


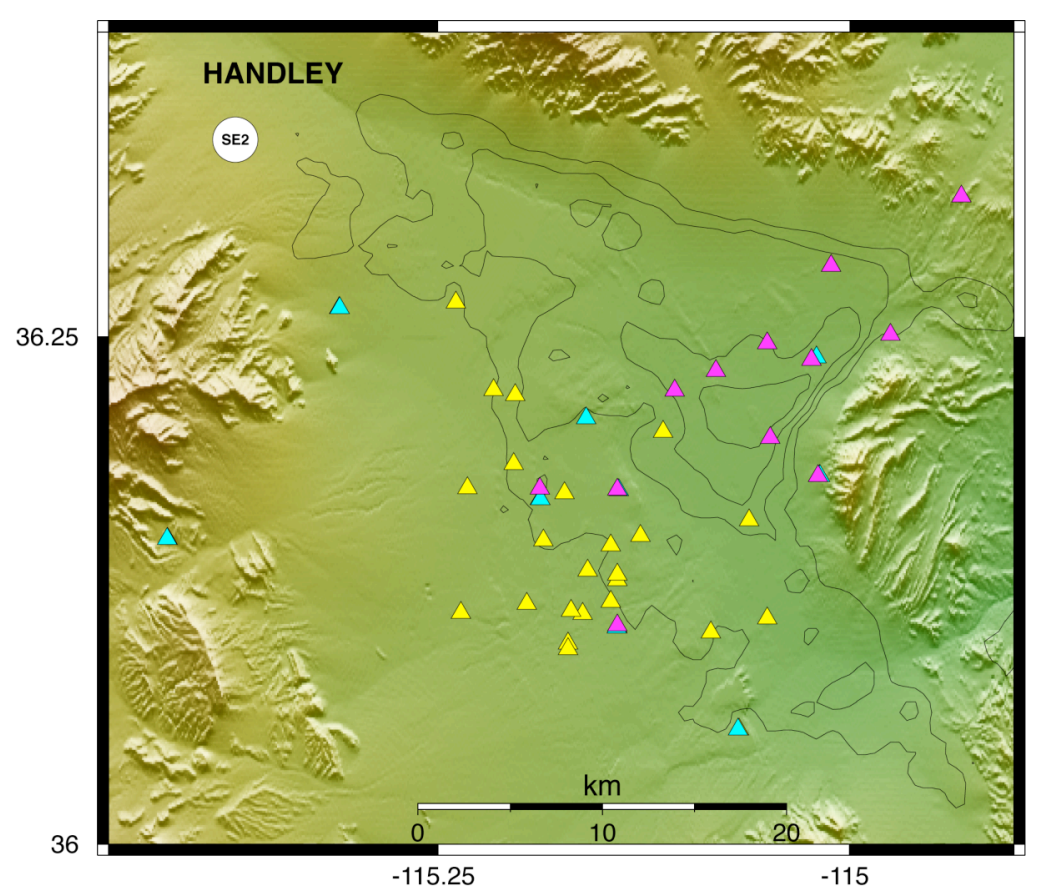

Figure 2.6 BLUME network stations (circles) in Las Vegas with good recordings of the HANDLEY explosion. Stations from the BLUME, LSM and LVVBB data sets and basin depths from Langenheim et al. (2000) are shown as in Figure 1.3

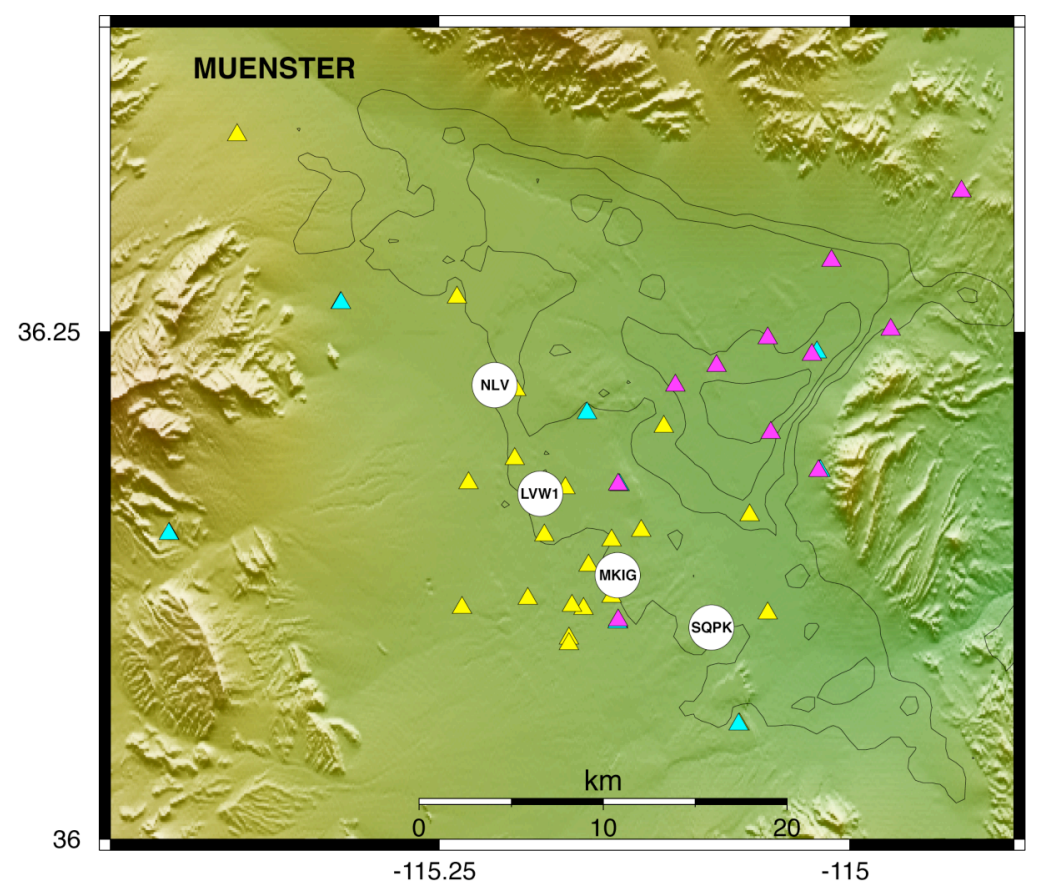

Figure 2.7 BLUME network stations (circles) in Las Vegas with good recordings of the MUENSTER explosion. Stations from the BLUME, LSM and LVVBB data sets and basin depths from Langenheim et al. (2000) are shown as in Figure 1.3 


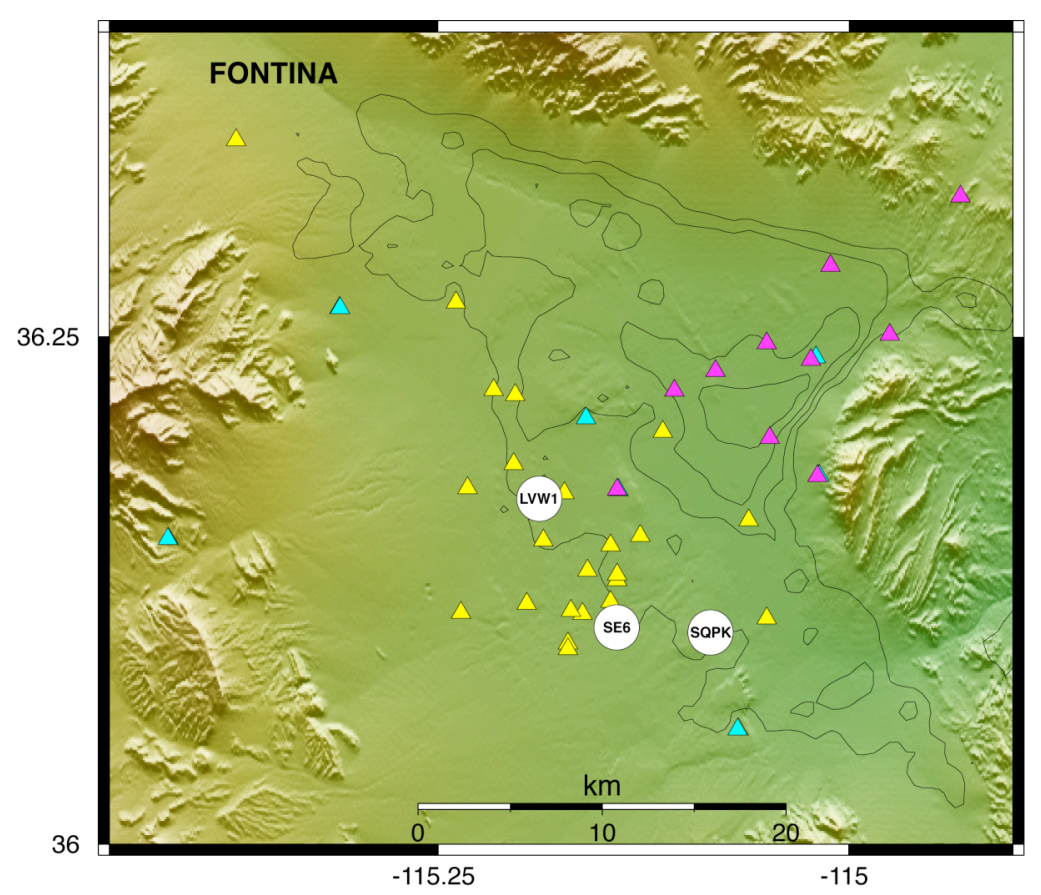

Figure 2.8 BLUME network stations (circles) in Las Vegas with good recordings of the FONTINA explosion. Stations from the BLUME, LSM and LVVBB data sets and basin depths from Langenheim et al. (2000) are shown as in Figure 1.3

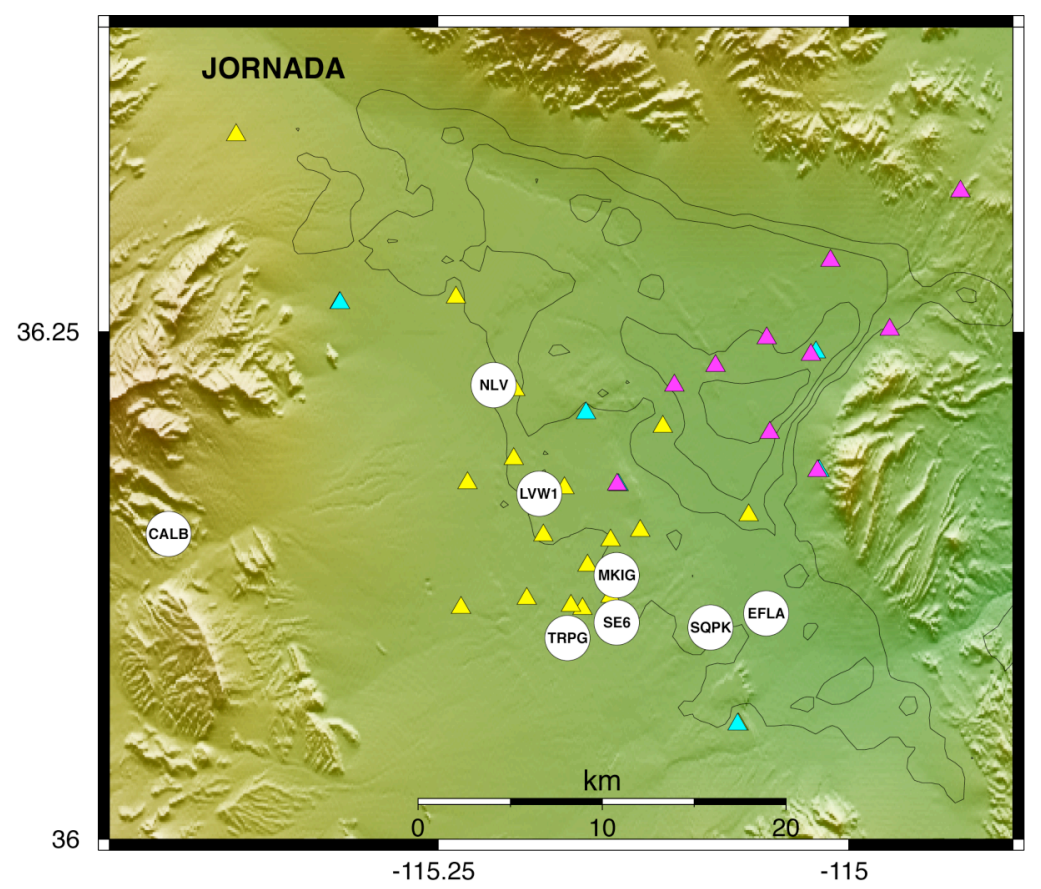

Figure 2.9 BLUME network stations (circles) in Las Vegas with good recordings of the JORNADA explosion. Stations from the BLUME, LSM and LVVBB data sets and basin depths from Langenheim et al. (2000) are shown as in Figure 1.3 


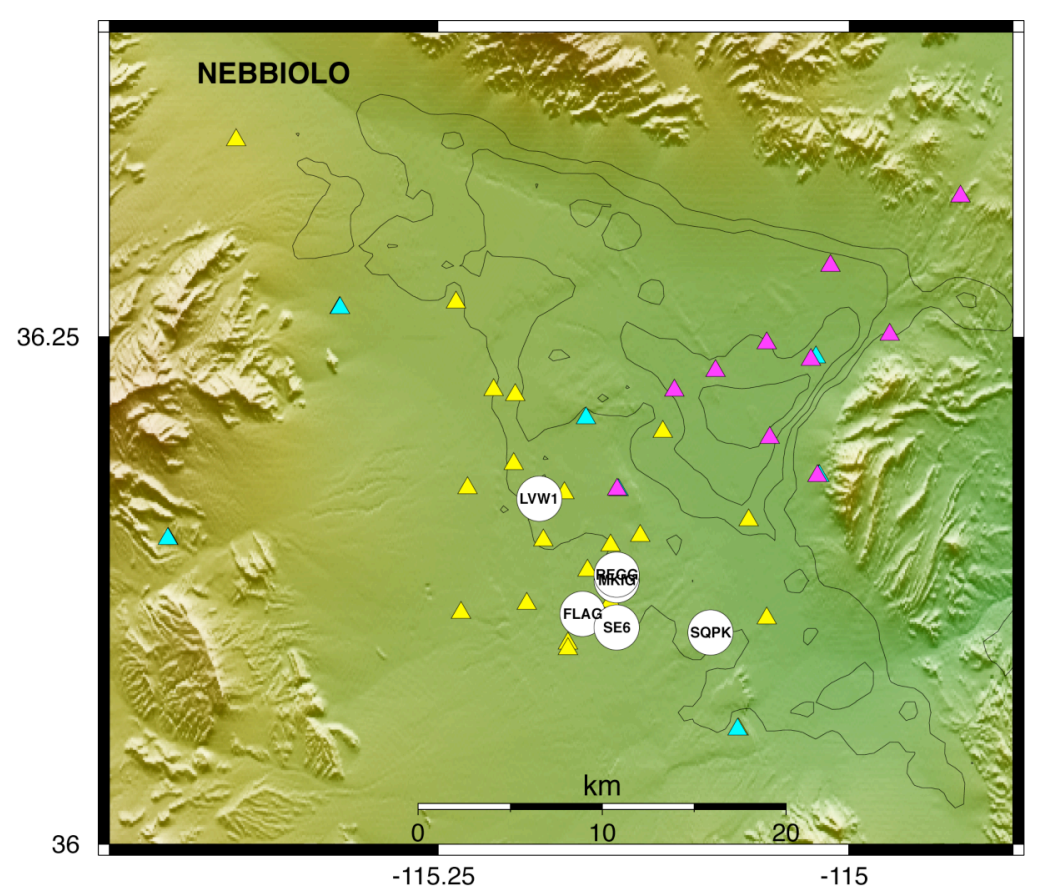

Figure 2.10 BLUME network stations (circles) in Las Vegas with good recordings of the NEBBIOLO explosion. Stations from the BLUME, LSM and LVVBB data sets and basin depths from Langenheim et al. (2000) are shown as in Figure 1.3

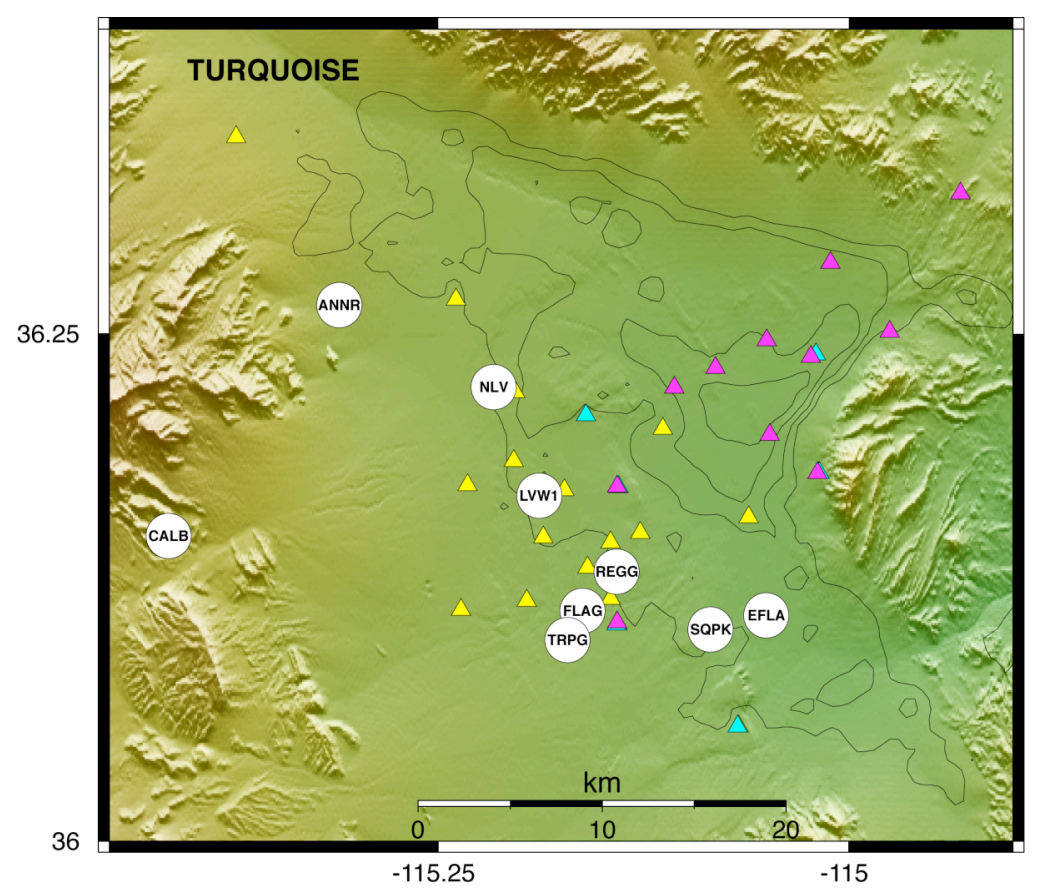

Figure 2.11 BLUME network stations (circles) in Las Vegas with good recordings of the TURQUOISE explosion. Stations from the BLUME, LSM and LVVBB data sets and basin depths from Langenheim et al. (2000) are shown as in Figure 1.3 


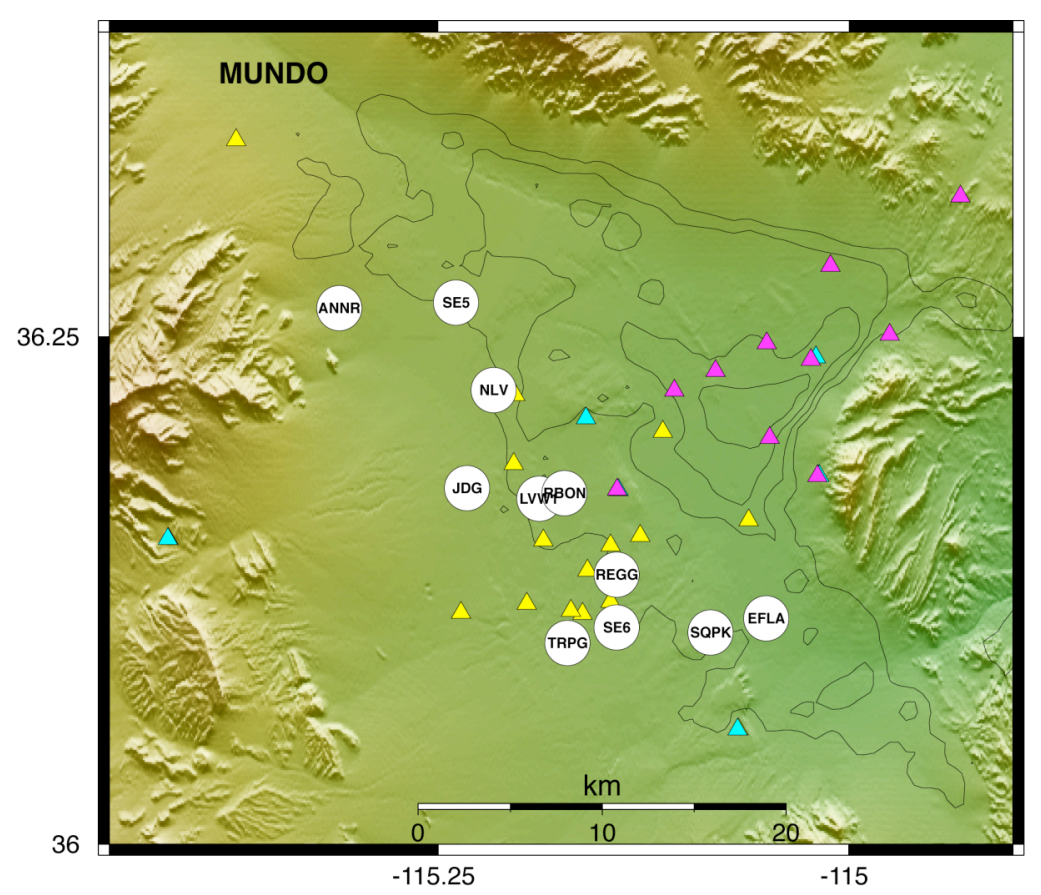

Figure 2.12 BLUME network stations (circles) in Las Vegas with good recordings of the MUNDO explosion. Stations from the BLUME, LSM and LVVBB data sets and basin depths from Langenheim et al. (2000) are shown as in Figure 1.3

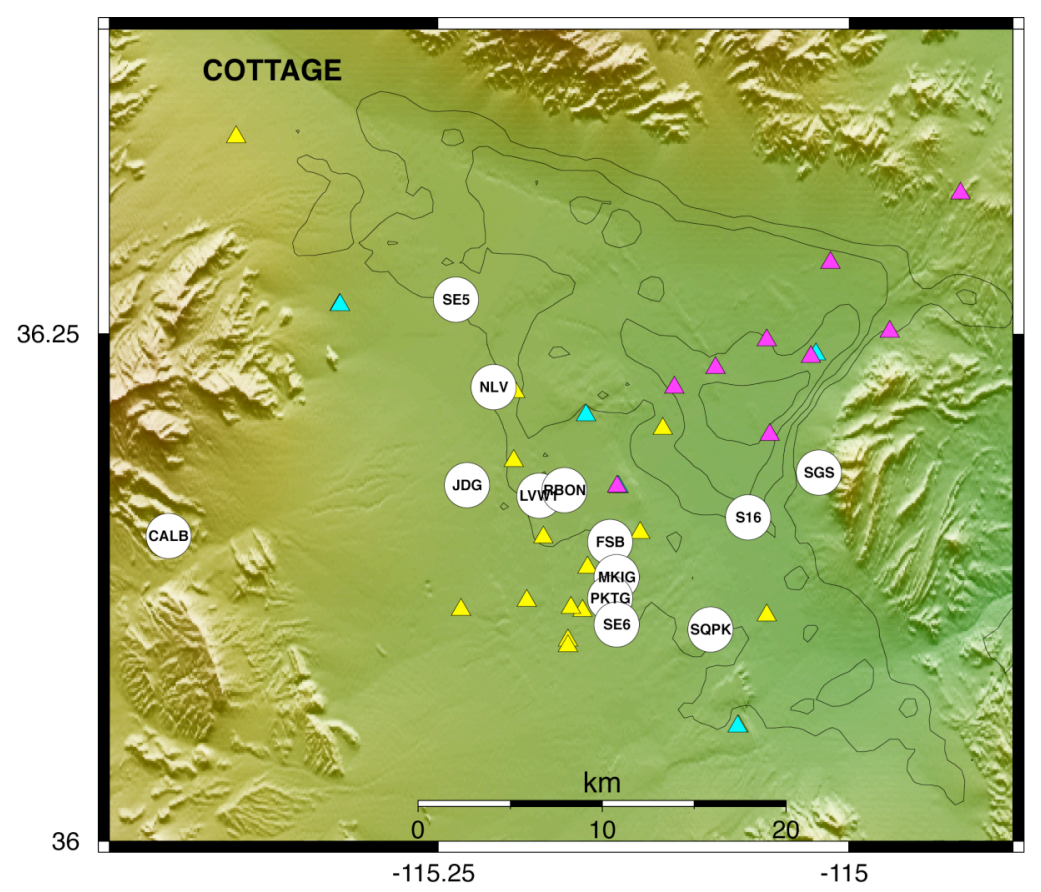

Figure 2.13 BLUME network stations (circles) in Las Vegas with good recordings of the COTTAGE explosion. Stations from the BLUME, LSM and LVVBB data sets and basin depths from Langenheim et al. (2000) are shown as in Figure 1.3 


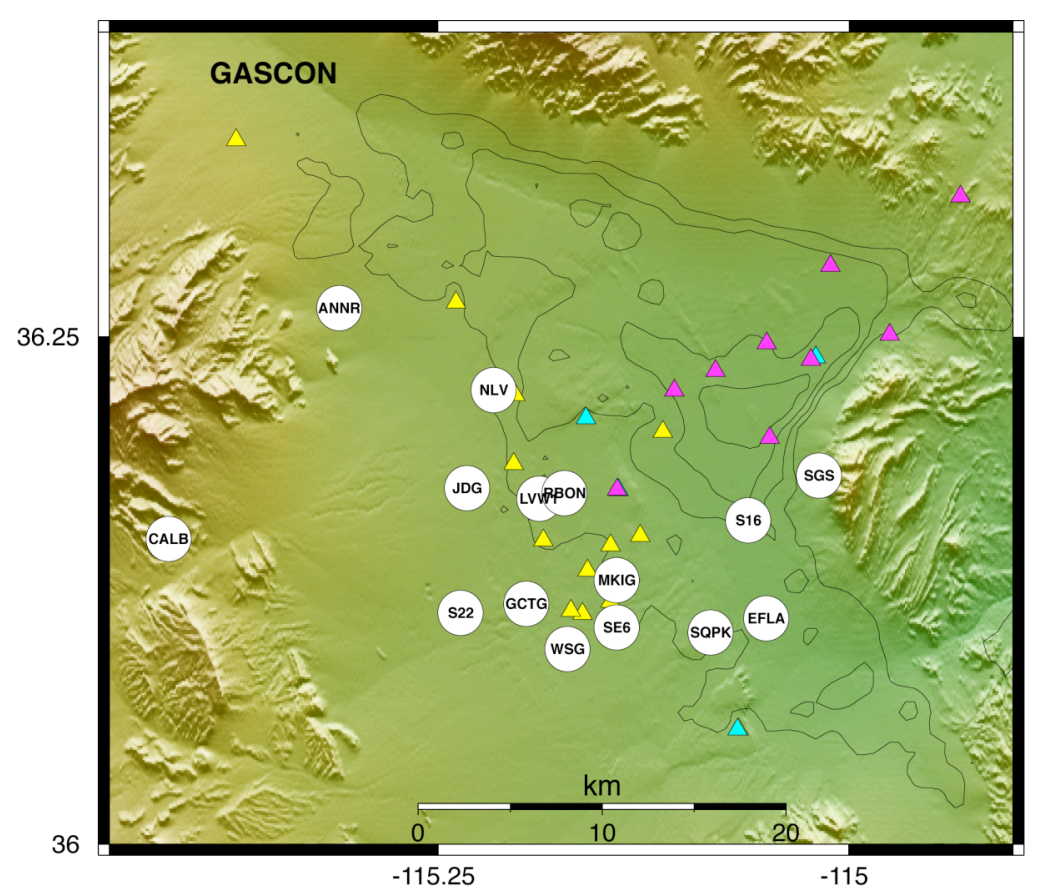

Figure 2.14 BLUME network stations (circles) in Las Vegas with good recordings of the GASCON explosion. Stations from the BLUME, LSM and LVVBB data sets and basin depths from Langenheim et al. (2000) are shown as in Figure 1.3

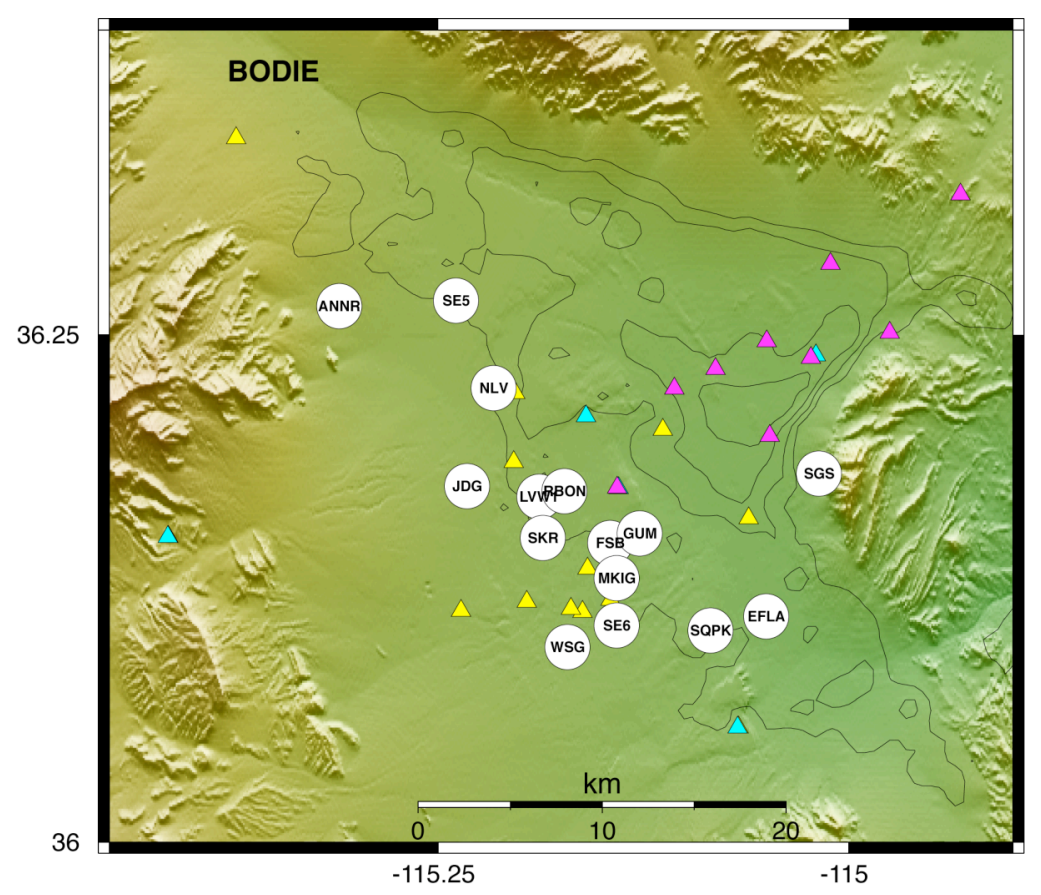

Figure 2.15 BLUME network stations (circles) in Las Vegas with good recordings of the BODIE explosion. Stations from the BLUME, LSM and LVVBB data sets and basin depths from Langenheim et al. (2000) are shown as in Figure 1.3 


\section{Ground Motion Data}

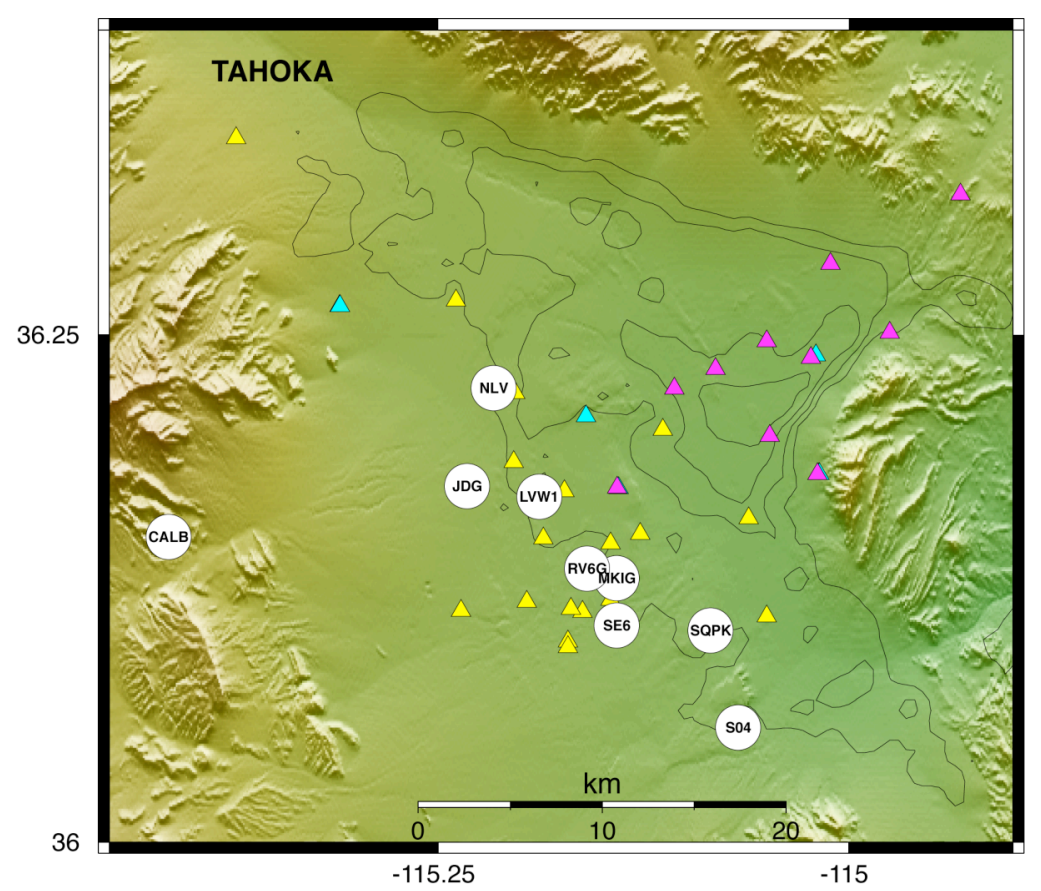

Figure 2.16 BLUME network stations (circles) in Las Vegas with good recordings of the TAHOKA explosion. Stations from the BLUME, LSM and LVVBB data sets and basin depths from Langenheim et al. (2000) are shown as in Figure 1.3

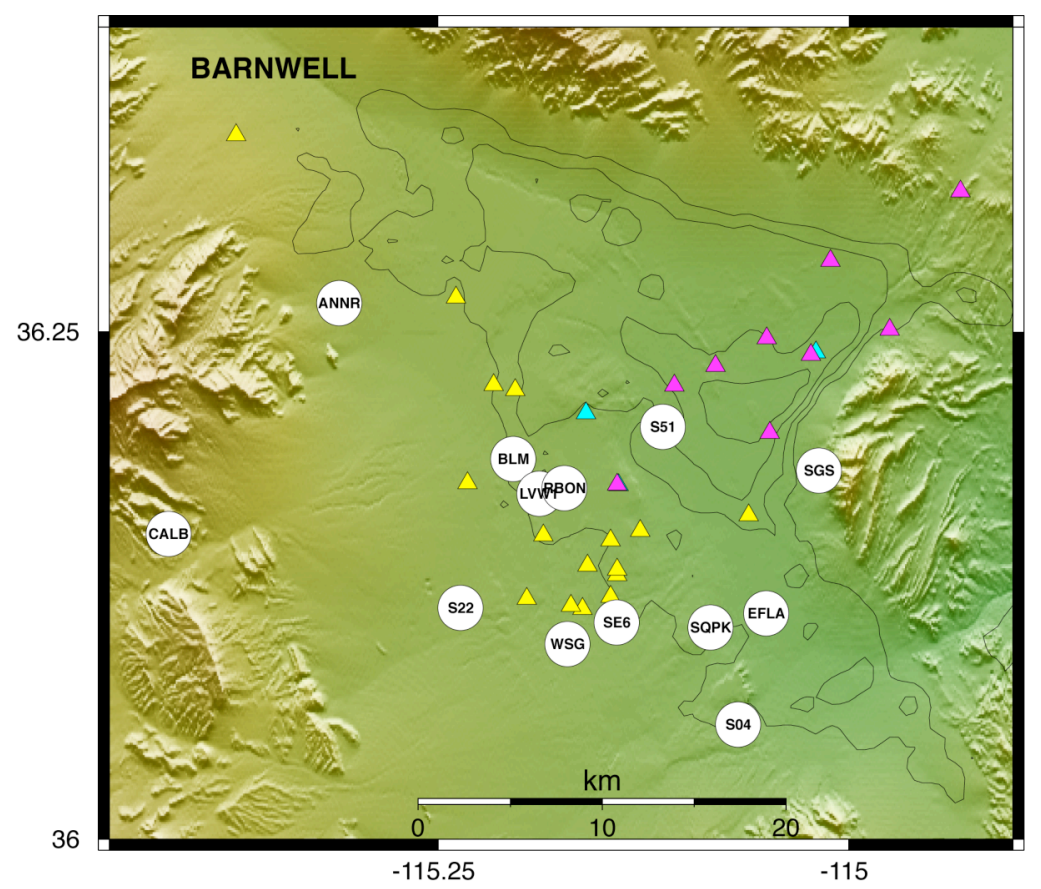

Figure 2.17 BLUME network stations (circles) in Las Vegas with good recordings of the BARNWELL explosion. Stations from the BLUME, LSM and LVVBB data sets and basin depths from Langenheim et al. (2000) are shown as in Figure 1.3 
As an example of our data set, we show (Figure 2.18) the north component velocity seismograms (band pass filtered 0.1-10 Hz) for the BARNWELL shot at six sites throughout the Valley (station locations are shown in Figure 2.17). Amplitudes at the sites SGS and CALB, on the Valley's periphery, are the smallest, while amplitudes within the basin are largest, particularly at RBON, LVW and S51. Note that the duration of elevated ground motion is quite long within the basin and the slower surface waves and coda tend to be longer period than the direct S-wave. The long duration and amplified ground motions are common within sedimentary basins. Note that accelerations from the nuclear explosion data considered were always below $20 \mathrm{~cm} / \mathrm{s}^{2}$ $(\sim 2 \% \mathrm{~g})$ and would generally be considered weak motion.
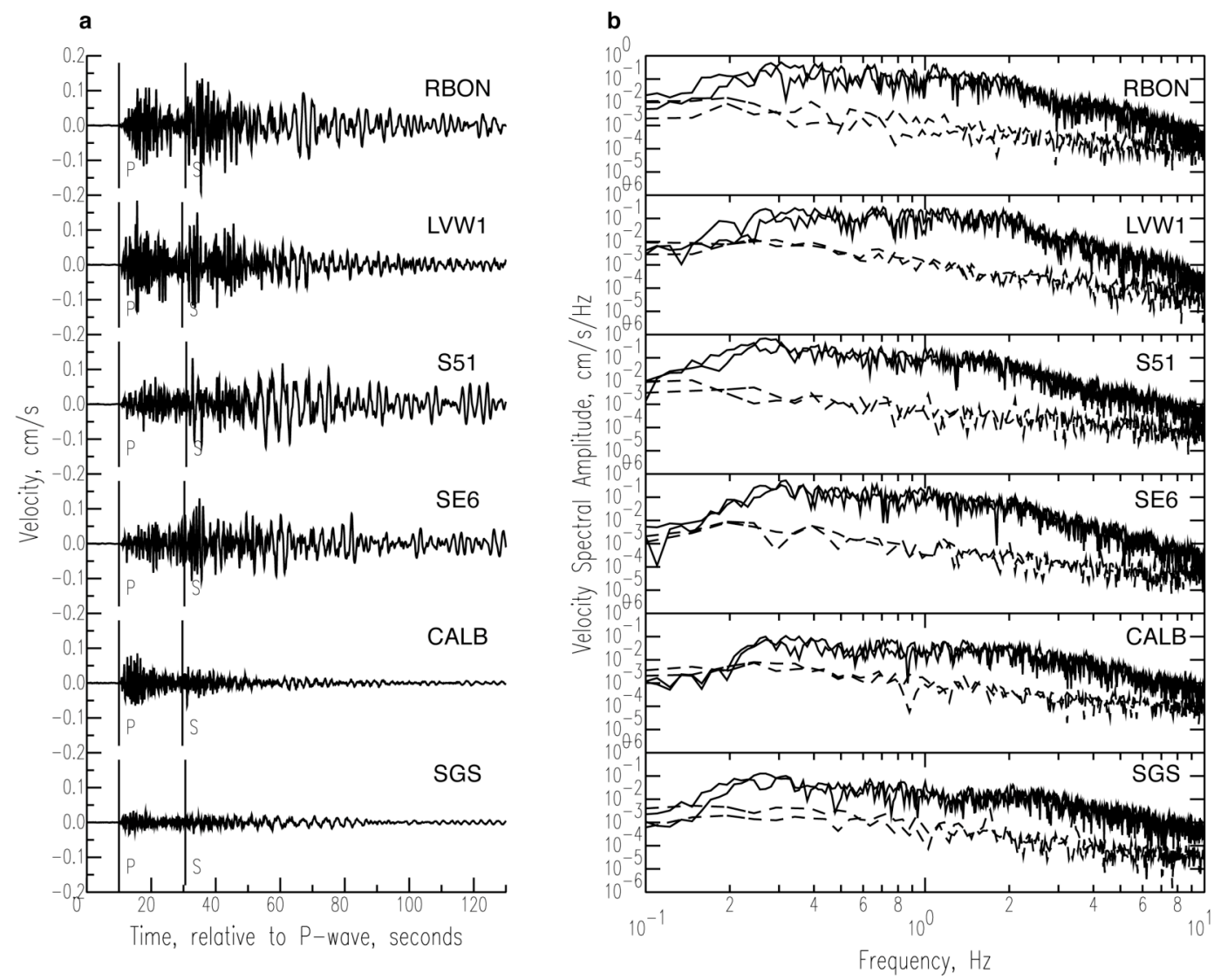

Figure 2.18. (a) North component velocity waveforms (filtered $0.1-10 \mathrm{~Hz}$ ) for the BARNWELL nuclear test at a few sites in LVV. (b) Horizontal component velocity amplitude (solid) and noise (dashed) spectra for the waveforms shown in (a). 
Figure $2.18 \mathrm{~b}$ shows the velocity amplitude spectra $(0.1-10 \mathrm{~Hz})$ of the S-wave and available pre-event noise windows for both horizontal components at the same sites as Figure 2.18a. Signal-to-noise ratios are quite high, generally greater than 10 , for all shots and sites in the band 0.2-10 Hz. The BLUME accelerographs were band-limited at the low end between 0.1 and $0.2 \mathrm{~Hz}$. The velocity spectra on both horizontal components have similar amplitudes. The peak amplitude occurs at around $0.2-0.4 \mathrm{~Hz}(2.5-5 \mathrm{~s})$ for these stations. The raw amplitude spectra of course contain source, path and site effects. In order to remove source and path effects and utilize both the explosion and earthquake data sets we measured site response relative to a hard rock site. 


\section{Peak Ground Motions}

\section{Peak Ground Motions}

In this section, we present the measured peak ground accelerations and velocities from the 13 NTS nuclear explosions recorded in LVV. These are helpful for putting the explosion-generated ground motions in context with known damage and perception criteria from strong-motion seismology.

Figure 3.1 shows the observed horizontal component peak ground acceleration (PGA) versus the peak ground velocity (PGV) for all 113 available explosion recordings. These were taken from the S-wave portions of the analyst previewed and picked waveforms. For reference in this plot are shown the regions defining the Modified Mercalli Intensity scale (Wald et al., 1999). The largest explosions (BOXCAR, HANDLEY, MUENSTER and FONTINA; see Table 2.1) resulted in the largest ground motions in Las Vegas. These explosions resulted in Mercalli Intensities or IV or less. For reference the Mercalli Intensity Scale classifications are given in Table 3.1. Clearly Mercalli Intensity IV is perceived on the ground, but does not generally result in significant damage to buildings. The amplification of motions due to structural response to buildings is treated in detail in the accompanying report by McCallen et al. (2004).

The peak ground motions plotted in Figure 3.1 simply show the peak ground motions and do not account for controlling factors such as distance (i.e. proximity to the seismic excitation), source size (i.e. the strength of the excitation at the source) and site response (i.e. amplification due to local geology). Figures 3.2 and 3.3 show the PGA and PGV versus distance from the source for the 13 NTS explosions. These figures also include the Modified Mercalli Intensity levels. We have many ground motion observations in Las Vegas clustered around 110-170 km. The large range of PGA and PGV values results from the range of explosion yields and site response. Even within a given explosion the PGA and PGV values can vary by almost a factor of ten for sites nearly equidistant to the source. This variability is due to amplification by the geologic structure near the recording sites. 


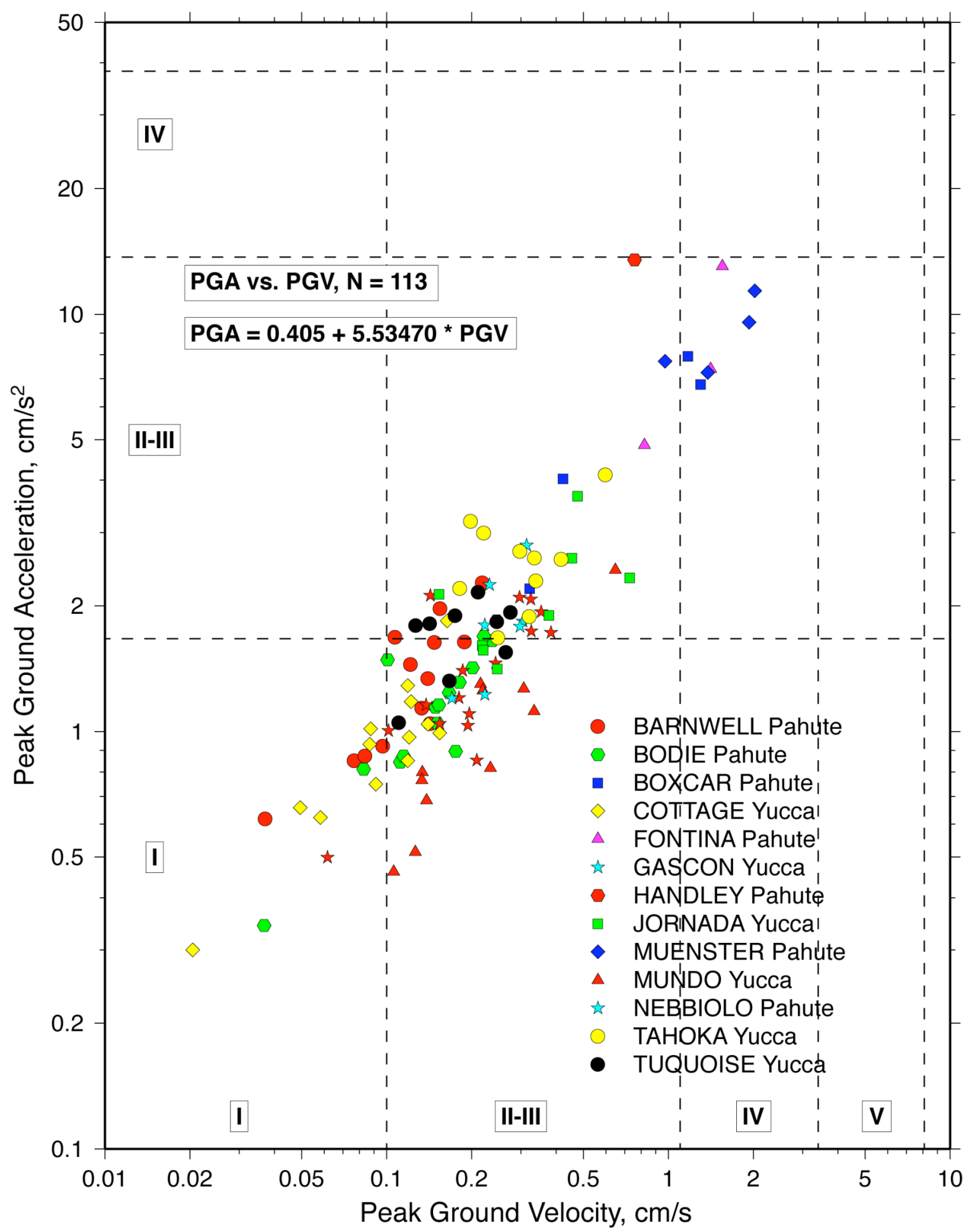

Figure 3.1. Peak ground acceleration $\left(\mathrm{PGA}, \mathrm{cm} / \mathrm{s}^{2}\right.$ ) versus peak ground velocity (PGV, $\mathrm{cm} / \mathrm{s}$ ) from 113 recordings of the 13 NTS explosions. The regression relation between PGA and PGV is provided. Also shown are the Modified Mercalli Intensity levels (Table 3.1). 


\section{Peak Ground Motions}

Table 3.1 Modified Mercalli Intensity Scale (Bolt, Bruce A. Earthquakes, W.H. Freeman and Co. 1993)

\begin{tabular}{|c|c|c|c|c|c|c|}
\hline $\begin{array}{c}\text { MMI } \\
\text { Value }\end{array}$ & $\begin{array}{c}\text { Peak } \\
\text { ACC } \\
\left(\mathrm{cm} / \mathrm{s}^{2}\right)\end{array}$ & $\begin{array}{l}\text { Peak } \\
\text { ACC } \\
(\% g)\end{array}$ & $\begin{array}{l}\text { Peak } \\
\text { VEL } \\
(\mathrm{cm} / \mathrm{s})\end{array}$ & $\begin{array}{c}\text { Perceived } \\
\text { Severity }\end{array}$ & $\begin{array}{l}\text { Damage } \\
\text { Summary }\end{array}$ & Full Description \\
\hline $\mathrm{I}$. & $<1.7$ & $<0.17$ & $<0.1$ & Not Felt & - & $\begin{array}{l}\text { Not felt. Marginal and long period } \\
\text { effects of large earthquakes. }\end{array}$ \\
\hline II. & $1.7-14$ & $\begin{array}{l}0.17- \\
1.4\end{array}$ & $0.1-1.1$ & Weak & - & $\begin{array}{l}\text { Felt by persons at rest, on upper } \\
\text { floors, or favorably placed. }\end{array}$ \\
\hline III & $1.7-14$ & $\begin{array}{l}0.17- \\
1.4\end{array}$ & $0.1-1.1$ & Weak & - & $\begin{array}{l}\text { Felt indoors. Hanging objects swing. } \\
\text { Vibration like passing of light trucks. } \\
\text { Duration estimated. May not be } \\
\text { recognized as an earthquake. }\end{array}$ \\
\hline IV & $14-38$ & $\begin{array}{l}1.4- \\
3.9\end{array}$ & $1.1-3.4$ & - & - & $\begin{array}{l}\text { Hanging objects swing. Vibration like } \\
\text { passing of heavy trucks; or sensation } \\
\text { of a jolt like a heavy ball striking the } \\
\text { walls. Standing motor cars rock. } \\
\text { Windows, dishes, doors rattle. } \\
\text { Glasses clink. Crockery clashes. In } \\
\text { the upper range of IV, wooden walls } \\
\text { and frame creak. }\end{array}$ \\
\hline V & $38-90$ & $\begin{array}{l}3.9- \\
9.2\end{array}$ & $3.4-8.1$ & Light & Objects Move & $\begin{array}{l}\text { Felt outdoors; direction estimated. } \\
\text { Sleepers wakened. Liquids } \\
\text { disturbed, some spilled. Small } \\
\text { unstable objects displaced or upset. } \\
\text { Doors swing, close, open. Shutters, } \\
\text { pictures move. }\end{array}$ \\
\hline $\mathrm{VI}$ & $90-176$ & $9.2-18$ & $8.1-16$ & Moderate & Objects Fall & $\begin{array}{l}\text { Felt by all. Many frightened and run } \\
\text { outdoors. Persons walk unsteadily. } \\
\text { Windows, dishes, glassware broken. } \\
\text { Knickknacks, books, etc., off shelves. } \\
\text { Pictures off walls. Furniture moved or } \\
\text { overturned. Weak plaster and } \\
\text { masonry D cracked. Small bells ring } \\
\text { (church, school). Trees, bushes } \\
\text { shaken (visibly, or heard to rustle). }\end{array}$ \\
\hline VII & $176-333$ & $18-34$ & $16-31$ & Strong & $\begin{array}{l}\text { Nonstructural } \\
\text { Damage }\end{array}$ & $\begin{array}{l}\text { Difficult to stand. Noticed by drivers } \\
\text { of motor cars. Hanging objects } \\
\text { quiver. Furniture broken. Damage to } \\
\text { masonry D, including cracks. Weak } \\
\text { chimneys broken at roof line. Fall of } \\
\text { plaster, loose bricks, stones, tiles, } \\
\text { cornices (also unbraced parapets } \\
\text { and architectural ornaments). Some } \\
\text { cracks in masonry C. Waves on } \\
\text { ponds; water turbid with mud. Small } \\
\text { slides and caving in along sand or } \\
\text { gravel banks. Large bells ring. } \\
\text { Concrete irrigation ditches damaged. }\end{array}$ \\
\hline
\end{tabular}




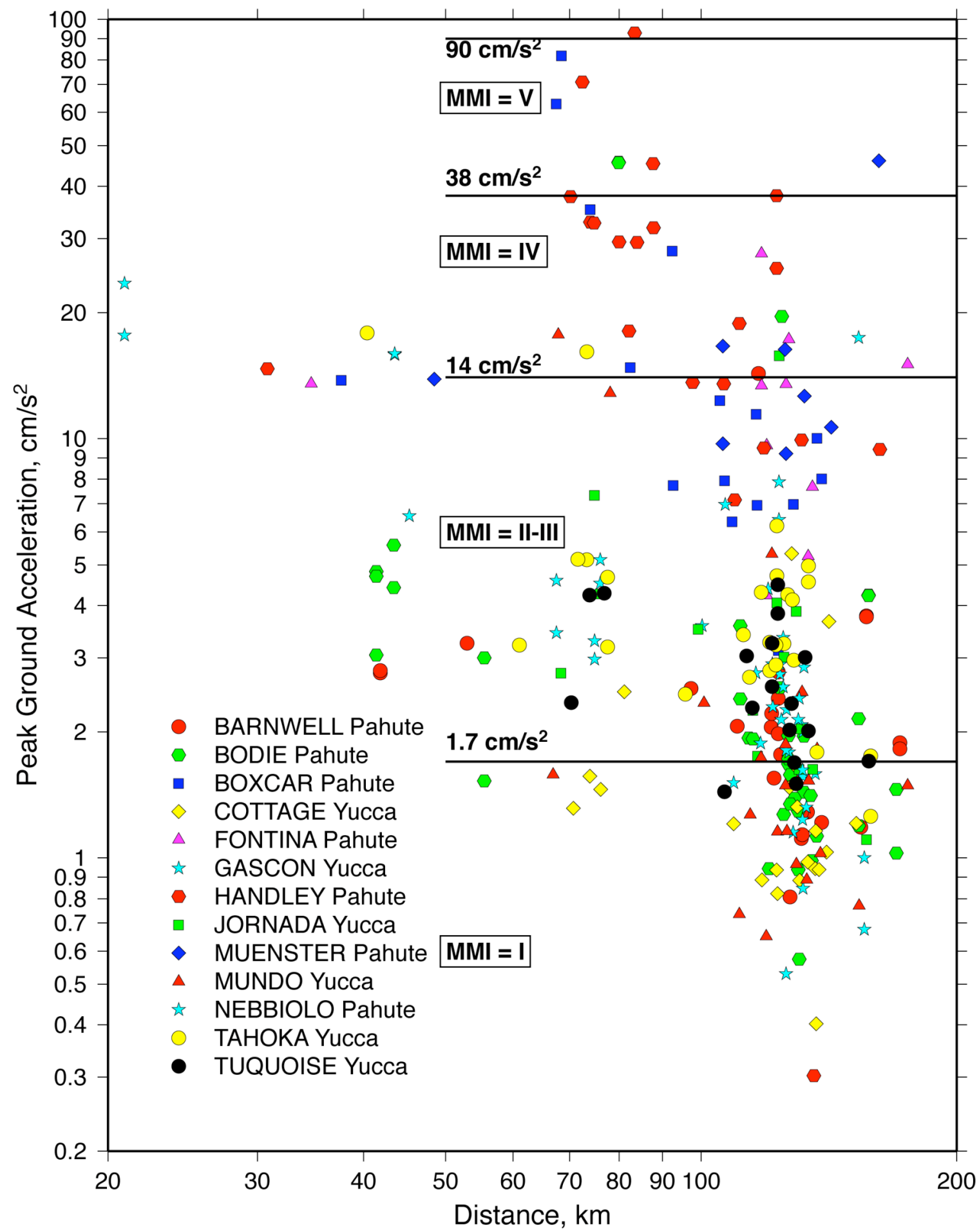

Figure 3.2. Peak ground acceleration versus source-station distance from 113 recordings of the 13 NTS explosions. Also shown are the Modified Mercalli Intensity levels (Table $3.1)$. 


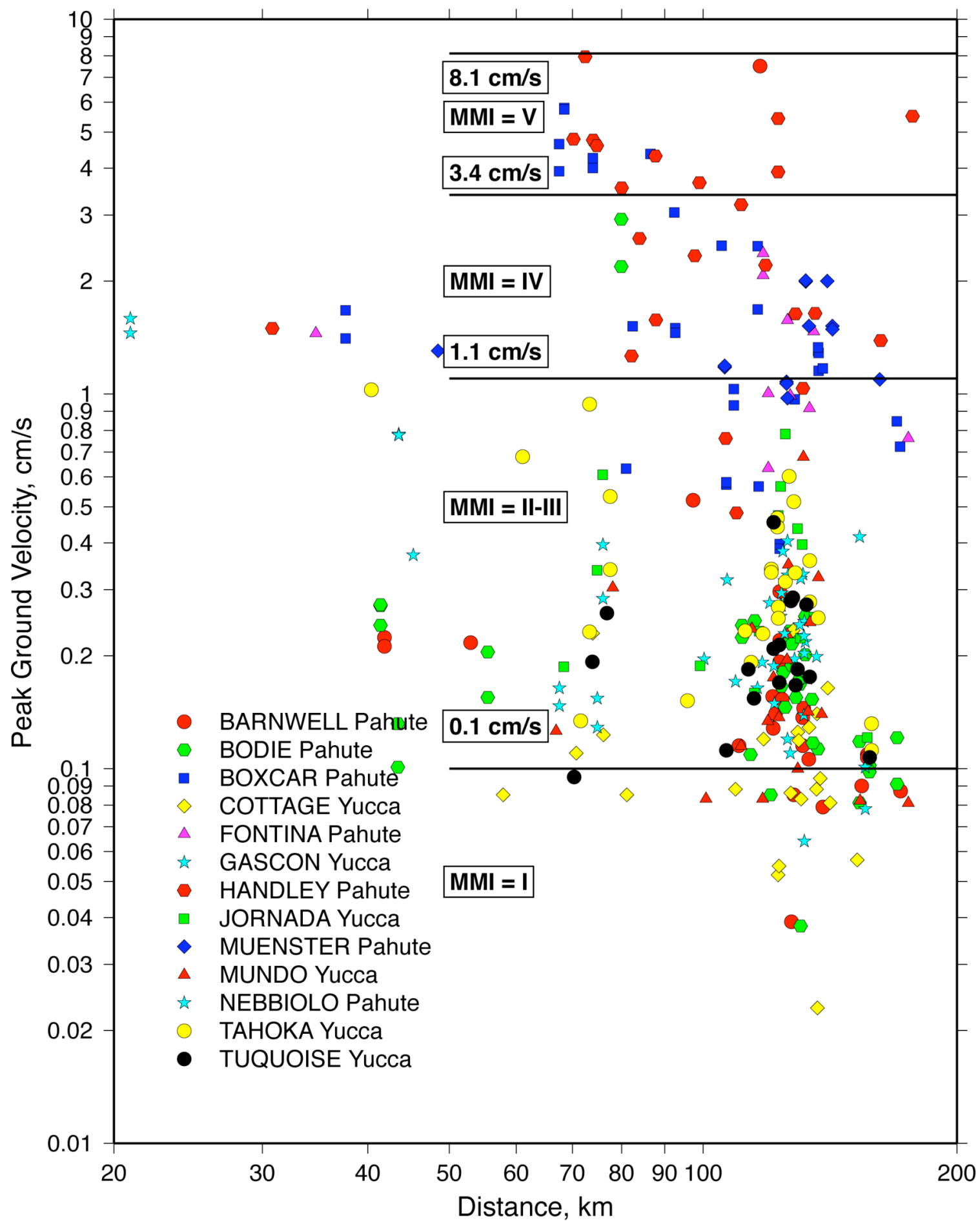

Figure 3.3. Peak ground velocity versus source-station distance from 113 recordings of the 13 NTS explosions. Also shown are the Modified Mercalli Intensity levels (Table $3.1)$. 


\section{Site Response and Basin Amplification}

In this section we will describe quantitative site response analysis using the data described in the Chapter 2. Much of this analysis was submitted for publication (Rodgers et al., 2004). We begin by reviewing site response methodologies and describing our choices of site response methods. We then describe the results of site response analysis. Site response is useful for bounding ground motion amplification around Las Vegas Valley, as well as for the specific ground motion scaling methodology we employ in Chapter 6.

\subsection{Site Response Methodology}

Site response measurements seek to quantify the effects of shallow velocity structure and local geology at a recording site (see for example Field et al., 2000; Kawase, 2003 for reviews). Site response estimates must remove source and path propagation effects from observed ground motion. Several methods have been developed to estimate site response over the last three decades. Spectral ratios have been widely used when multiple observations of an event are recorded (e.g., Borcherdt, 1970; Borcherdt and Gibbs, 1976; King and Tucker, 1984; Field et al., 1992). The Standard Spectral Ratio (SSR; Borcherdt, 1970; Borcherdt and Gibbs, 1976) uses the ratio of Fourier amplitude spectra of one site relative to a reference site. Safak (1997) gives detailed analysis of site response measurement techniques when a pair of records is available, including alternatives to the SSR. Key to spectral ratio methods is the selection of the reference site, which ideally is located on hard rock and has little or no amplification relative to the motion input into the basin. The reference site must be close enough to sites of interest so that source and propagation effects are sufficiently similar and cancel when forming the spectral ratio. Studies have shown that hard rock sites can have amplification, deamplification due to tunnel and borehole effects, weathering of near-surface rock and/or topographic effects (Tucker et al., 1984; Steidl et al., 1996; Yu and Haines, 2003). If the shallow shear velocities or NEHRP soil profile types (BSSC, 1995; 1998) at the sites are known, they can be used to classify sites and identify reference site(s) (e.g., 
Martirosyan et al., 2003). Another class of site response estimation techniques requiring multiple stations is the Generalized Inversion Method. These techniques seek to simultaneously model source, propagation and site contributions to ground motion spectral amplitudes and can be used when event-station geometries sample different propagation paths (Andrews, 1986; Boatwright et al., 1991; Hartzell, 1992). Frequencydependent S-wave coda amplitudes have been modeled in a similar fashion (Phillips and Aki, 1986).

When recordings at a reference site are not available or only single station data are available, researchers have used the Horizontal-Vertical Spectral Ratio (HVR) technique. This technique was developed to study microtremor (Nakamura, 1989) and is also referred to as the receiver function technique (Langston, 1979). Lermo and ChavezGarcia (1993) applied this method to earthquake ground motions. Several recent studies have compared site response estimation methods (e.g., Field and Jacob, 1995; Lachet et al., 1996; Bonilla et al., 1997; Riepl et al., 1998). These studies generally report that spectral ratio and generalized inversion techniques yield similar site response estimates, but uncertainties can be different depending on the data weighting. These studies also report that HVR site response estimates result in similar peak response frequencies as two- or multiple-station methods, but amplifications are often lower than SSR estimates.

The LVV stations considered in this study are in relatively close proximity $(\sim 30 \mathrm{~km})$ considering that the explosions and earthquakes are at regional epicentral distances (110$235 \mathrm{~km}$ ). The paths to Las Vegas stations exit the source region along very similar azimuths. For such geometries, source radiation pattern and propagation effects are common among recording stations. Our data are well suited for the SSR method as originally described by Borcherdt (1970). Sites SGS/ST17 and CALB/ST06 are located outside of the deepest part of the sedimentary basin on the flanks of the Frenchman Mountain and the Spring Mountains, respectively (Figure 1.2). These sites consistently observed the weakest ground motion for any given event (Figure 2.18a). Geotechnical investigations (Luke et al, 2002; Liu et al., 2004) indicate that the slowness averaged shear velocities in the upper 30 meters, $V_{30}$, at SGS/ST17 and CALB/ST06 are 695 and 
$889 \mathrm{~m} / \mathrm{s}$, respectively (nearly at or above $760 \mathrm{~m} / \mathrm{s}$, the NEHRP B, "rock" soil characterization). This suggests that SGS and CALB are appropriate reference sites. Because SGS/ST17 was closer to our basin sites and consistently had lower ground motions than CALB/ST06, we chose to use SGS/ST17 as our reference site. The CALB site is located in a small basin (Calico Basin) and is further from the central Las Vegas sites, making it less desirable. Our results are not significantly different when we used CALB/ST06 as the reference site, although amplifications above $1 \mathrm{~Hz}$ were slightly smaller when we used CALB as a reference site.

Site response was estimated with the Standard Spectral Ratio (Borcherdt, 1970; Borcherdt and Gibbs, 1976). Waveforms were selected based on visual inspection and signal-to-noise. We extracted three-component $\mathrm{S}$-wave ground motions using windows of 60-second length and applied a 5\% Hanning taper. Fourier amplitude spectra were measured on the two horizontal components. Noise amplitudes were computed from the available pre-P-wave window in a similar fashion. Only data with signal amplitudes greater than three times the pre-event noise were used in the analysis, although signal-tonoise ratios were typically greater than ten. We computed the ratio of the root mean square spectral amplitude of the horizontal ground motions to estimate the site response between the $\mathrm{k}^{\text {th }}$ basin site relative to the reference site, $\mathrm{j}$ :

$$
S R_{k}^{j}(f)=\frac{\sqrt{\left(A_{k}^{n}(f)\right)^{2}+\left(A_{k}^{e}(f)\right)^{2}}}{\sqrt{\left(A_{j}^{n}(f)\right)^{2}+\left(A_{j}^{e}(f)\right)^{2}}}
$$

where superscripts $n$ and $e$ indicate north-south and east-west components, respectively. When multiple events were observed site response curves were averaged and uncertainties were computed using the standard deviation of the log-averaged mean (Field and Jacob, 1995).

We also computed Horizontal-Vertical Spectral Ratio (HVR; Lermo and Chavez-Garcia, 1993) using the S-wave spectral amplitudes as described above. The root mean square horizontal component spectra were divided by the vertical component spectrum to form 
the HVR. Because this method does not require observations at the reference site, we were able to use all thirteen nuclear explosions at the BLUME sites. Since noise samples were limited for the BLUME data, we did not attempt to compute microtremor HVR's (Nakamura's method).

\subsection{Site Response Results}

Site response measurements for the BLUME, LSM and LVVBB data sets are presented in Figures 4.1, 4.2 and 4.3, respectively. Site response from the SSR method at the BLUME sites includes uncertainties whenever possible (Figure 4.1).
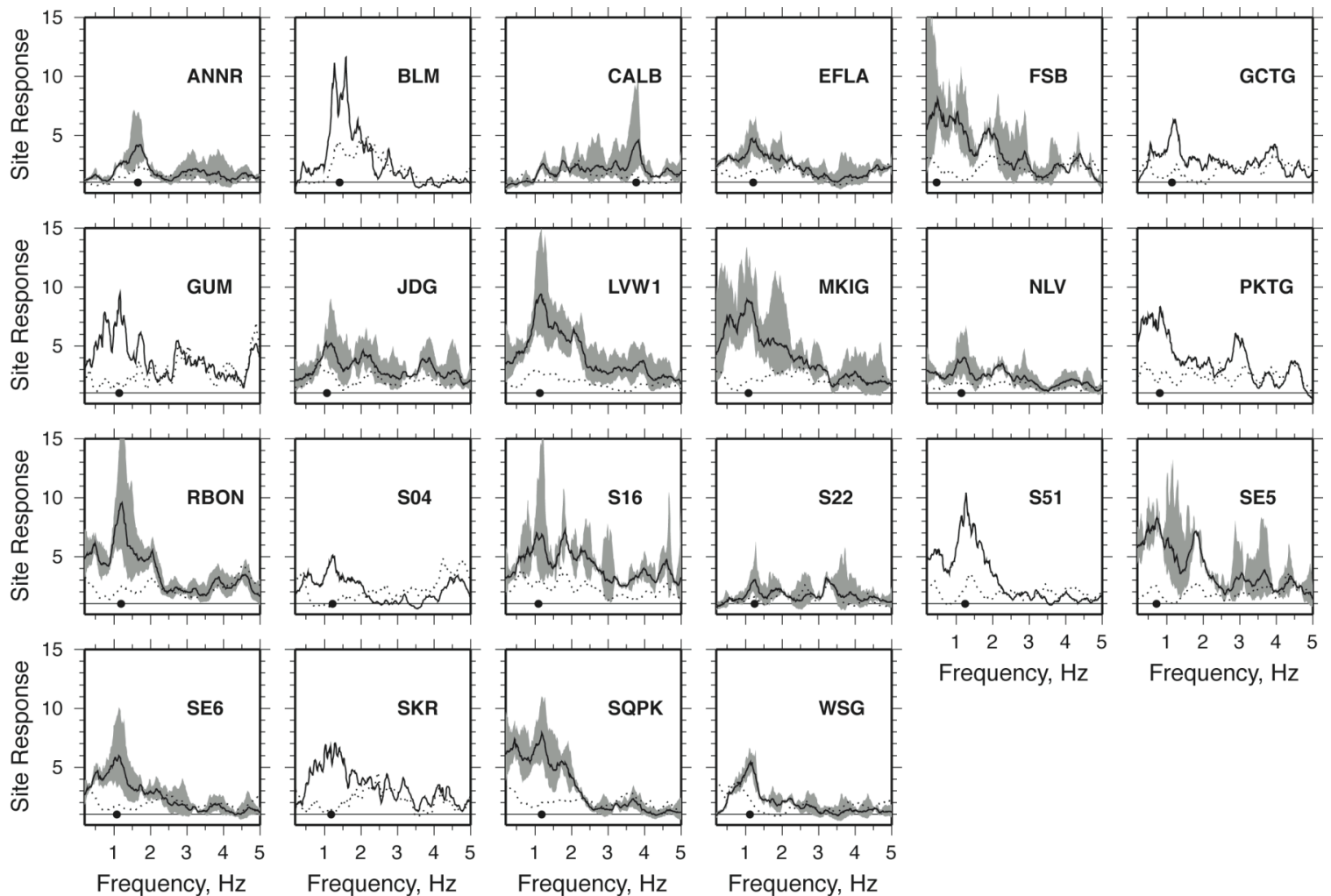

Figure 4.1. Site response estimates (log-average) at the BLUME sites from the SSR method (black lines) with uncertainties (gray, 2 standard deviations of the mean) and HVR method (dotted lines). The lowest frequency of peak SSR response is indicated by the black circle. 

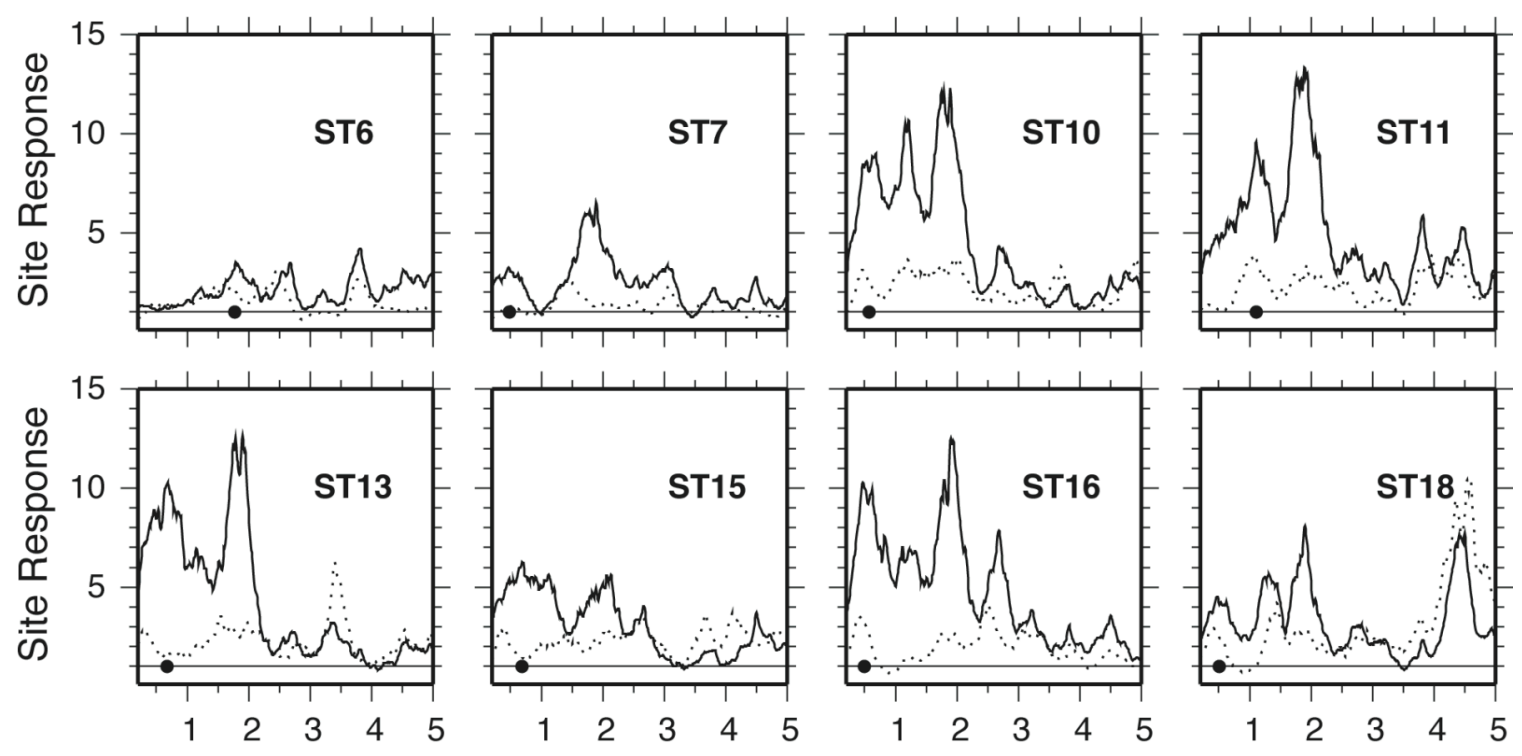

Frequency, $\mathrm{Hz}$

Frequency, $\mathrm{Hz}$

Frequency, $\mathrm{Hz}$

Frequency, $\mathrm{Hz}$

Figure 4.2. Site response estimates at the LSM sites from the SSR method (black lines) and HVR method (dotted lines). The lowest frequency of peak SSR response is indicated by the black circle.
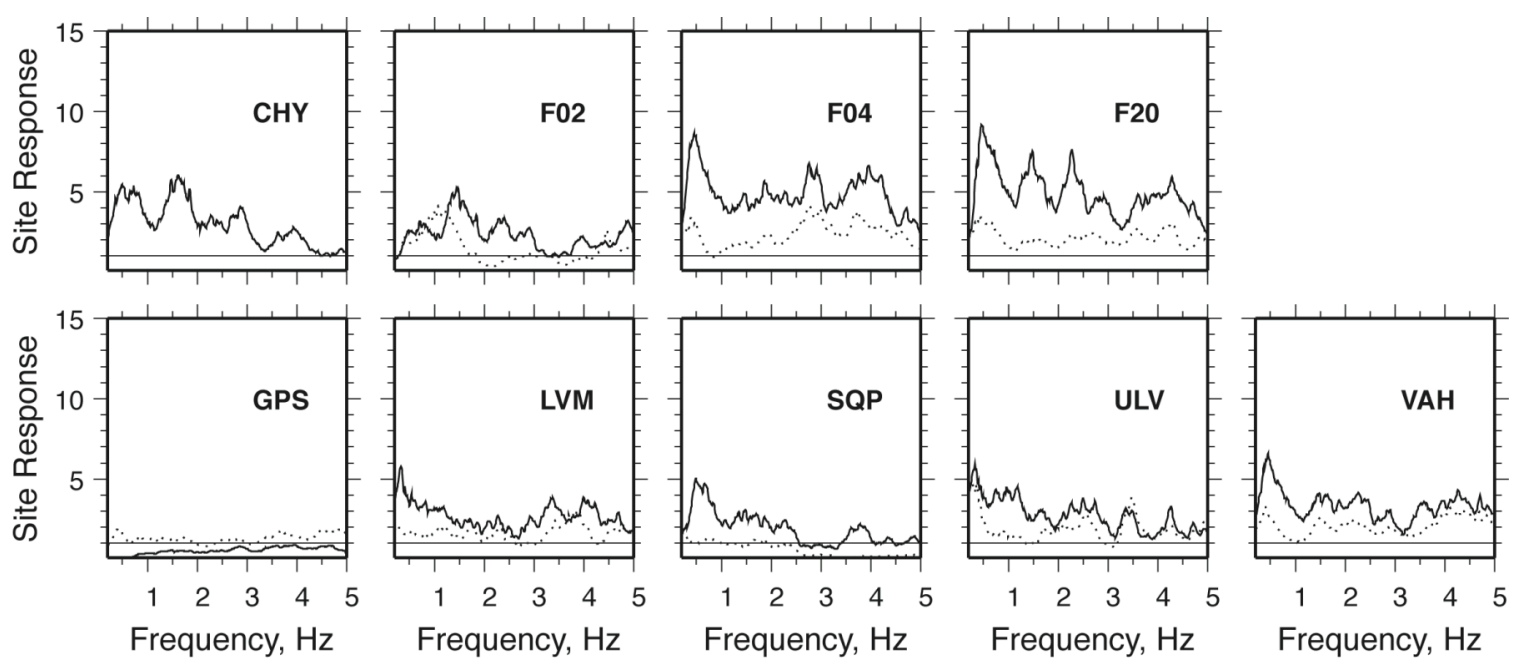

Figure 4.3. Site response estimates at the LVVBB sites from the SSR method (black lines) and HVR method (dotted lines).

Many stations have peak SSR site response in the range $0.5-2 \mathrm{~Hz}$ and are quite large, approaching a factor of ten. Uncertainties for the BLUME log-averaged site response estimates are typically large at the peak response near $1 \mathrm{~Hz}$ due to variability in the individual curves. The uncertainties properly bound the actual variability in the 
individual site response curves. Site response curves from the HVR method often show peaks at the same frequencies as the SSR curves but the amplification is typically less than the SSR curve. This is consistent with previous reports (Field and Jacob, 1995; Lachet et al., 1996; Bonilla et al., 1997; Riepl et al., 1998). Our results generally show good agreement between the SSR and HVR amplifications for frequencies above about 2 $\mathrm{Hz}$.

Many BLUME sites show a peak near $1 \mathrm{~Hz}$, while the LSM sites show multiple peaks. The lowest frequency peak is identified in the site response estimates shown in Figures 4.1 and 4.2 for the BLUME and LSM data, respectively. The LVVBB sites in the northern part of the basin, specifically CHY, F02, F04, F20 and VAH show multiple peaks (Figure 4.3) similar to the LSM sites ST10 and ST16 (Figure 4.2). Where possible, we compared site response curves from the SSR method using the different data sets.

Figure 4.4 shows the SSR curves for five sites in common between data sets.
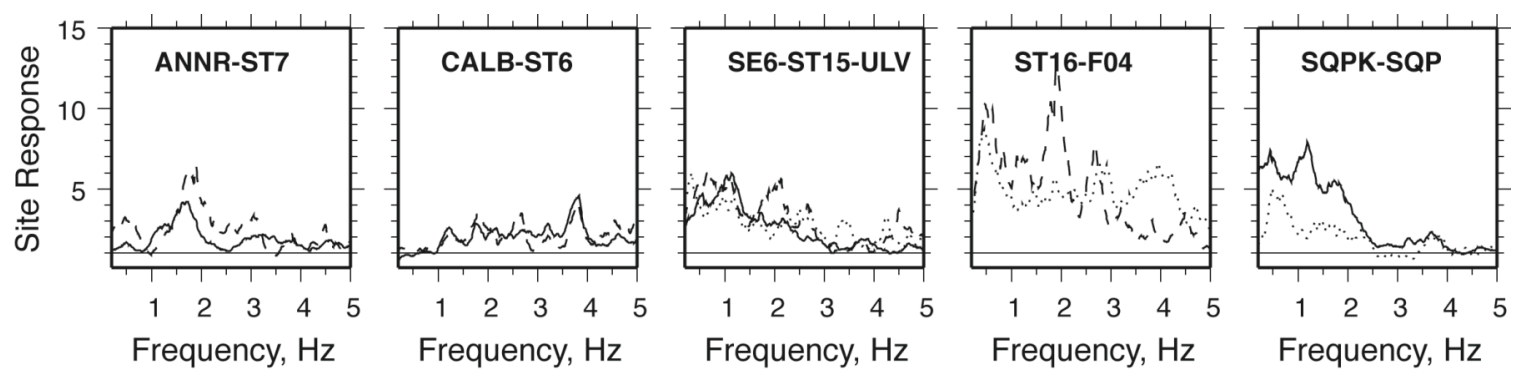

Figure 4.4. Comparison of SSR site response curves for sites in common to the BLUME (solid), LSM (dashed) and LVVBB (dotted) data sets.

The agreement is generally good, but some discrepancies are seen for large amplitude peaks at ST16-F04 and SQPK-SQP. One of the challenges of this study is the integration of site response measurements from different data sets without specific details on the historical site installations. The BLUME and LSM sites were installed in locations that have changed dramatically due to rapid urbanization of LVV. This is especially acute for the SGS/ST17 site near Grant Stewart Reservoir in a relatively new housing development on the flank of Frenchman Mountain. We expect that some of the discrepancies seen in 
Figure 4.4 are due to different behavior at the BLUME and LVVBB site SGS. We return to this issue later.

To illustrate the spatial variability in site response across LVV, we show band-averaged SSR measurements at each site plotted in map view in Figure 4.5.
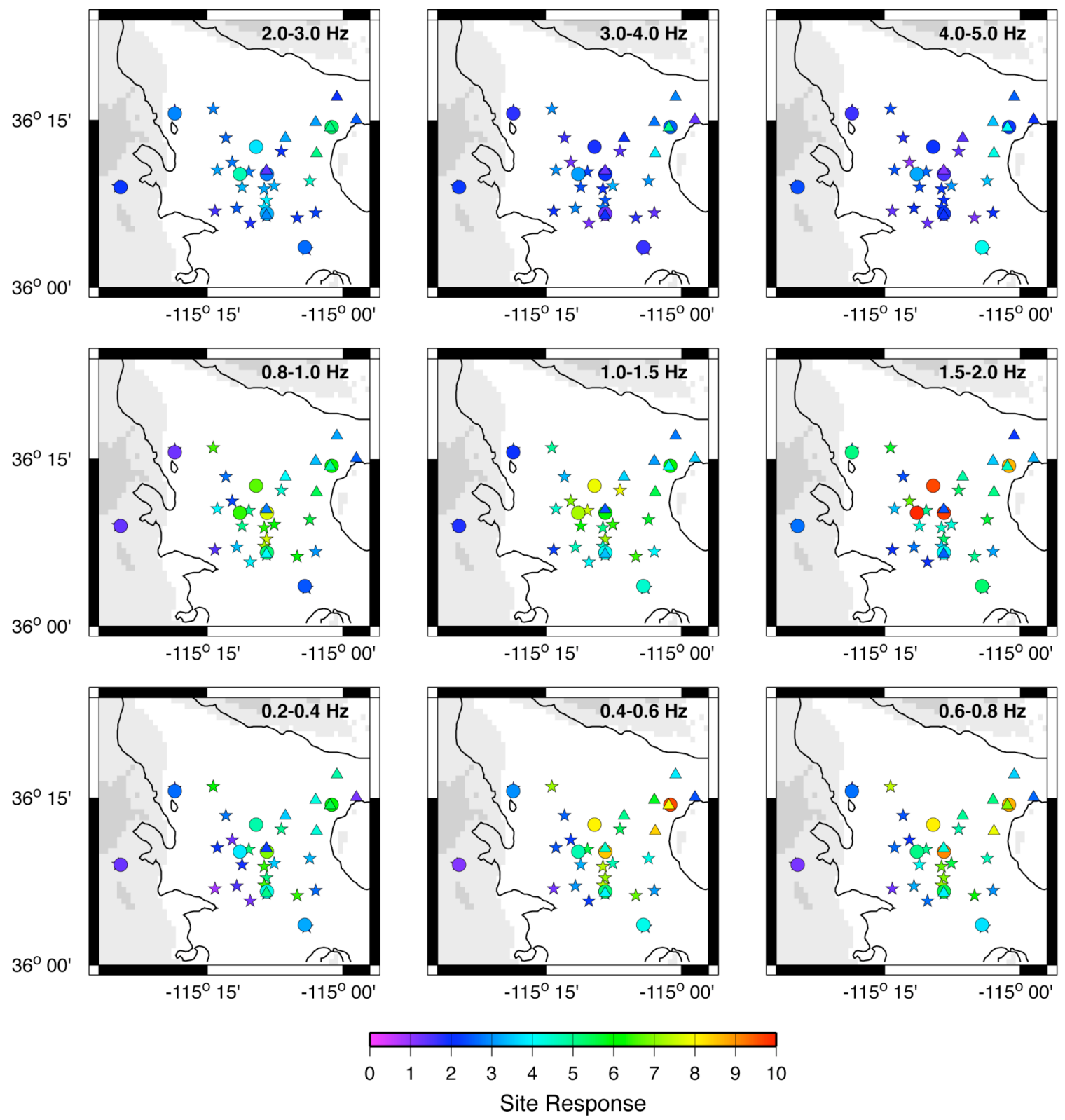

Figure 4.5. Map of band-averaged SSR site response estimates in LVV from the BLUME (stars), LSM (circles) and LVVBB (triangles) data sets. In each map the basin contact from Langenheim et al. (2000) is shown (black lines). 
Site response is lower on the Valley's west side where the basin depth is less than about 1 $\mathrm{km}$. Larger amplifications for frequencies below $2.0 \mathrm{~Hz}$ are observed in the central and northern sections of LVV where the basin depth exceeds $1 \mathrm{~km}$. These maps suggest a correlation with basin depth based on the model of Langenheim et al. (2001a).

\subsection{Understanding Site Response Amplification}

In this section we seek to understand the factors that control site response amplifications shown in figure 4.5. Numerous studies have shown the dependence of amplification on shallow shear velocities (e.g. Anderson et al., 1996; Boore and Joyner, 1997; Harmsen, 1997; Field et al., 2000; Martirosyan et al., 2002). However at the time of this report, we have limited geotechnical shear velocity profiles near the sites of amplification measurements. The map of amplifications (Figure 4.5) suggests a correlation of amplification with basin depth.

Site response in the same frequency bands is plotted versus the basin depth in Figure 4.6. The depth to basin was computed as the average depth in a $1 \mathrm{~km}$ square beneath each site (Langenheim et al., 2001a). This figure shows a striking correlation between site response and basin depth, especially for frequencies between 0.2 and about $2.0 \mathrm{~Hz}$. The BLUME sites cover the central and southern portion of LVV where the basin depth is generally less than $3 \mathrm{~km}$. LSM and LVVBB sites contribute information on the northern, deeper part of LVV. The BLUME data are consistent with the LSM data in these linear trends. However, the LVVBB data show lower amplifications versus basin depth, especially in the band $0.8-3.0 \mathrm{~Hz}$. This may be due to amplification at the LVVBB SGS site relative to the BLUME SGS site. Linear regression fits of band-averaged site response versus basin depth are shown in each plot. We computed regressions for all three data sets together and the BLUME and LSM data together. The BLUME and LSM data show a stronger correlation versus basin depth than the combined data set, regardless of the choice of reference site (SGS/ST17 or CALB/ST06). 

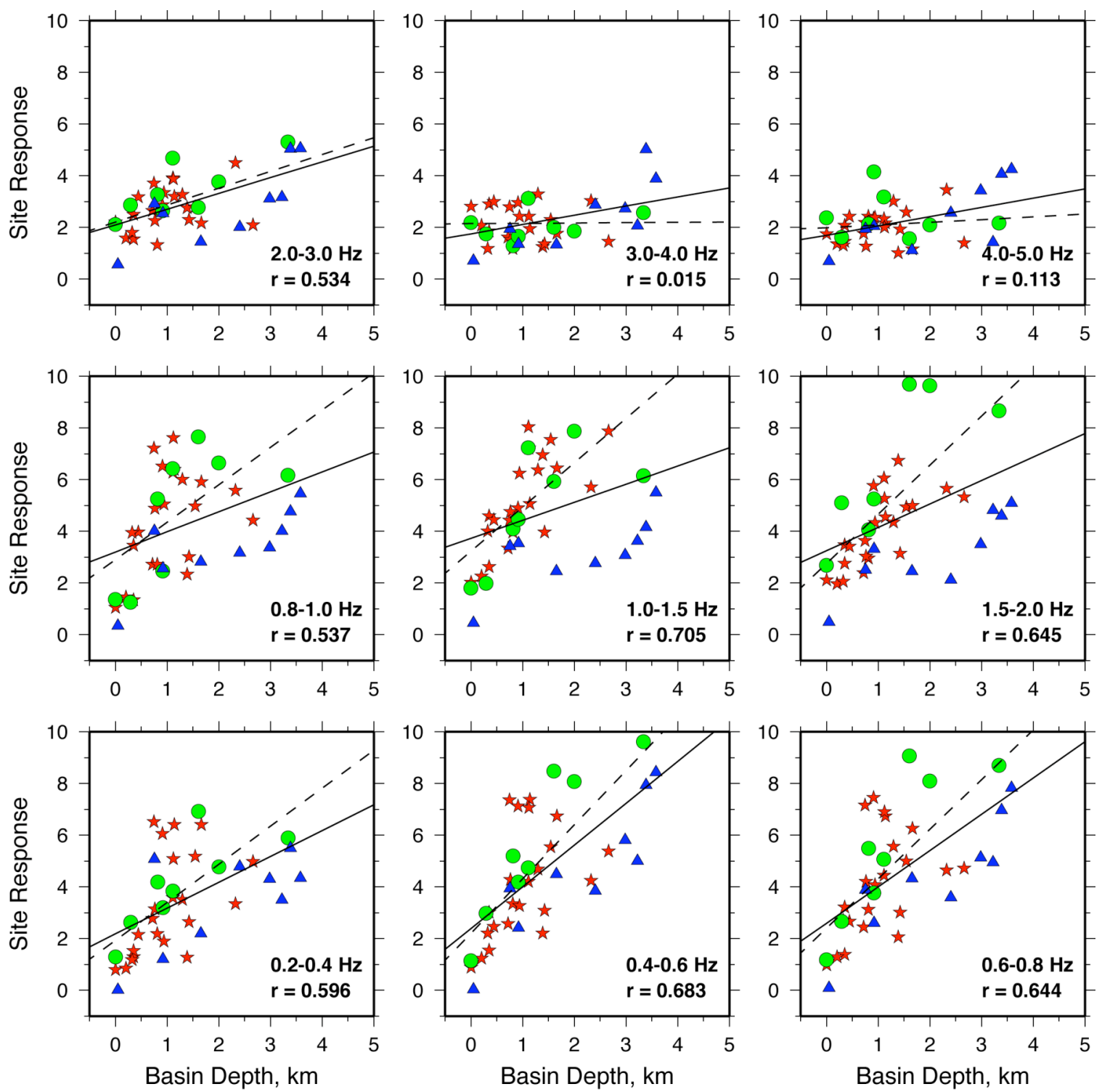

Figure 4.6. Band-averaged SSR site response estimates in LVV versus basin depth from the model of Langenheim et al. (2000) for the BLUME (stars), LSM (circles) and LVVBB (triangles) data sets. Linear regression fits for all three data sets (solid line) and the combined BLUME and LSM data sets (dashed) are shown. The linear correlation, $r$, of the joint BLUME and LSM data set is given in each panel.

Considering the standing wave explanation of the fundamental mode resonance of a layer over a half-space, the relationship between the resonant frequency, $f_{0}$, is $f_{0}=\beta / 4 h$, where $\beta$ is the shear wave velocity and $h$ is the thickness (Kramer, 1996). For the entire sedimentary column (up to $4 \mathrm{~km}$ ) to contribute to the observed site response peaks, the 
shear velocities would have to take unrealistically high values. To explore the possible dependence of site response with basin depth, we plotted the frequencies of peak SSR site response versus basin depth and in map view (Figure 4.7). Note that the frequencies of peak response cluster near frequencies $0.6,1.2$ and $2.0 \mathrm{~Hz}$ and do not show a trend with basin depth. In fact sites with very different basin depths have similar peak frequencies (e.g. S22, NLV, SE6, SQPK, S51, Figure 4.1).
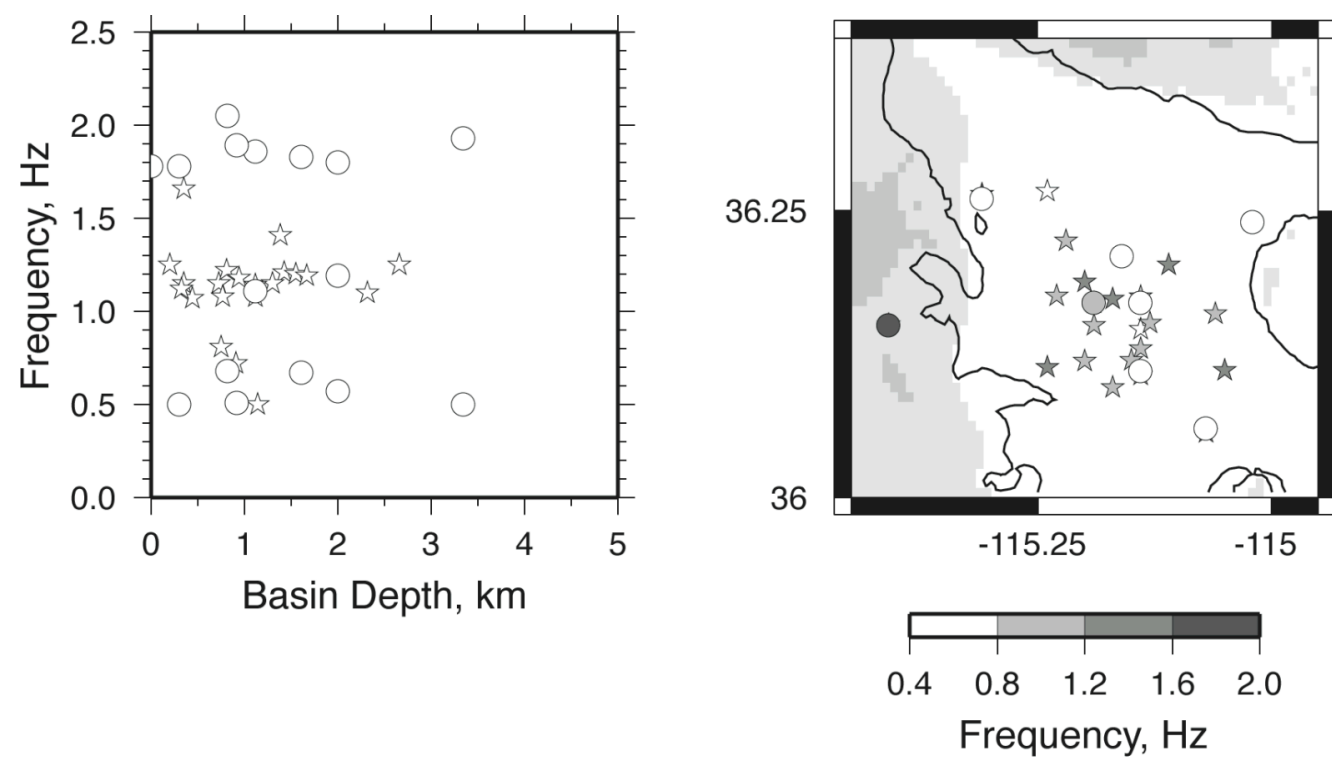

Figure 4.7. (a) Frequencies of peak response at BLUME and LSM sites versus basin depth. (b) Map of lowest frequency of peak response at BLUME and LSM sites projected at site location.

The correlation of site-specific amplification with basin depth (Figure 4.6) does not prove a causal relationship, but simply provides a convenient and suggestive way to display the data. The deeper sections of the basin are likely to have higher velocity consolidated sediments (Tabor, 1982; Snelson et al., 2003) that have little influence on amplification. It is possible that basin depth is correlated with low-velocity near-surface sediments due to transport of recent alluvial fill to lower elevations in the northern, deeper basin. It is well known that low shallow shear wave velocities are likely to result in higher site response (e.g., Anderson et al., 1996). We compared site response curves at locations where we have preliminary geotechnical shear velocity results (Luke et al., 2002; Liu et al., 2004). We represented each profile by the slowness-averaged shear wave velocity for 
the upper 30 meters $\left(\mathrm{V}_{30}\right)$. These indeed show that the large amplification at LVW1 occurs with the lowest $\mathrm{V}_{30}$ and the sites with lower amplification have higher $\mathrm{V}_{30}$ (Figure 4.8). In the following section, we attempt to understand the observed site response with a series of modeling experiments.

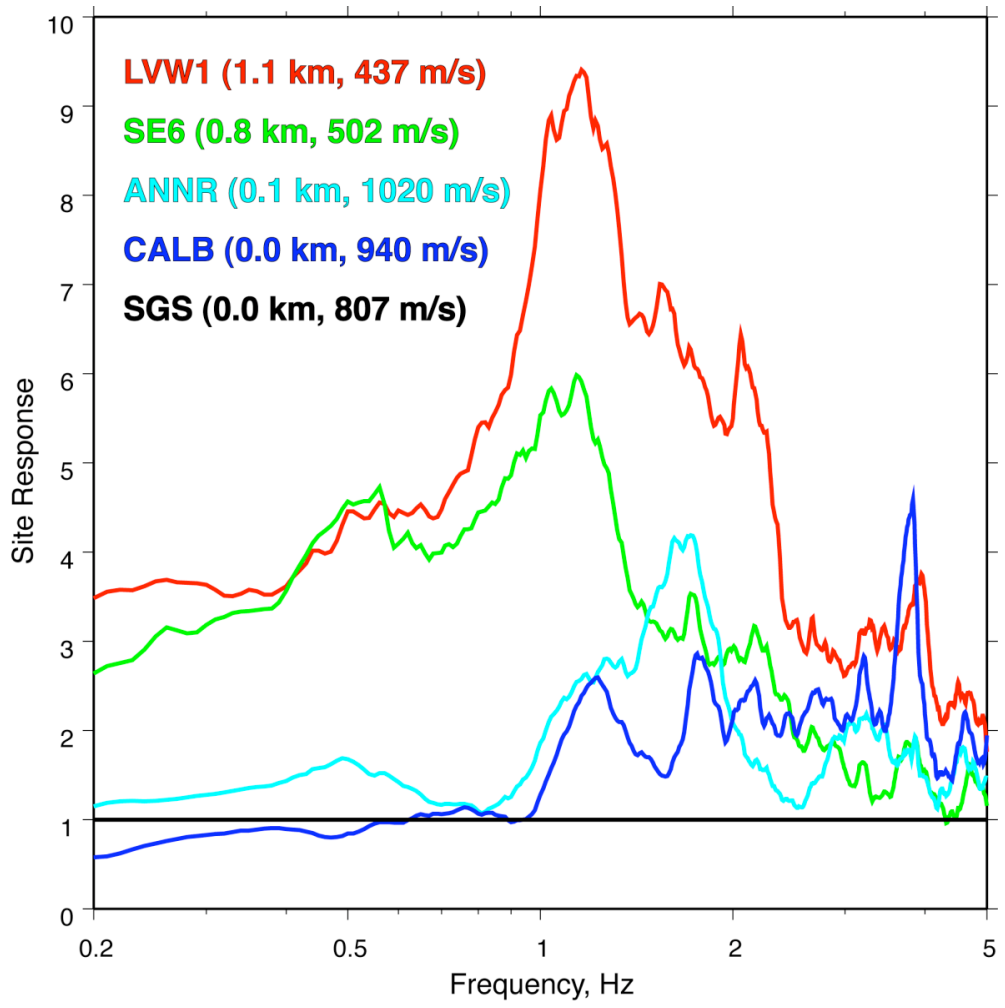

Figure 4.8. Site response curves for BLUME sites LVW1, SE6, ANNR, CALB and SGS. The basin depth and preliminary V30 at each site are shown.

Many studies have investigated the relationship between site response and geotechnical velocities and/or geologies (e.g. Boore and Joyner, 1997; Harmsen, 1997; Field et al., 2000; Martirosyan et al., 2002). Recent geotechnical surveys report shallow shear-wave velocities in Las Vegas. These include spectral analysis of surface waves (SASW) and Refraction Microtremor (ReMi) surveys (Liu and Luke, 2004) at distributed locations throughout LVV as well as a 15-km ReMi transect through central Las Vegas (Scott et al., 2005). The seismic velocity profiles used in this study are available online (Luke, 2005). The combination of new site response and geotechnical velocity measurements presents a unique new opportunity to investigate seismic wave amplification in a highly urbanized sedimentary basin. Figure 4.9 shows the locations of our site response and 
geotechnical measurements. Of the 68 reported shear wave velocity profiles, 12 locations are within $1.5 \mathrm{~km}$ of an observed site response, with most location pairs closer than 0.5 $\mathrm{km}$. These 12 sites provide the basis for investigating the dependence of site response amplifications on geotechnical shear wave velocities.

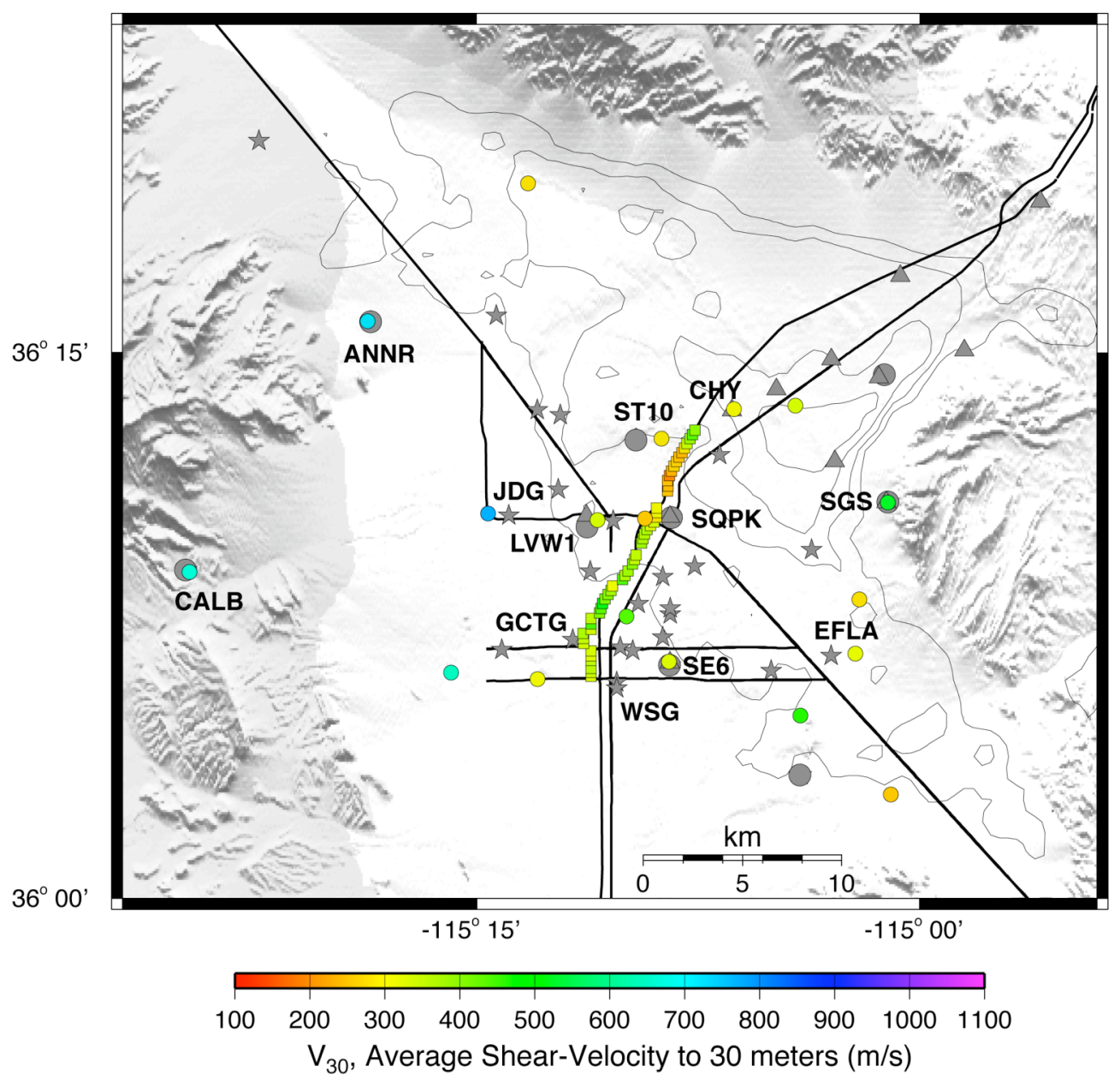

Figure 4.9 Map of Las Vegas Valley showing major roads, the basin model (contour interval $1 \mathrm{~km}$ ) from Langenheim et al. (2001) and seismic stations from various networks used in this study: BLUME (stars); LSM (circles); and LVVBB (triangles). Also shown are the geotechnical survey sites are color-coded by their V30 values.

Figure 4.10 shows the band-averaged site response amplification versus slownessaveraged geotechnical shear wave velocities using averaging depths of 10, 30 and 100 meters, $v_{d}$. Note that the amplifications decrease rapidly as the shear velocities increase and change little over a range of higher velocities. 

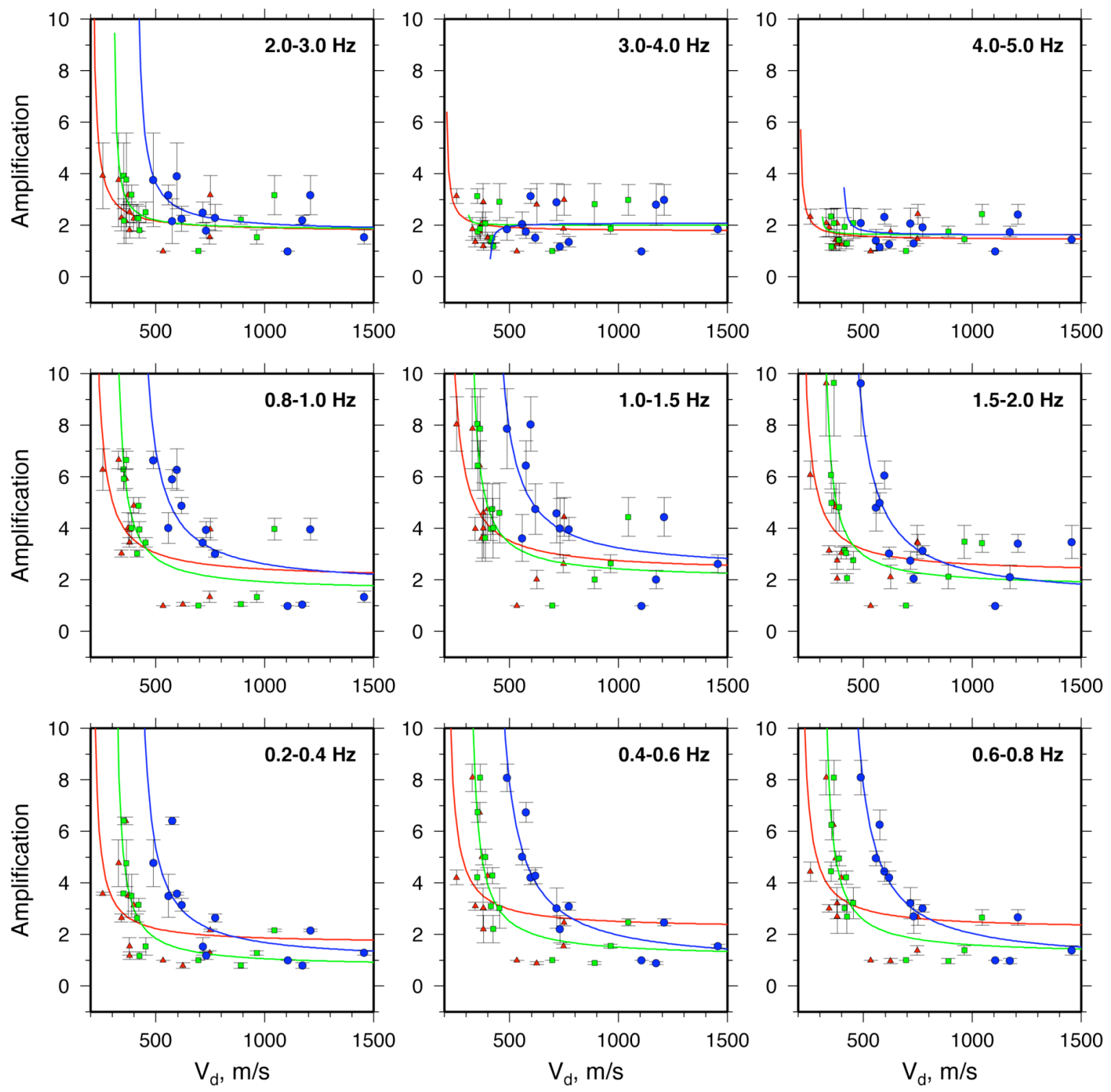

Figure 4.10 Band-averaged site response versus slowness-averaged shear velocities using averaging depths of $10 \mathrm{~m}$ (red triangles), $30 \mathrm{~m}$ (green squares) and $100 \mathrm{~m}$ (blue circles). The fit to the data with the function in equation (1) is shown with the colorcoded lines.

We tried several functional forms to fit these data with standard regression analysis. The rapid decrease in site response amplification at a given frequency, $A\left(v_{d} ; f\right)$, as a function of $v_{d}$ is well modeled with a function of the form:

$$
A\left(v_{d} ; f\right)=A_{r}+\frac{a}{\left(v_{d}-v_{d}^{r e f}\right)}
$$


Where $v_{d}^{r e f}$ is a reference velocity, set a priori to be less than all average geotechnical velocities, $v_{d}$, to a given depth, $d$. We fit the observed amplifications as a function of $v_{d}$, solving for the constants $A_{r}$ and $a$. The site response is asympototic to $A_{r}$ as shear velocity increases. This is the average response of high velocity rock sites, approaching values of 1-3. Several sites in the western portion of the basin have high geotechnical shear velocities despite being within the deep $(>0.5 \mathrm{~km})$ alluvial basin.

The function fits to the data are shown with observed amplifications in Figure 4.10. The amplifications are fit well for frequencies with largest variation (i.e. below $2.0 \mathrm{~Hz}$ ). To illustrate the goodness-of-fit for the functional form in eq. (1), we plot the root-meansquare (RMS) reduction of the data as a function of frequency for each depth average (10, 30 and $100 \mathrm{~m}$ ) in Figure 4.11. The behavior of amplification with average geotechnical velocities shows that lower frequencies $(<2.0 \mathrm{~Hz})$ are well fit by equation (1) using the velocity averages to 30 and $100 \mathrm{~m}$ depth, with the fit decreasing with frequency. The velocity average to $10 \mathrm{~m}$ depth has little control on amplification, with only modest influence on intermediate frequencies $(1.0-3.0 \mathrm{~Hz})$.

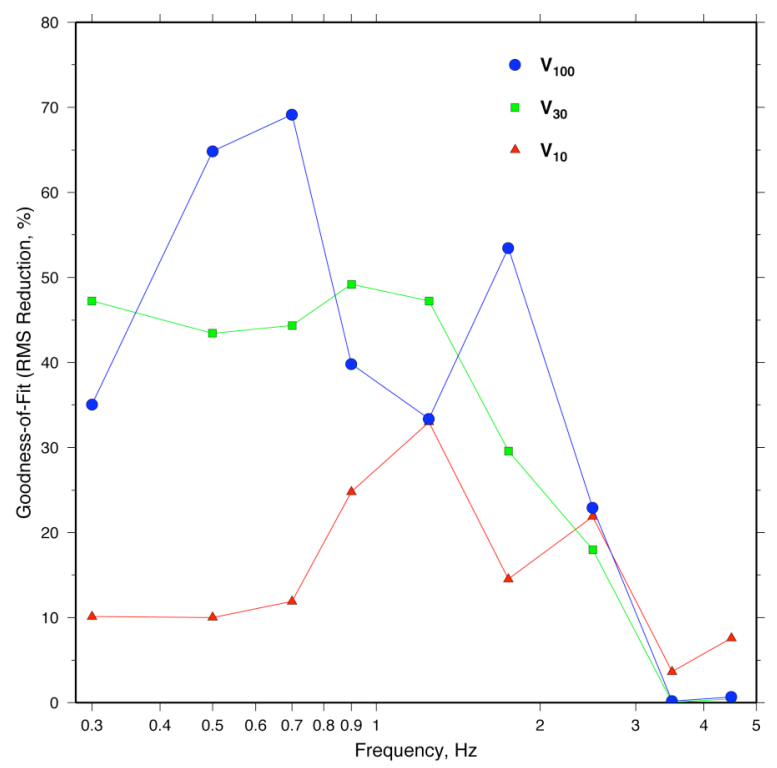

Figure 4.11 Goodness-of-Fit (RMS reduction) for equation (1) as a function of frequency for depth averaged velocities to 10,30 and $100 \mathrm{~m}$. 


\subsection{Site Response Conclusions}

In this chapter, we combined different data sources to estimate site response across a wide area of Las Vegas Valley (LVV). Our measurements greatly expand the coverage of LVV over previous studies. Site amplification is variable, with site-averaged amplifications approaching a factor of ten. However the frequencies of peak site response are relatively stable and low frequency $(0.5-2.0 \mathrm{~Hz})$. These results confirm and extend the conclusions of Murphy and Hewlett (1975) and Su et al. (1998) that lowfrequency amplification exposes Las Vegas to ground motion hazard from distant earthquakes. Our extensive site response results can be used in seismic hazard assessment, to scale observed ground motions and/or predict ground motion from possible scenario explosions and/or earthquakes.

The correlation of amplification with basin depth is intriguing. The fact that the frequencies of peak site response are relatively stable across LVV suggests that basin depth is not the only controlling factor for the large amplitude low frequency $(<1.5 \mathrm{~Hz})$ site response peaks. A standing wave explanation of the fundamental mode resonance of a layer over a half-space yields unrealistic basin shear velocities.

The frequency dependent behavior of amplification with shallow shear velocity averages shows that $v_{30}$ and $v_{100}$ have a strong influence on amplifications below about $1 \mathrm{~Hz}$. Shallower velocities, averaged to 10 meters depth, $v_{10}$, has a modest influence on higher frequency amplifications, 1-3 Hz. In our comparisons of amplification with the average shear velocity to $30 \mathrm{~m}\left(v_{30}\right)$, we find larger amplifications and stronger dependence than observations from the San Francisco and Los Angeles regions (Borcherdt, 1994; Harmsen, 1997), or recent observations from Anchorage, Alaska (Martirosyan et al., 2002), although other studies are based on larger data sets. The stronger dependence of

amplification on shallow shear velocities in the Basin and Range province compared with other regions implies that ground motion hazard could be underestimated using site amplification relationships derived from other regions. Further investigation of site 
amplification and its relationship to geotechnical shear wave velocities is needed. The establishment of dependence of site amplification with average geotechnical shear velocities can allow for the projection of site effects to a number of locations with geotechnical surveys (Figure 4.9). Future studies will confirm these relationships and be used to make shake maps of Las Vegas Basin. We attempt to understand the frequency dependent site response by numerical modeling in the next Chapter. 


\section{Two-Dimensional Elastic Finite Difference Modeling}

In this chapter we describe a series of numerical experiments to determine the factors that control basin amplification. The objective of these experiments is to understand specific frequency-dependent site response in Las Vegas, however, the results have general applicability to other basins.

\subsection{Finite Difference Modeling}

In an attempt to better understand the structure controlling site response in Las Vegas we performed a series of two-dimensional (2D) finite difference calculations. Threedimensional (3D) elastic finite difference simulations (e.g., Graves, 1996) have been used to understand and predict ground motions for past and scenario earthquakes (e.g., Olsen et al., 1995, Stidham et al., 1999). Low seismic velocity near-surface material in sedimentary basins require close grid spacing in order to satisfy numerical accuracy conditions for finite difference solutions. The simulation of ground motion response up to $1 \mathrm{~Hz}$ in $3 \mathrm{D}$ for ranges typical of the NTS-LVV paths $(\sim 130 \mathrm{~km})$ requires high performance parallel computing resources (Larsen, 2002). We instead chose to perform a series of $2 \mathrm{D}$ simulations on a desktop system that allowed us to easily investigate a range of models and experiment with various features of the models. 2D simulations cannot correctly represent spherical geometric spreading and out-of-plane propagation effects. However, since the goal of our modeling is to reproduce the low-frequency amplification of basin sites relative to a hard-rock reference site, 2D modeling is adequate. We used the LLNL-developed E3D $4^{\text {th }}$ order staggered grid finite difference code (Larsen and Schultz, 1995). These calculations were performed for a $233 \mathrm{~km}$ by $75 \mathrm{~km}$ box with 0.05 $\mathrm{km}(50 \mathrm{~m})$ grid spacing. Accurate calculations were possible for frequencies up to 1.5 $\mathrm{Hz}$.

5.2 Modeling Experiments 
We used a cross-section from the LSM epicenter to LVV through the Langenheim et al. (2001a) basin model to determine the depth to basement (Figure 5.1).

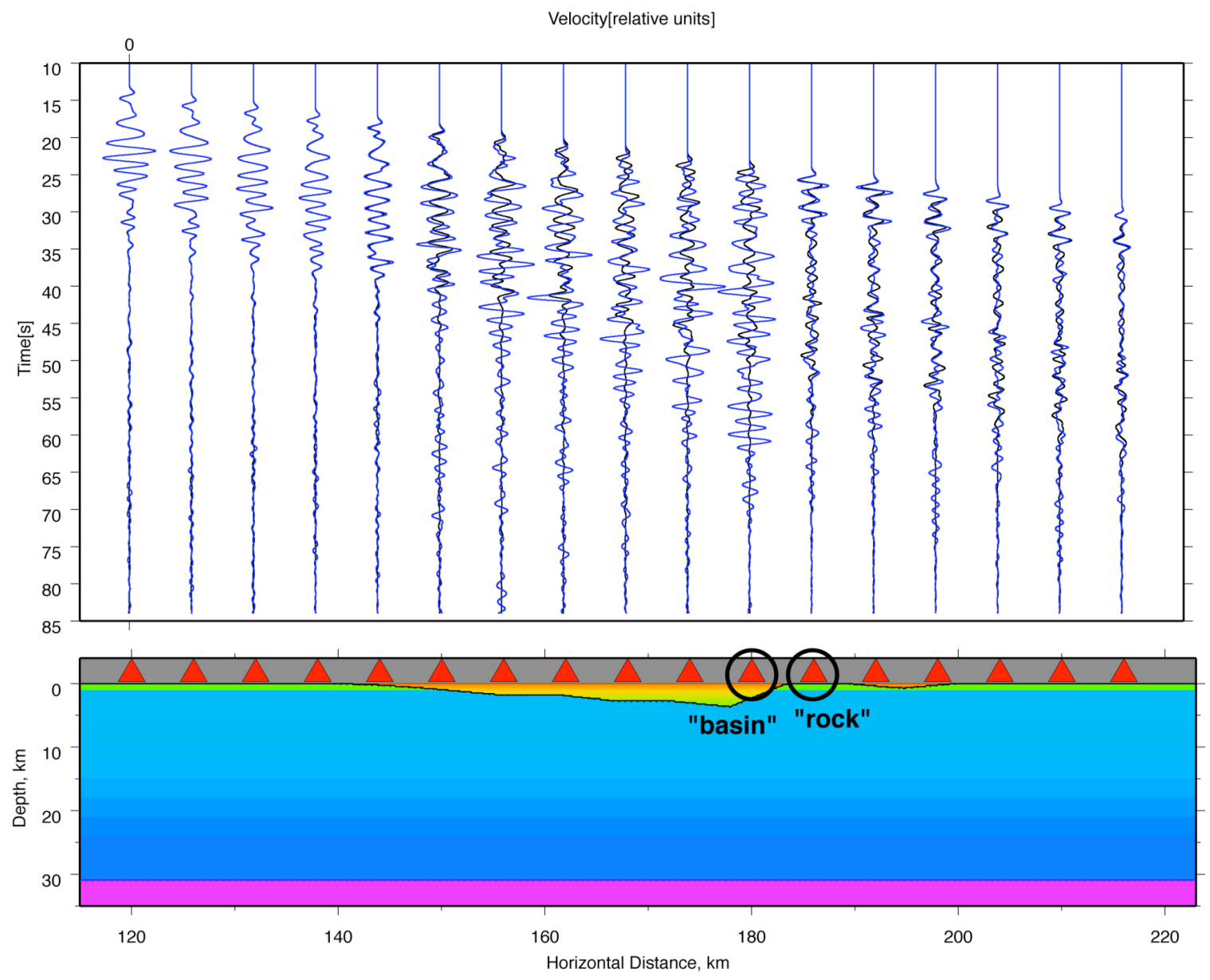

Figure 5.1. (top) Horizontal component synthetic waveforms for the plane-layered background model (black) and the 2D model with basin structure (blue). (bottom) Crosssection of the 2D model showing color-coded shear-wave velocities. Stations where synthetic seismograms are output are shown as red triangles. Circled "basin" and "rock" stations are used in the site response modeling experiments shown in Figure 5.2 and 5.3.

We fixed the velocity profile through the crystalline crust and mantle, but allowed the velocity profile in the basin to vary with special emphasis on the shallowest velocities (< $250 \mathrm{~m}$ ). The crystalline crustal and mantle model is based on Patton and Taylor (1984), but we increased the surface velocities to be consistent with hard rock lithologies (NEHRP A classification) at the surface (Table 5.1). A double-couple source for the Little Skull Mountain earthquake at approximately $100 \mathrm{~km}$ from the basin provided the excitation. The horizontal and vertical component ground velocities were sampled at 
regular intervals within and adjacent to the basin. We then computed the horizontal component SSR between the basin sites and the reference site. To illustrate the effects of low-velocity sediments, Figure 5.1a compares the response of a 1D crystalline crustal model (solid lines) and a 2D model with the sedimentary basin (dashed lines). Note the higher amplitudes and longer duration of the sedimentary response. However, the reference site adjacent to the basin has a similar, lower amplitude response for both models.

Table 5.1. "Hard rock" velocity model for finite difference simulations based on Patton and Taylor (1984).

\begin{tabular}{|r|r|r|r|r|r|r|}
\hline $\begin{array}{c}\text { Depth } \\
(\mathrm{km})\end{array}$ & $\begin{array}{c}\text { Thickness } \\
(\mathrm{km})\end{array}$ & $\begin{array}{c}\mathrm{V}_{\mathrm{P}} \\
(\mathrm{km} / \mathrm{s})\end{array}$ & $\begin{array}{c}\mathrm{V}_{\mathrm{S}} \\
(\mathrm{km} / \mathrm{s})\end{array}$ & $\begin{array}{c}\rho \\
(\mathrm{gm} / \mathrm{cc})\end{array}$ & \multicolumn{1}{|c|}{$\mathrm{Q}_{\mathrm{P}}$} & \multicolumn{1}{c|}{$\mathrm{QS}_{\mathrm{S}}$} \\
\hline 0.0 & 1.00 & 3.210 & 1.900 & 2.330 & 190 & 85 \\
\hline 5.80 & 4.8 & 5.930 & 3.500 & 2.770 & 190 & 85 \\
\hline 10.0 & 4.2 & 5.950 & 3.510 & 2.770 & 190 & 85 \\
\hline 12.0 & 2.0 & 5.970 & 3.520 & 2.780 & 386 & 172 \\
\hline 15.0 & 3.0 & 6.000 & 3.540 & 2.780 & 386 & 172 \\
\hline 18.0 & 3.0 & 6.070 & 3.580 & 2.790 & 386 & 172 \\
\hline 21.0 & 3.0 & 6.200 & 3.660 & 2.810 & 386 & 172 \\
\hline 24.0 & 3.0 & 6.310 & 3.720 & 2.830 & 233 & 103 \\
\hline 27.0 & 3.0 & 6.360 & 3.750 & 2.840 & 233 & 103 \\
\hline 31.0 & 4.0 & 6.410 & 3.778 & 2.850 & 233 & 10 \\
\hline 61.0 & 30.0 & 7.900 & 4.400 & 3.200 & 112 & 50 \\
\hline 101.0 & 40.0 & 7.900 & 3.300 & 3.300 & 72 & 31 \\
\hline 117.0 & 16.0 & 7.900 & 4.100 & 4.120 & 210 & 93 \\
\hline 137.0 & 20.0 & 7.900 & 4.050 & 3.400 & 240 & 107 \\
\hline
\end{tabular}

We investigated the sensitivity of the amplification at the basin sites to the shear and compressional velocities and density in a $250 \mathrm{~m}$ thick surface layer of the basin.

Although the modeling is limited by the 2-D approximation, we can compare the relative amplification between two stations with the Standard Spectral Ratio for different values of elastic parameters. In Figure 5.2, we illustrate the difference between two characteristic stations, located at a basin and a rock site (marked by circles in Figure 5.1), for shear velocities equal to $500,750,1000,1250$ and $1500 \mathrm{~m} / \mathrm{s}$ in the shallowest $250 \mathrm{~m}$ for frequencies up to $1 \mathrm{~Hz}$. Decreasing the surface shear velocity clearly affects the 
amplitude, as well as the duration of the predicted ground motion. This experiment demonstrates that in order to get realistic predictions of the ground motion, low shear wave velocities in the surface layer must be considered.
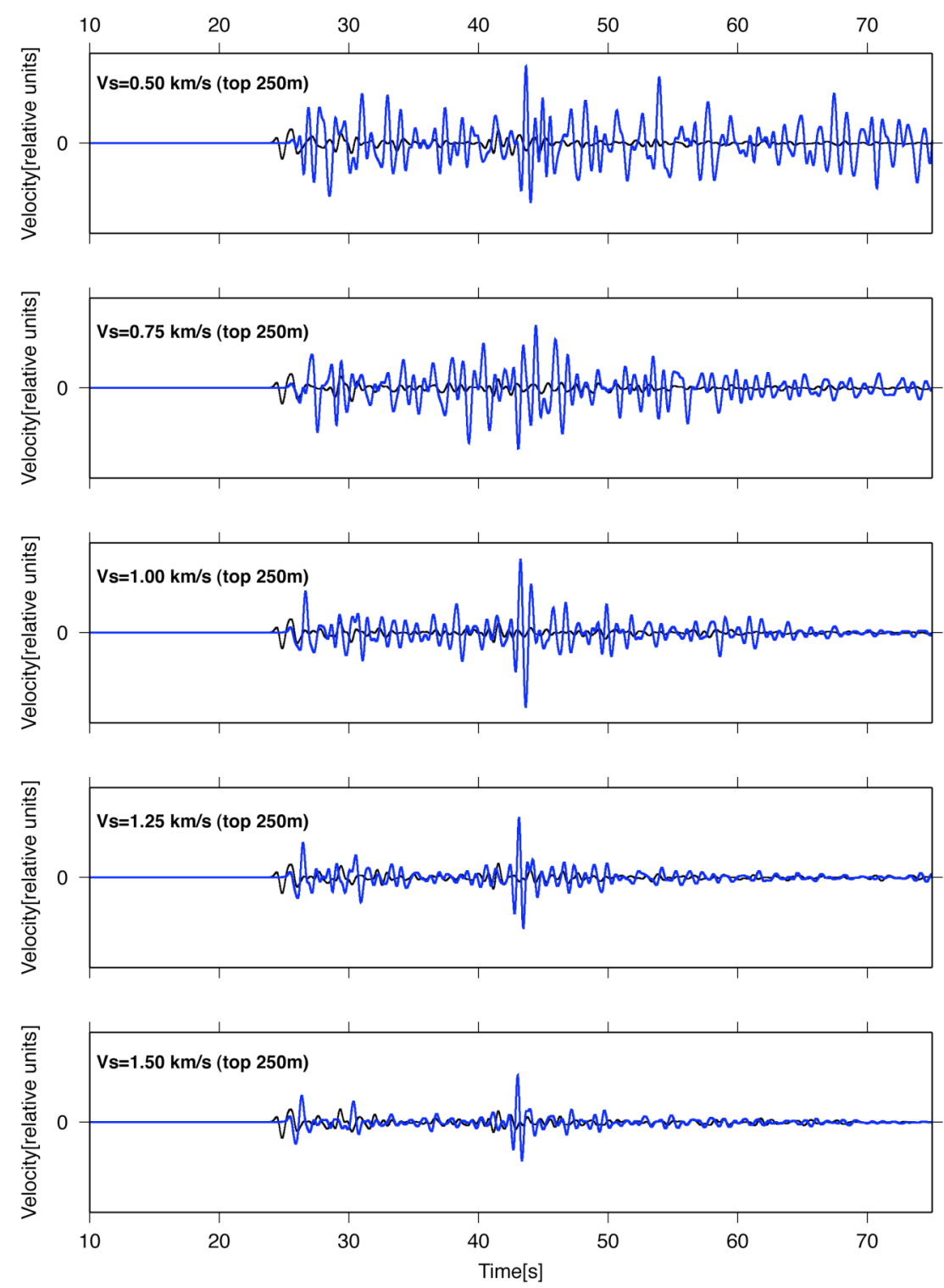

Figure 5.2. Horizontal component waveforms for the "basin" (blue) and "rock" (black) sites for synthetic experiments illustrated in Figure 9. Each panel shows the results using different shallow shear velocities within the upper $250 \mathrm{~m}$ of the basin. These shear velocities range from $500-1500 \mathrm{~m} / \mathrm{s}$ (top, bottom, respectively).

Figure 5.3 shows observed site response at two sites with high amplification, ST10 and RBON (see Figure 4.1). The ST10 site response curve shows the larger peak near $0.6 \mathrm{~Hz}$ 
and both curves show the peak response near $1.2 \mathrm{~Hz}$. Recall many sites show the peak near $1.2 \mathrm{~Hz}$ (Figure 4.7).

(a)

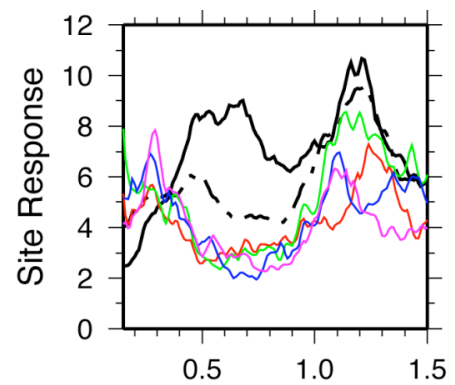

(b)

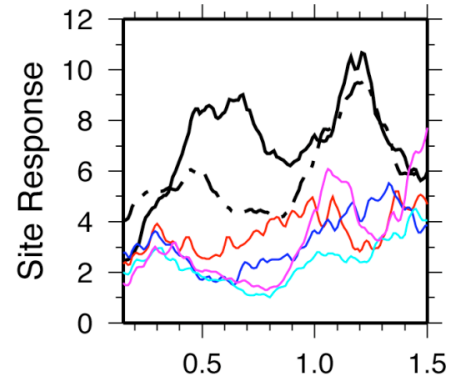

(c)

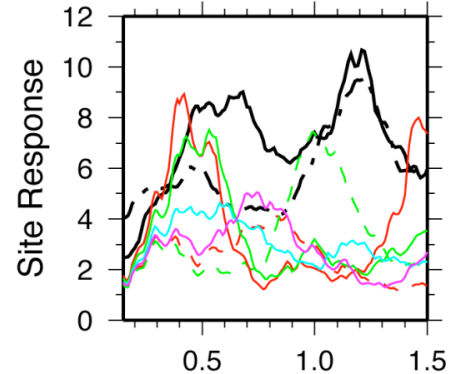

(d)

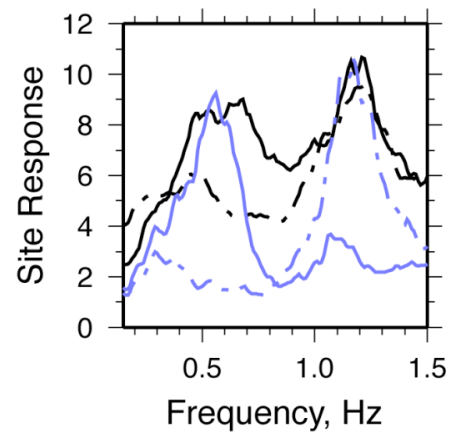

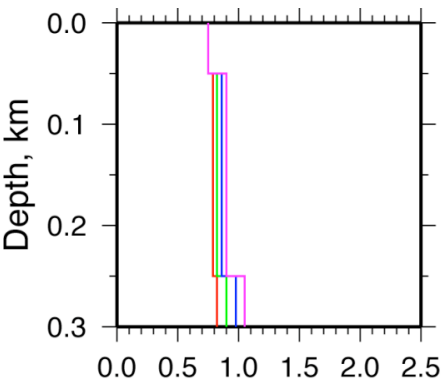
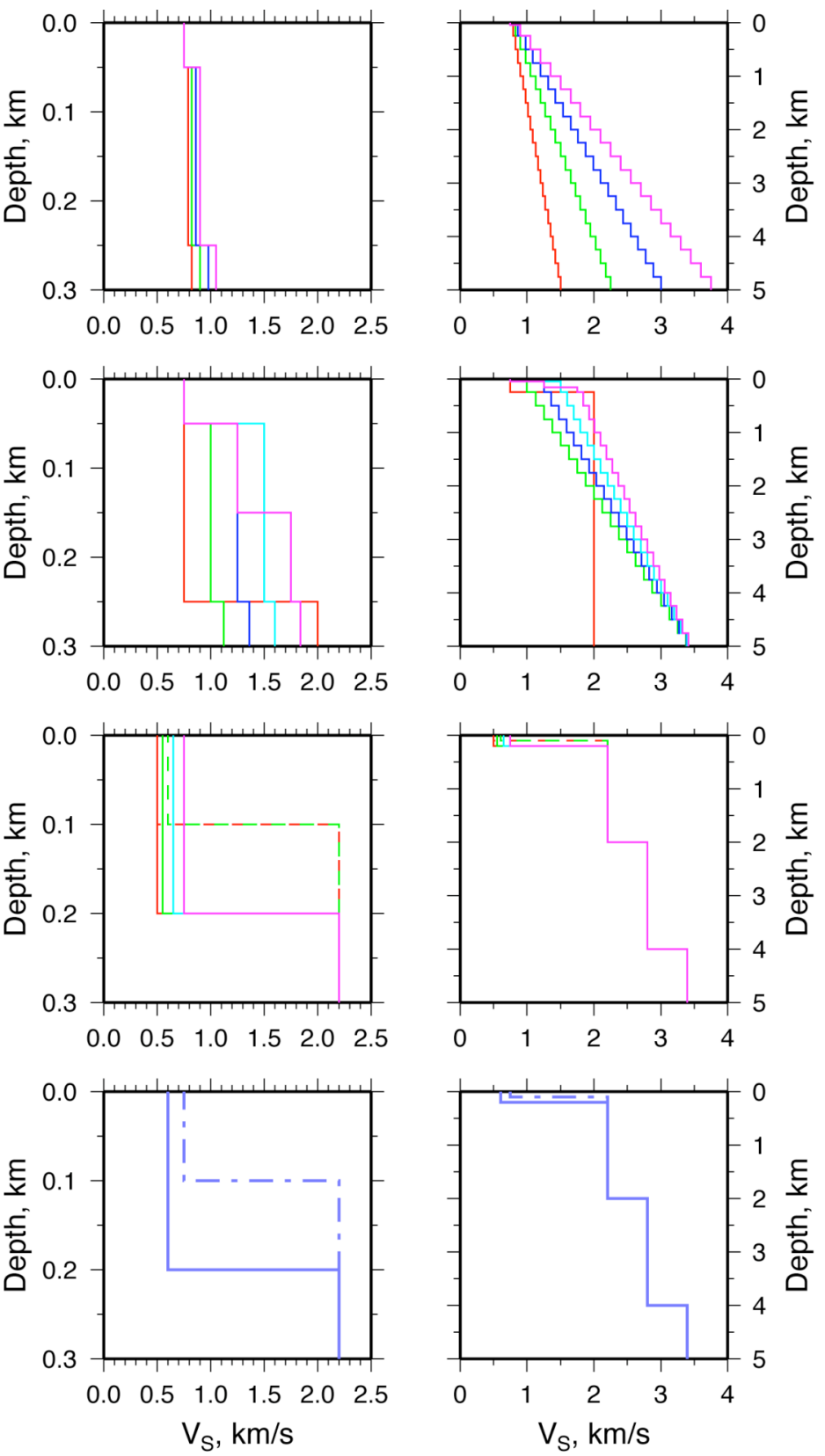

Figure 5.3. Observed and simulated SSR site response at ST10 (solid black) and RBON (black dashed) (left panels). Sedimentary velocity models are shown for the shallow (center panels) and deep (right panels) sections: (a) linear gradient ("stair step") models, (b) linear gradient models with a near-surface velocity jump; (c) layered models with low near-surface velocities in the upper $100 \mathrm{~m}(750 \mathrm{~m} / \mathrm{s})$ or $200 \mathrm{~m}(600 \mathrm{~m} / \mathrm{s})$; and (d) bestfitting layered models with velocity jumps at 100 and $200 \mathrm{~m}$. Theoretical site response curves (left) are color-coded to the velocity models (center and right). 
Figure 5.3 also shows the sedimentary models investigated in the numerical experiments. We chose a range of models including discretized linear gradients ("stair step" models), layered models and low shallow velocities. Figure 5.3a illustrates the site response resulted from discretized linear gradient models with greatly different average velocities. These models result in a peak at relatively low frequencies $(\sim 0.3 \mathrm{~Hz})$ and another in the range 1.0-1.4 Hz. One model in particular results in a peak near $1.2 \mathrm{~Hz}$ similar to the observations. However, all the models predict a large low-frequency response at about $0.3 \mathrm{~Hz}$. Models with a linear gradient in the sedimentary section and a discontinuous near surface low velocity layer result in lower amplitude peaks near $0.3 \mathrm{~Hz}$ and $1.0 \mathrm{~Hz}$ (Figure 5.3b). A uniform basin model with near surface low velocities is considered in Figure 5.3b, but fails to produce peaks seen in the observed site response curves. Using estimates of sedimentary velocities from preliminary seismic refraction analysis (Snelson et al., 2003), we investigated models with four layers and varied the near-surface velocities (Figure 5.3c \& 5.3d). Some of these models result in large amplitude peaks near 0.4 and $1.0 \mathrm{~Hz}$ (Figure 5.3c). Two models produce peaks of similar amplitude and frequency as the observations (Figure 5.3d). These models have low velocity shallow layers: $600 \mathrm{~m} / \mathrm{s} \& 200 \mathrm{~m}$ thick producing a peak at $0.6 \mathrm{~Hz}$ and $750 \mathrm{~m} / \mathrm{s} \& 100 \mathrm{~m}$ thick producing a peak at $1.2 \mathrm{~Hz}$. While the models shown in Figure $5.3 \mathrm{~d}$ do not match both peaks near 0.6 and $1.2 \mathrm{~Hz}$, they certainly illustrate that the near-surface low velocities strongly impact site response and specific combinations of layer thickness and velocity can predict features in the site response observations.

\subsection{Site Response Modeling Conclusions}

While our 2D finite difference modeling can capture most of the important physics of wave propagation in the basin, other factors are clearly important, such as topography and lateral velocity variations within the basin and surrounding crust. The basin subsurface is likely to be composed of lenses of different materials with different velocities and densities. Our modeling did not address the effects of such structures. It is also likely that larger scale three-dimensional effects also play a role in the observed site response (e.g., Olsen, 2000; Larsen, 2002). As more detailed models of structure in and 
around LVV emerge, including fine structure near the surface, resource demanding highperformance computations will result in a better understanding of the observed site response. 


\section{Empirical Transfer Functions to Predict Ground Motion Time-Series}

This section describes a frequency-domain transfer function methodology to predict explosion ground motion time-series using observations at a reference site. The methodology can scale motions from a reference site to another site for the same event (site scaling) or to scale a reference motion from one event to another at the same site (source scaling). The observed motions at a reference site are decomposed into Fourier amplitude and phase spectra. The amplitude spectrum is then multiplied by a Scaling Ratio. The scaled amplitude spectrum and unaltered phase spectrum are then transformed back into the time domain to result in a ground motion time series. For site scaling, the Scaling Ratio is taken as the Standard Spectral Ratio site response curve (relative to the reference site). To scale motions for a given explosion at a given site to a different explosion, the Scaling Ratio is taken as the ratio of estimated S-wave source spectra from coda wave analysis. We apply this method to near regional distance (100$180 \mathrm{~km}$ ) horizontal component S-wave recordings of Nevada Test Site (NTS) nuclear tests at several sites in Las Vegas. For the cases where we can compare ground motions, we obtain excellent agreement between predicted and observed ground motion features (i.e. time-series and peak and root mean square velocities and accelerations).

\subsection{Background on Ground Motion Scaling}

Ground motion prediction is an important and well-studied topic in seismology, especially with regard to strong motions of large damaging earthquakes. As part of LLNL's Enhanced Test Site Readiness program, we are interested in generating ground motion time-series at sites in Las Vegas Valley (LVV) for nuclear explosion events at the Nevada Test Site (NTS). We illustrate the method for both site and source scaling using ground motion time-series from Nevada Test Site (NTS) nuclear explosions recorded in Las Vegas, Nevada. The data and method are described in the next section, followed by a validation of the method. The method is applied to scale motions to new sites and for different events. We conclude the section with a brief discussion. 


\section{Empirical Transfer Functions to Predict Ground Motion Time-Series}

6.2 Data

The waveform data used in this study come from three sources: the Blume and Associates Seismic Safety Program network (BLUME); recordings of the June 29, 1992 Little Skull Mountain earthquake (LSM) and our own temporary deployment of seismometers (the Las Vegas Valley Broadband Deployment - LVVBB). These data sets are described in Chapter 2.

\subsection{Empirical Transfer Function Methodology}

The horizontal component S-wave velocity ground motions were extracted based on analyst picks. We then removed the mean, tapered (5\% Hanning taper) and computed the fast Fourier transform of each time-series. The Fourier amplitude spectrum was multiplied by the Scaling Ratio. The scaled amplitude and unaltered phase spectra were inverse Fourier transformed to the time domain, resulting in scaled motions. To scale motions from a reference site to a new site, the Scaling Ratio was taken as the Standard Spectral Ratio (target site spectrum divided by reference site spectrum, described in Chapter 4). These were computed as the vector average of the horizontal S-wave windows as described in Rodgers et al. (2004). To scale motions from one event to another at the same site, the Scaling Ratio was taken as the ratio of S-wave source spectra (target event spectrum divided by the reference event spectrum). Source spectra from a large set of NTS explosions were computed from coda wave analysis (Mayeda and Walter, 1996). For both site and source scaling we limited the transformations to the pass band 0.2-5.0 Hz. The signal-to-noise was best in this band for the NTS explosion data. The BLUME data generally had poor instrument sensitivity at frequencies below $0.2 \mathrm{~Hz}$.

Figure 6.1 illustrates the method for scaling a single component motion time-series from the BARNWELL nuclear test observed at the SGS site to the SE6 site. For the Scaling Ratio we use the Standard Spectral Ratio (SSR) site response curves estimated as described in Chapter 4. Notice that the Scaling Ratio shown in Figure 6.1a indicates that 
low frequencies $(0.3-1.5 \mathrm{~Hz})$ are amplified by as much as a factor of six. The resulting scaled time-series (Figure 6.1b) shows that the lower frequencies are amplified, especially the $\sim 1 \mathrm{~Hz}$ energy in the early part of the record and the lower frequency later arriving surface waves. Notice that the basic waveform shape is not altered because scaling modifies only the amplitude (and not phase) spectrum of the reference site recording.

(a)

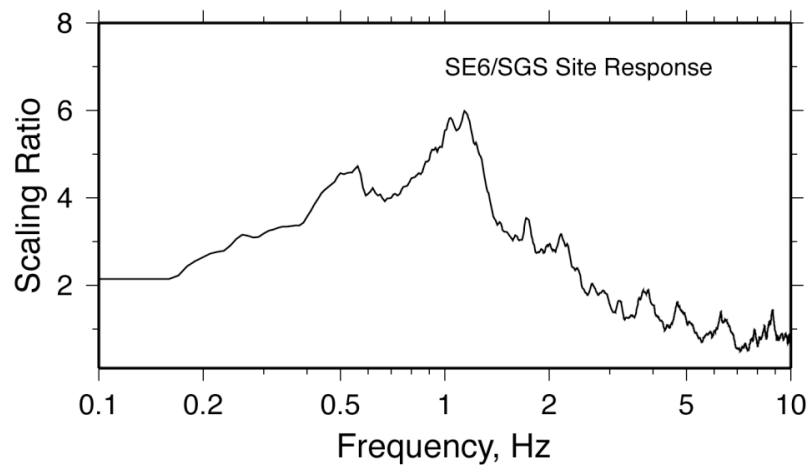

(b)

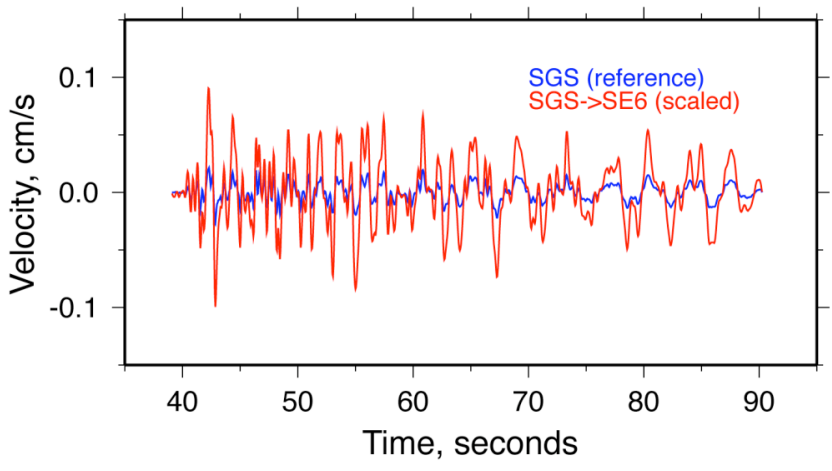

(c)

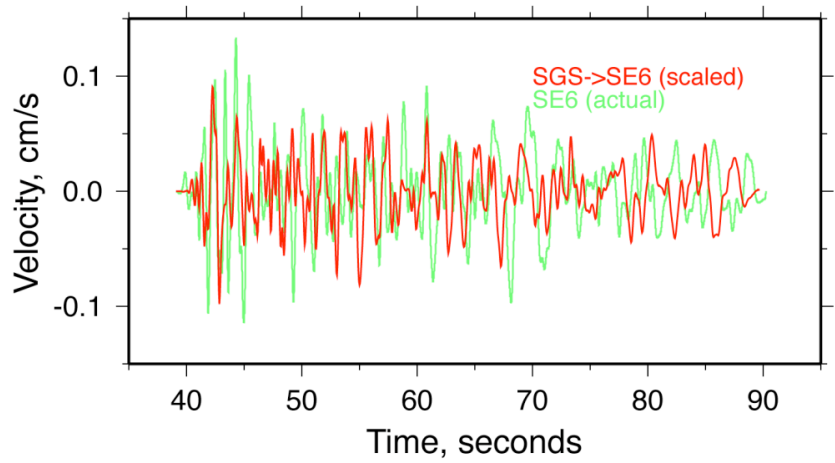

Figure 6.1. Site scaling the north-component BARNWELL explosion recording at SGS to the SE6 site. (a) Scaling Ratio taken as the Standard Spectral Ratio between target and reference sites, SE6 and SGS, respectively. (b) Reference (blue) and scaled (red) north component velocity seismograms. (c) Comparison of the actual motion at SE6 (green) with the scaled motion (red). 
The scaled motion is compared with the actual motion of the BARNWELL event at SE6 (Figure 6.1c). While we do not expect to predict the time-series wiggle-for-wiggle, the procedure results in good agreement with major features of the actual ground motion, such as the peak velocity and overall root mean-square velocities.

For the source scaling case, we use estimates of the S-wave source spectra derived from coda analysis by Mayeda and Walter (1996). Figure 6.2 shows the source spectra for the JORNADA and COTTAGE nuclear explosions. These explosions were both conducted in Yucca Flat and thus had very similar propagation paths to stations in LVV.

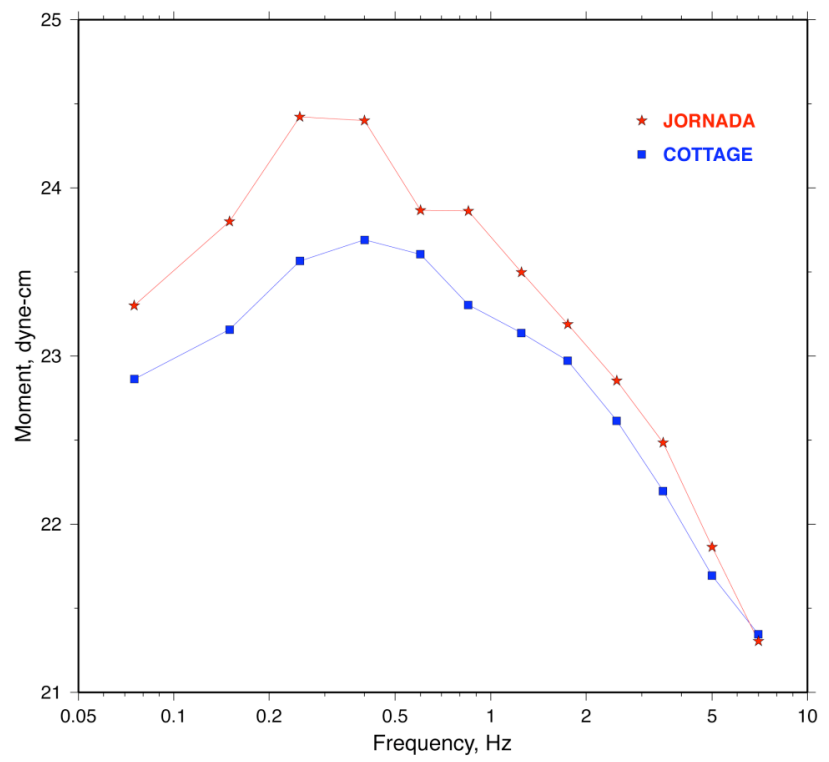

Figure 6.2. Source spectra for the JORNADA and COTTAGE explosions derived from S-wave coda analysis (Mayeda and Walter, 1996).

In Figure 6.3 we show an example of the JORNADA explosion recorded at station NLV scaled to the COTTAGE explosion and compared with the actual recording of the COTTAGE explosion at NLV. Figure 6.3a shows the estimated source spectral ratio. The reference motion at NLV and scaled motion are shown in Figure 6.3b. The comparison is good and comparable to that for site scaling (Figure 6.3c). 

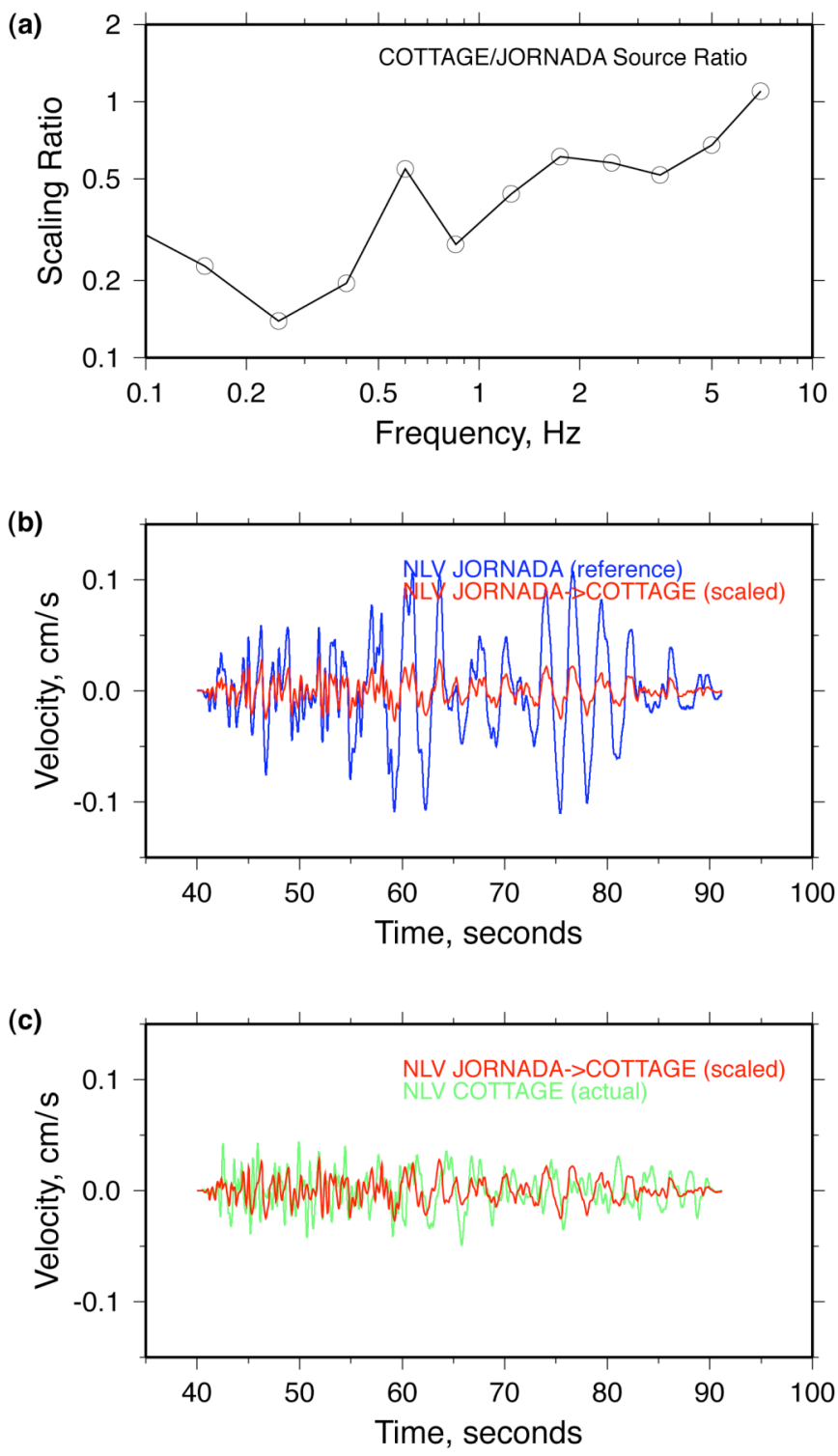

Figure 6.3. Source scaling the north-component JORNADA explosion recording at NLV to the COTTAGE explosion. (a) Scaling Ratio taken as the ratio of S-wave source spectra (Mayeda and Walter, 1996) between target and reference explosions, COTTAGE and JORNADA, respectively. (b) Reference (blue) and scaled (red) north component velocity seismograms at NLV. (c) Comparison of the actual motion at NLV (green) with the scaled motion (red).

\subsection{Validation of the Method}

In order to test the ground motion scaling method presented above, we compared the scaled ground motions with a wide range of actual recordings for those cases where we could obtain estimates of the Scaling Ratio. The results are presented for both the site 
and source scaling. Comparisons are made between peak and root mean-square (RMS) velocities and accelerations for the observed and predicted horizontal component ground motions.

For the site scaling method we have six explosions that were recorded at two reference sites, stations SGS and CALB of the BLUME network. We were able to compare motions at many sites. Figure 6.4 compares the peak velocities and accelerations. The comparison is quite good over a range of nearly two orders of magnitude.

(a)

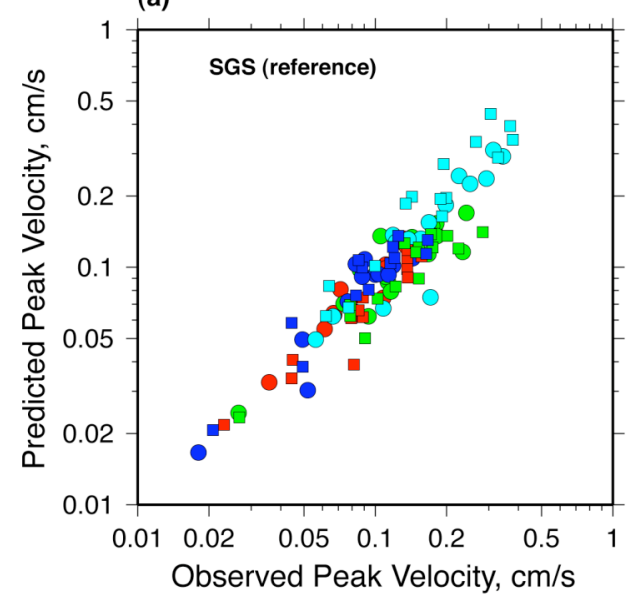

(c)

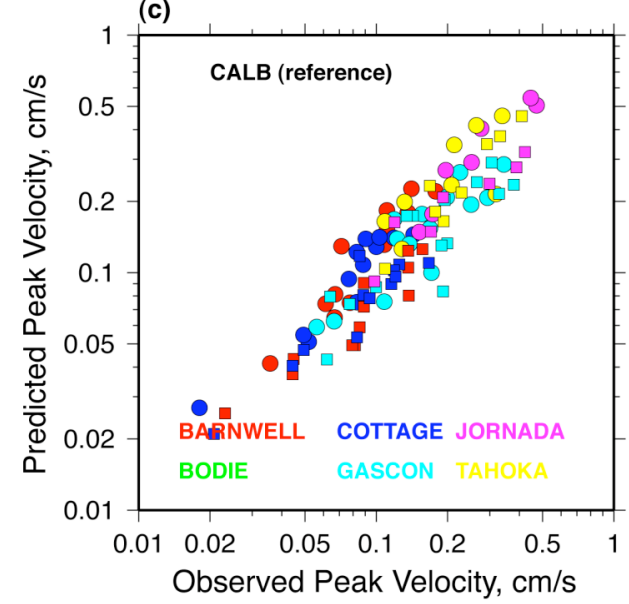

(b)

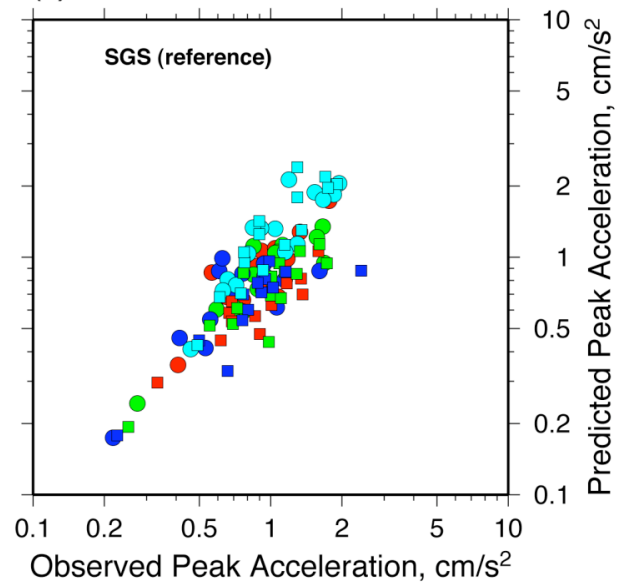

(d)

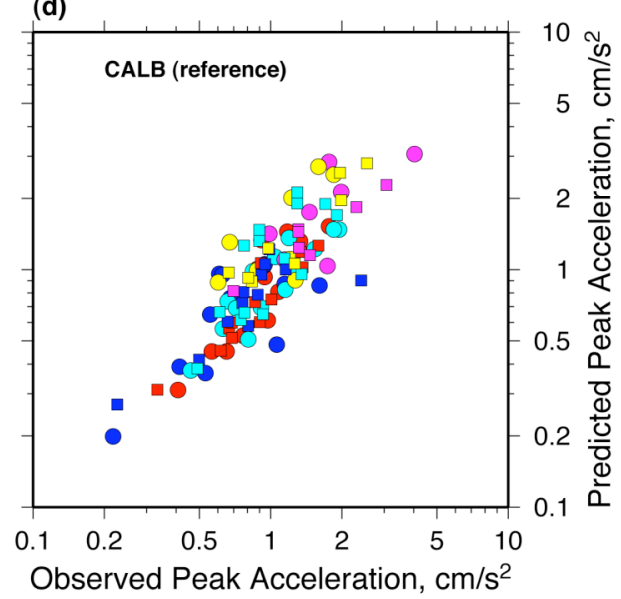

Figure 6.4. Comparison of observed and predicted peak velocities and accelerations for the site scaled motions: (a) peak velocities using reference motions at SGS; (b) peak accelerations using reference motions at SGS; (c) peak velocities using reference motions at CALB; (d) peak accelerations using reference motions at CALB. In all plots the events are color-coded with key in (c) and the squares and circles represent north and east motions, respectively. 
Figure 6.5 compares the RMS velocities and accelerations. The comparison of RMS motions is better than the peak motions. This is not surprising because the peak motions are likely to be more scattered, while the RMS motions are more stable.

(a)
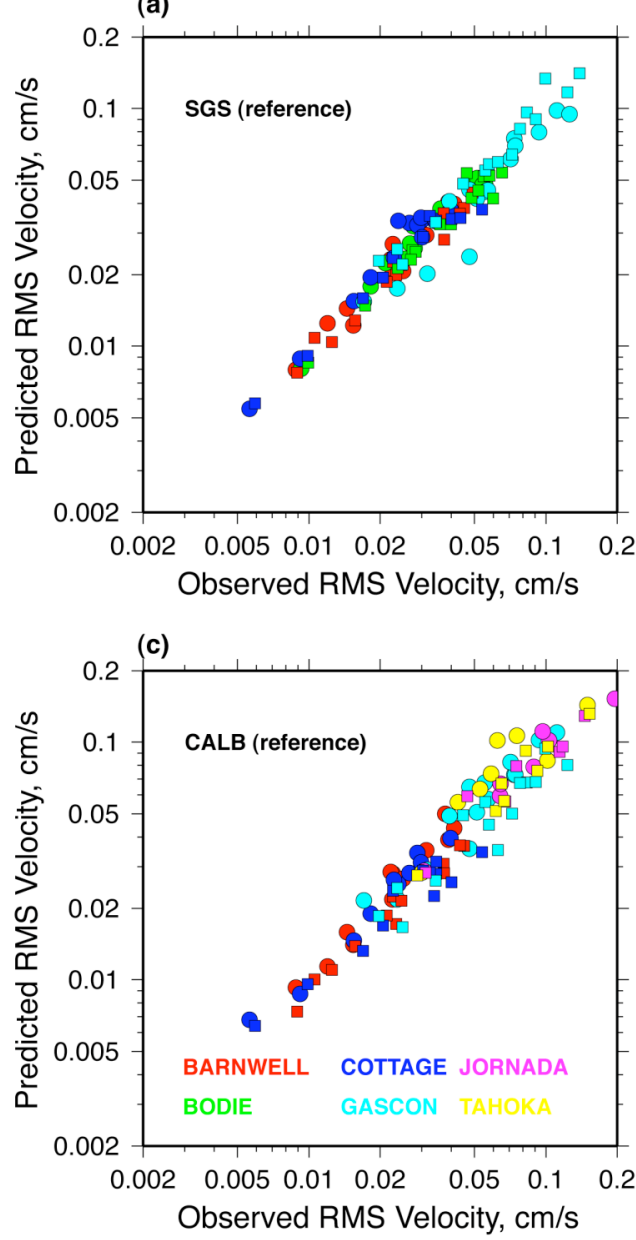

(b)

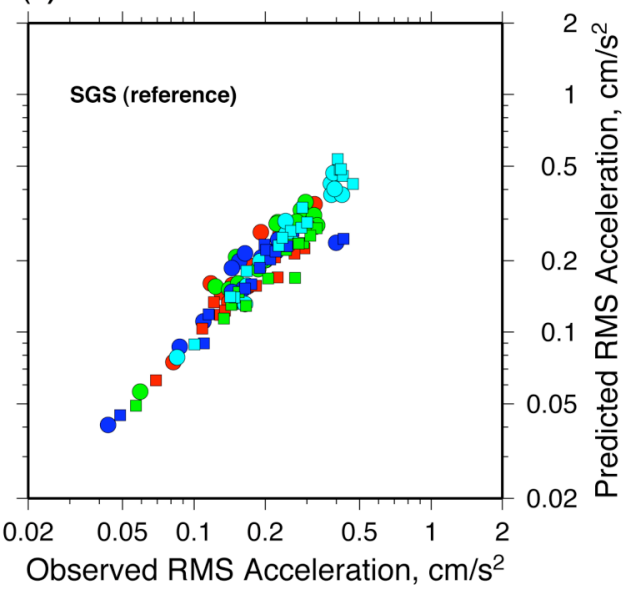

(d)

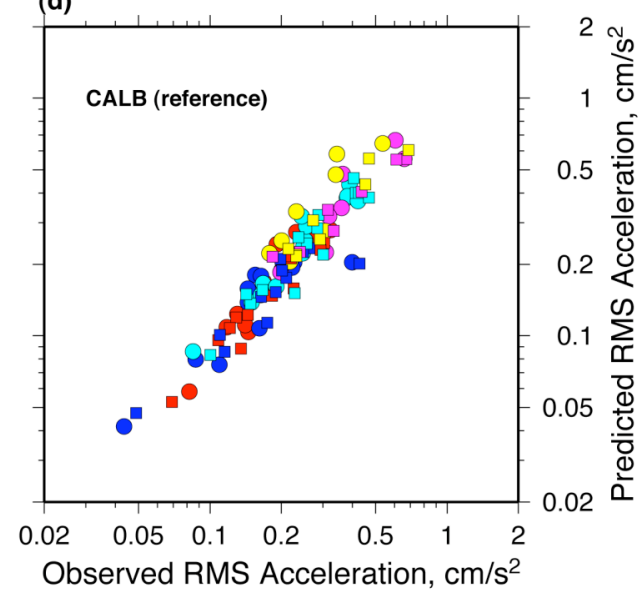

Figure 6.5. Comparison of observed and predicted RMS velocities and accelerations for the site scaled motions: (a) RMS velocities using reference motions at SGS; (b) RMS accelerations using reference motions at SGS; (c) RMS velocities using reference motions at CALB; (d) RMS accelerations using reference motions at CALB. In all plots the events are color-coded with key in (c) and the squares and circles represent north and east motions, respectively.

For the source scaling case, we compared the observed and predicted motions of the COTTAGE explosion, shown in Figure 6.3. For this event we used the JORNADA motions as the reference event and scaled the motions for five sites. Figure 6.6 compares 
the observed and predicted peak and rms ground motions for the COTTAGE explosion, using both JORNADA and TAHOKA as the reference source. We obtained good comparisons of observed and predicted RMS motions. However, the peak velocities and accelerations are quite scattered.

(a)

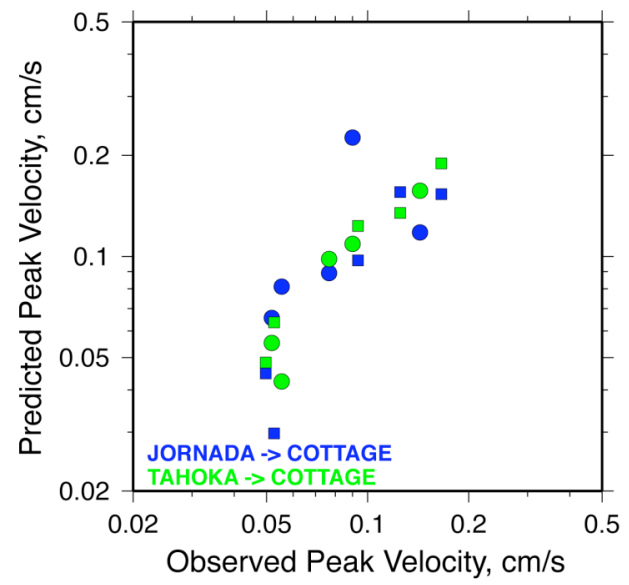

(c)

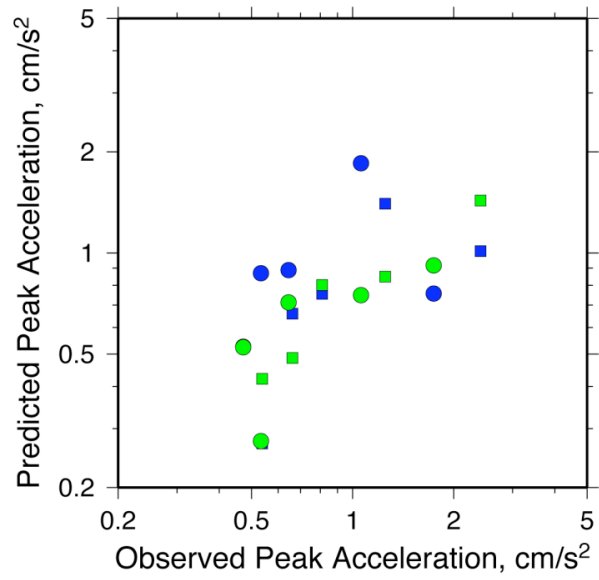

(b)

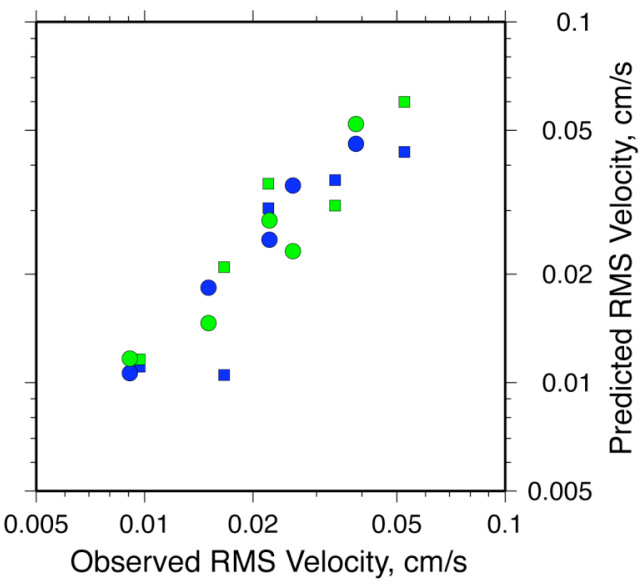

(d)

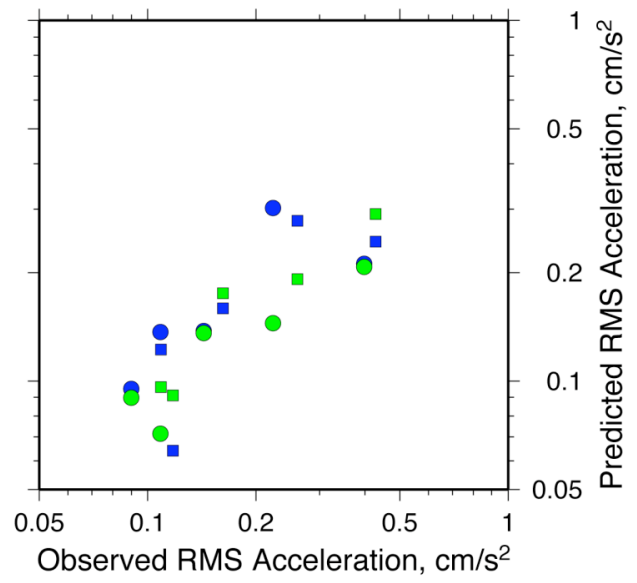

Figure 6.6. Comparison of peak and RMS ground motions for the source scaled motions: (a) peak velocities; (b) RMS velocities; (c) peak accelerations; and (d) RMS accelerations. In all cases we show the predicted motions for the COTTAGE explosion based on reference explosions JORNADA (blue) and TAHOKA (green) with squares and circles represent north and east motions, respectively.

\subsection{Site Scaling Ground Motion Prediction in Las Vegas}

We applied the method described above to scale ground motions to new sites and for different explosions. For the site scaling case, we used the method to extend observations 
of single explosions at one site to a set of more widely distributed stations. For the source scaling case we scaled motions at a single site from a single explosion to a set of different explosions with a wide range of moment magnitudes.

For the site scaling case, we used SSR estimates of site response based on the reference sites SGS (BLUME and LVVBB) and ST17 (LSM) and described above and in Rodgers et al. (2004). Using ground motions from the BARNWELL explosion at the BLUME site SGS, we scaled motions to 35 different sites around Las Vegas Valley, including the BLUME, LSM and LVVBB networks. Figure 6.7 shows the predicted peak accelerations and velocities for the BARNWELL explosion scaled to the new sites.
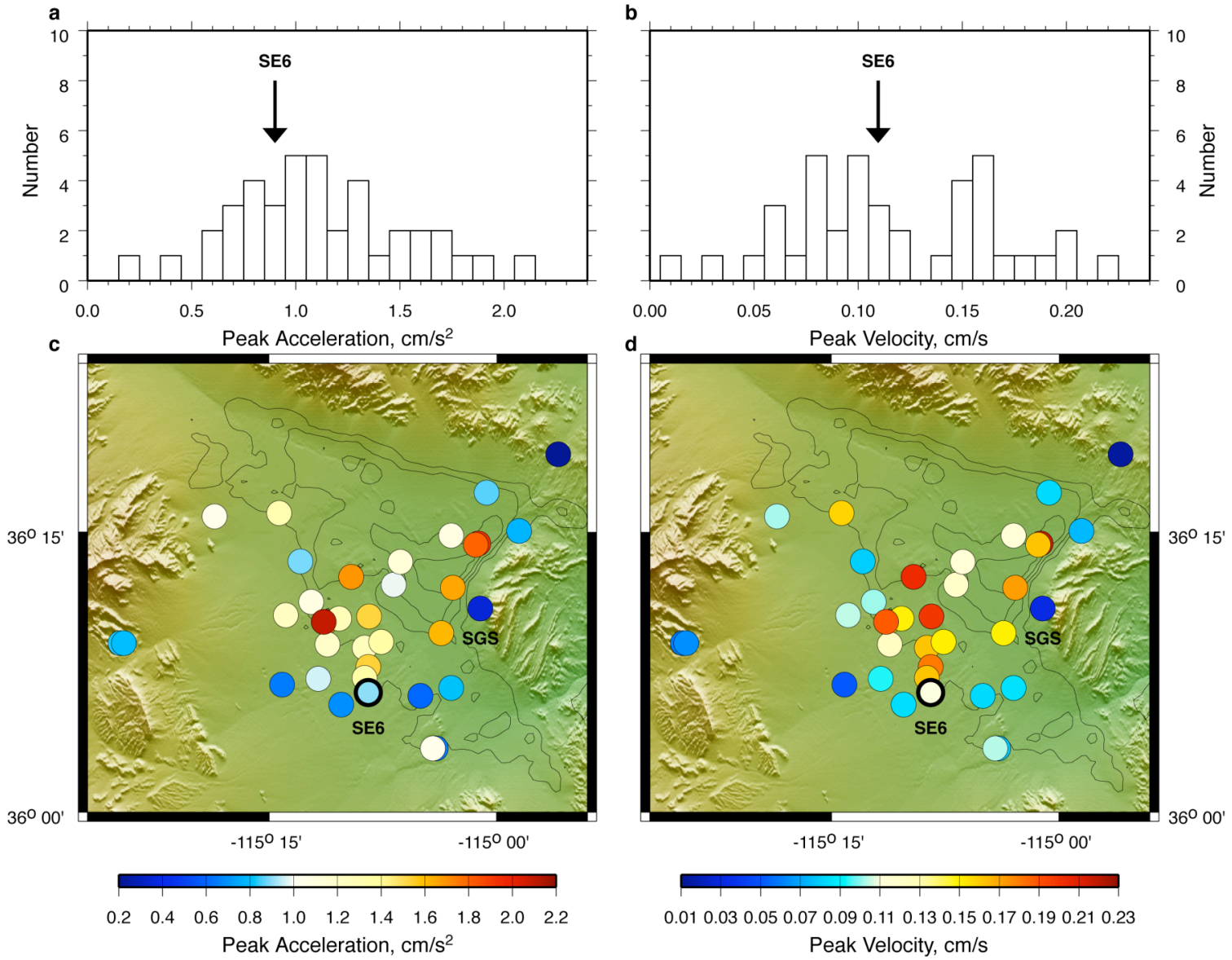

Figure 6.7. Predicted peak accelerations and velocities for the BARNWELL explosion using reference motions at station SGS: (a) and (b) show histograms of the peak values; while (c) and (d) show the peak values in map view. The peak ground motions and location of station SE6 are indicated. In (c) and (d) 1-km contours show the depth to basement by Langenheim et al. (2001). 
Not surprisingly, the spatial pattern of the predicted peak ground motions is generally consistent with the band-averaged SSR values shown in Figure 4.5. These maps indicate lower ground motions on the western, southern and eastern periphery of the basin (e.g. sites SGS, CALB/ST06, S22, WSG, S04, EFLA, F02, GPS, LVM) and higher motions in the central (e.g. sites LVW1/ST11, RBON. MKIG, S51, PKTG, ST13) and deeper basin (e.g. ST16, F20, F04). Station SE6 (indicated in Figure 6.7) recorded most nuclear explosions in our data set. It also had peak accelerations and velocities larger than the average of the BLUME network sites (also indicated in the histograms of peak motions). When the motions are scaled to the LSM and LVVBB sites, the mean ground motions increase slightly. Thus SE6 approximately represents the average peak ground motions in Las Vegas Valley from NTS explosions. We will use this observation later in our analysis of source scaled ground motions (next section).

\subsection{Site Scaling Ground Motion Prediction in Las Vegas}

For the source scaling case, we used the extensive database of NTS explosion source spectra based on S-wave coda and compiled by Mayeda and Walter (1996) and Sweeney and Mayeda (2004). This database contains source (moment rate) spectra and momentmagnitude, $\mathrm{M}_{\mathrm{W}}$, estimates from hundreds of nuclear explosions at NTS. We selected events in the Yucca Flat and Pahute Mesa areas of NTS and used the JORNADA and BARNWELL events observed at station SE6 in Las Vegas as our reference ground motions. Figure 6.8 a shows a map of the events considered for each test area. The events spanned a range of size $\left(\mathrm{M}_{\mathrm{W}}\right)$. Figure $6.8 \mathrm{~b}$ and $6.8 \mathrm{c}$ show histograms of moment magnitudes for each area. Events in Yucca Flat tended to have a wider range of magnitudes, including smaller events. 
(a)

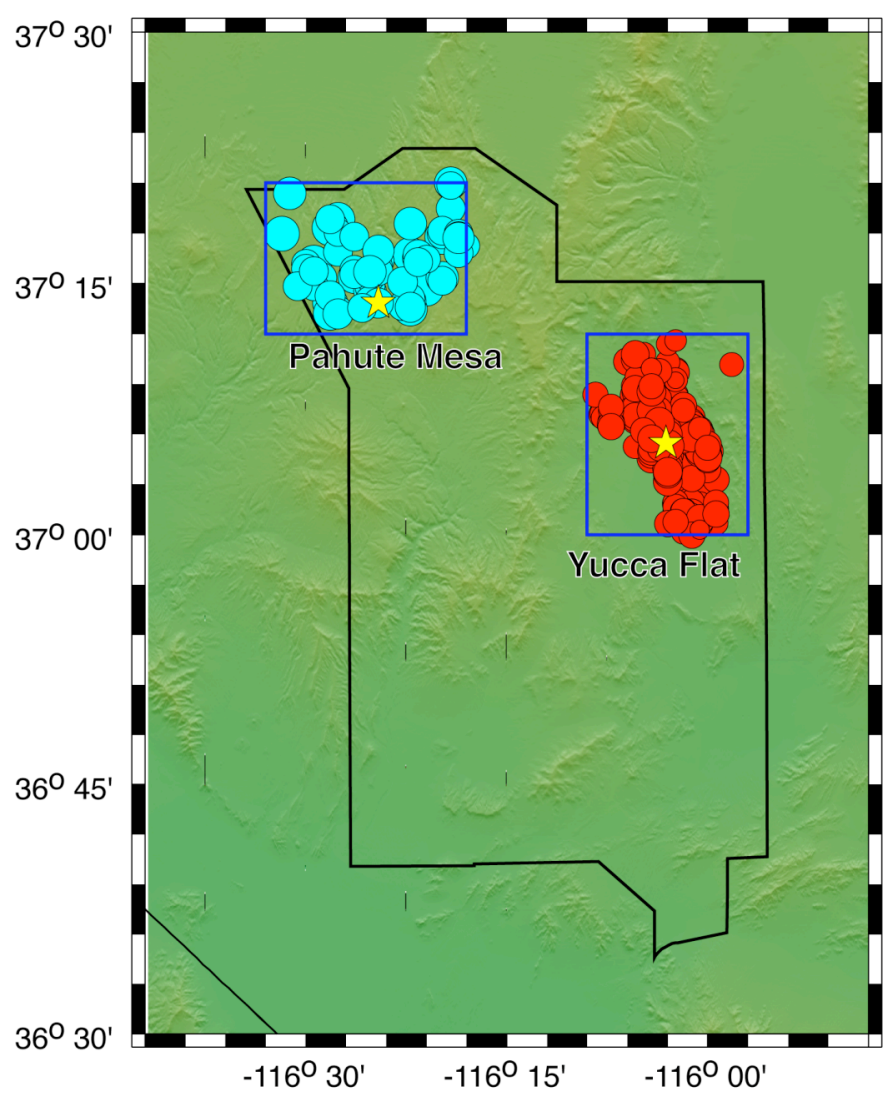

(b)

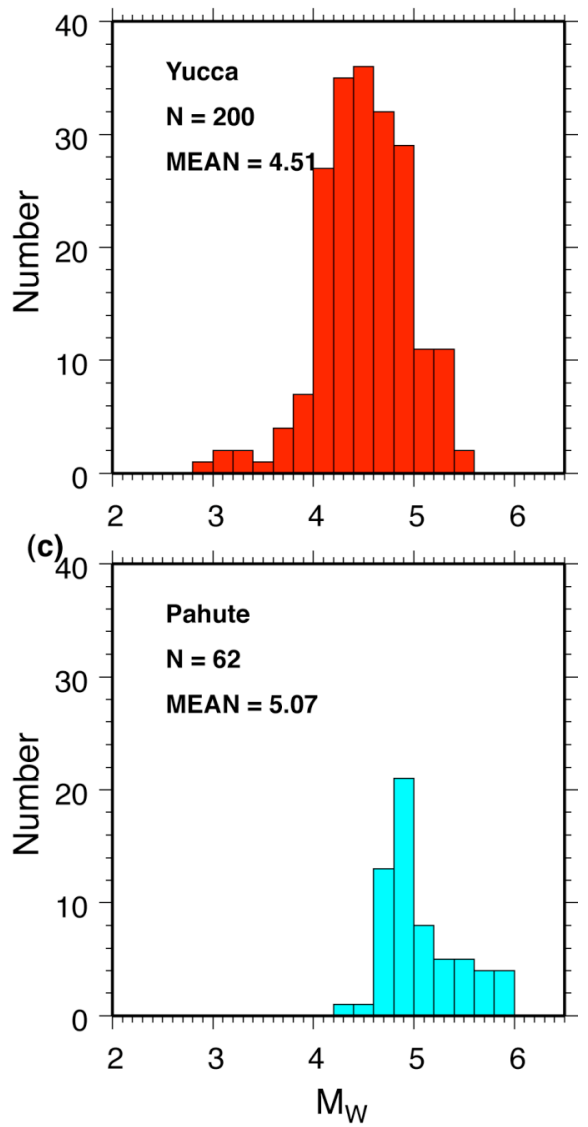

Figure 6.8. (a) Map of the Nevada Test Site (NTS). Reference events JORNADA and BARNWELL are indicated (yellow stars) along with the target events for source scaling in Yucca Flat (red circles) and Pahute Mesa (cyan circles). The bounding boxes show the regions used for selecting events near each reference event. Histograms of moment magnitude, $\mathrm{M}_{\mathrm{W}}$, for the target events in (b) Yucca Flat and (c) Pahute Mesa.

Figure 6.9 shows the estimated peak (horizontal components) ground acceleration at station SE6 in Las Vegas from the source-scaled ground motion time-series versus moment magnitude, $\mathrm{M}_{\mathrm{W}}$. Also shown in Figure 6.9 is the threshold of human ground acceleration perception, $1.0 \mathrm{~cm} / \mathrm{s}^{2}$ (e.g. Anderson, 2003) and the value $1.7 \mathrm{~cm} / \mathrm{s}^{2}$ is based on the Modifed Mercalli Intensity Scale from comparisons of instrumental motions and reported felt intensities (Wald et al., 1999). We computed the regression of the $\log _{10}$ PGA versus $\mathrm{M}_{\mathrm{W}}$ for the JORNADA events alone. Given that that station SE6 has approximately the mean peak ground motion (as discussed above), we plotted the upper bound of the regression (dashed line in Figure 6.9) as the regression line plus a factor of two (0.301 $\log _{10}$ units). 


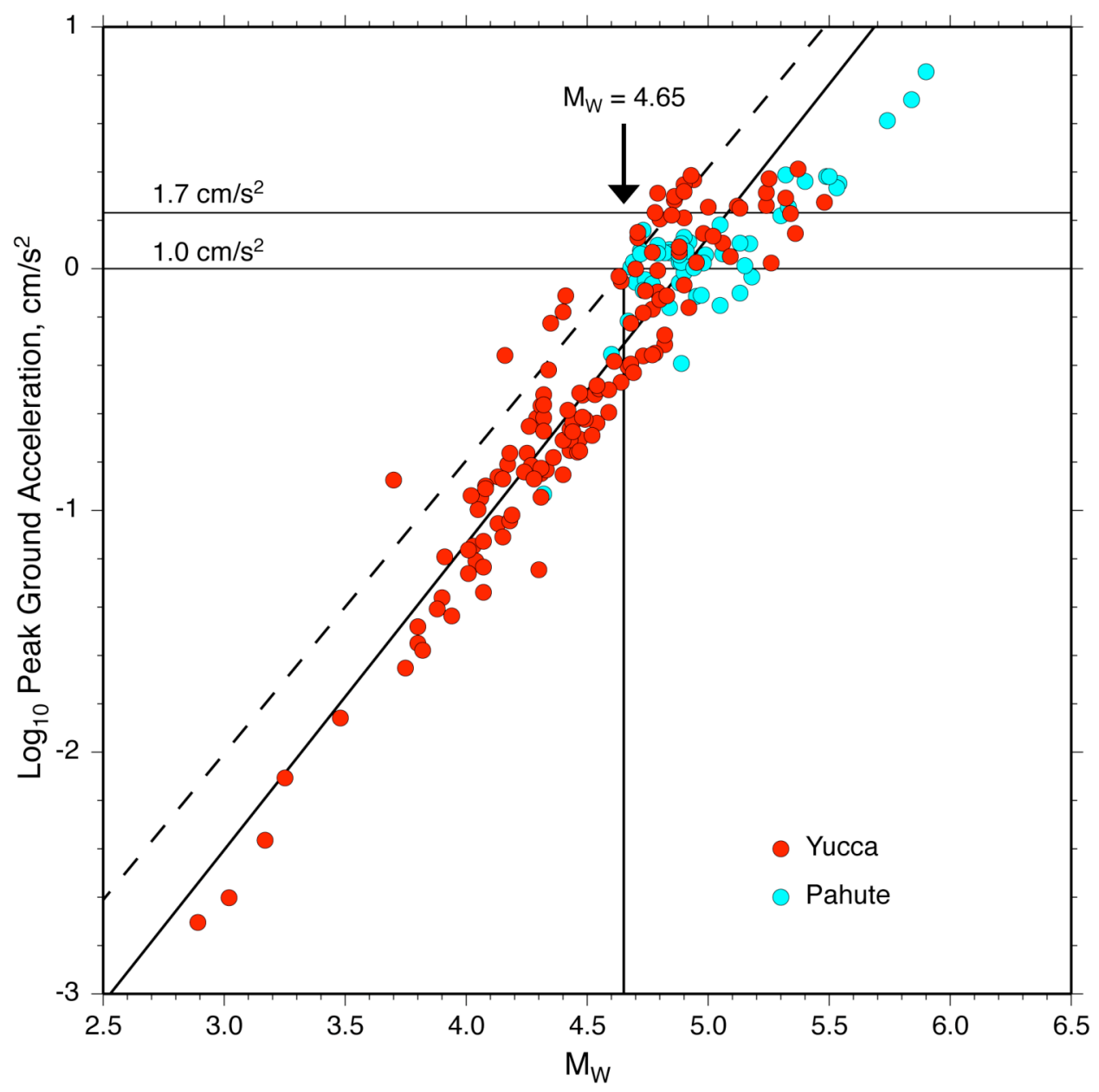

Figure 6.9. Predicted peak ground acceleration at station SE6 from scaled motions versus the moment magnitude, $\mathrm{M}_{\mathrm{W}}$, based on $\mathrm{S}$-wave coda analysis. The human perception thresholds of 1.0 and $1.7 \mathrm{~cm} / \mathrm{s}^{2}$ are shown (see text).

\subsection{Empirical Transfer Function Conclusions}

The use of the empirical transfer function methodology described above is valuable for extending limited ground motion observations to new sites (site-scaling) or to events of different size (source-scaling). 


\section{Analysis of Las Vegas Valley Broadband Deployment Data}

The Las Vegas Valley Broadband (LVVBB) Deployment collected data over a fourmonth period (September 2002 to January 2003). The deployment is described above in Section 2. These data were analyzed in various ways. Site response at these stations was estimated from regional earthquakes, as described in Section 4. In the following sections we describe four separate analyses: teleseismic P-wave travel time residuals; teleseismic $\mathrm{P}$-wave receiver functions; teleseismic S-wave site response; and microtremor site response.

\subsection{Teleseismic P-Wave Travel Time Residuals}

In this section, we report investigations that seek whether the Las Vegas basin (a smallscale basin) could be unambiguously detected using teleseismic P-wave travel time offsets from broadband records. We present evidence that the pattern of the observed seismic travel times in Las Vegas Valley is coherent across the basin regardless of the azimuth of the incoming energy, indicating that the basin structure and geology control the differential travel time residuals. This information can be used along with other geophysical and geotechnical data to constrain basin shape and its velocity structure. The magnitude of travel time residual due to the basin structure is significant (up to 0.5 seconds).

During the time period our broadband seismic network was operating in Las Vegas (September 2002 - January 2003), more than 30 teleseismic events with moment magnitudes larger than 6.0 occurred worldwide. Here, we discuss P-wave travel times of 12 of these events with favorable signal to noise ratio, i.e., the events for which we were able to determine clear $\mathrm{P}$ wave arrivals. The event locations and the path geometry is shown in Figure 7.1. The azimuthal coverage that we obtained using this configuration of events is relatively good, with the exception of a gap in the coverage from eastern azimuths. 


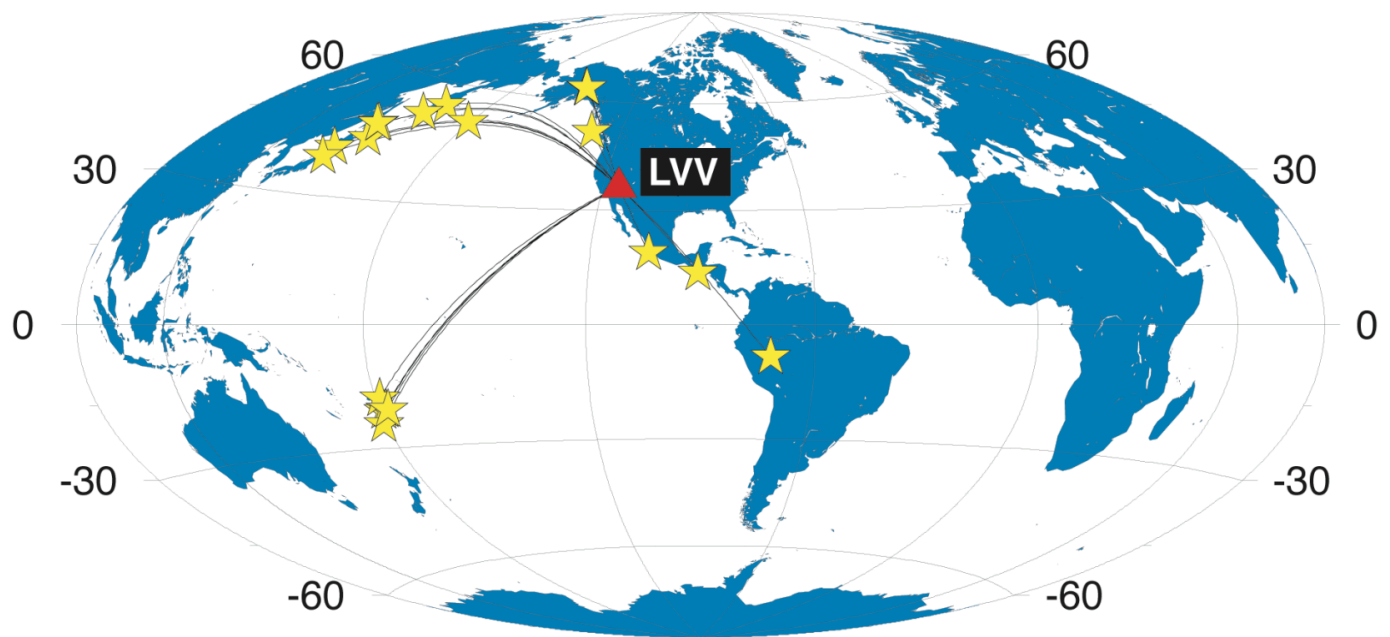

Figure 7.1. Geographical distribution of the teleseismic events used in this study. The position of the Las Vegas Valley (triangle) is shown with respect to the events used in travel times and site response analysis (stars). Surface projection of great-circle paths is shown by solid lines.

Because the source in our case is far away from the network, the ray paths through Earth to each individual stations of our network are virtually the same. They differ only immediately beneath the receivers, so we expect that any difference in the travel time data with respect to the $1 \mathrm{D}$ model prediction must stem from the topography and shallow structure of the crust affecting the incident wave field under Las Vegas.

Ideally, we would use station SGS - situated at a rock site, as a reference station, because it has good signal-to-noise ratio and records waveforms that do not vary significantly from one earthquake to another. However, due to problems in operation, data from several earthquakes are either of a bad quality or missing. Therefore, we used station named F02, located in the northeastern corner of the basin, whose data were of excellent quality and more consistently available. The teleseismic site response curves that were calculated for F02 display a "rock-type station" behavior (Rodgers et al., 2004; Tkalcic et al., 2003), although regional earthquake data show some site response relative to the station SGS. Indeed, station F02 is thought to lie on a relatively thin layer of sediments very close to the basin edge. 
In the first step we band-pass filter the waveforms with an acausal filter between 0.1 and $1.0 \mathrm{~Hz}$, but only when necessary to filter out the noise. This does not impact differential travel time residuals. Most of the time, signal-to-noise was favorable so that we could use the raw waveforms. We performed a cross-correlation of the reference $\mathrm{P}$ waveform (i.e., only first quarter of the $\mathrm{P}$ arrival cycle) with $\mathrm{P}$ waveforms of each station, and calculate differential travel time with respect to the reference station travel time. The estimated error in these measurements is 0.1-0.2 seconds or less. In order to account for the differences in travel times among stations due to slightly different length of the path for each station for a given earthquake, we corrected each path according to the travel time estimated from the reference Earth model akl35 (Kennett et al., 1995). We computed residuals by subtracting the ak135-predicted times from the observed differential travel times.

For a given event, the absolute variation of residuals is greater than $0.2 \mathrm{~s}$, reaching almost $0.5 \mathrm{~s}$ for the largest of the Sea of Okhotsk events, one of the best-recorded earthquakes. A comparable result for travel times was obtained in a recent study of the Santa Clara Valley (Dolenc et al., 2004). As we noted, in Figure 7.2 we plot the travel time residuals with respect to station F02 for 12 teleseismic events (Figure 7.1). In these images, the arithmetic means were removed (Figure 7.2). We applied a continuous curvature algorithm to produce color surface contours of travel time residuals (Wessel and Smith, 1991). The number and configuration of stations available for each event varies and somewhat determines the final shape of the contours, but the overall pattern of residuals and the gradient direction remain unchanged regardless of the direction of the incoming energy. Our resulting travel time residual gradient matches very well with the direction of the steepest gravity gradient (Langenheim et al., 2001a) shown by the solid gravity isolines (Figure 7.2). At first glance, this could be an artifact caused by a combination of an elongated shape of the area, which is defined by the configuration of the locations of participating stations in the basin for each particular event, and the direction of incoming energy for most events, which is nearly perpendicular to this shape. However, the gradient does not change direction (nor sign) for the energy entering from the southwestern quadrant (Tonga-Fiji events) (Figure 7.2). Therefore, we conclude that the 
signal observed is realistic and that it provides an additional constraint to previously published basin depth estimates.

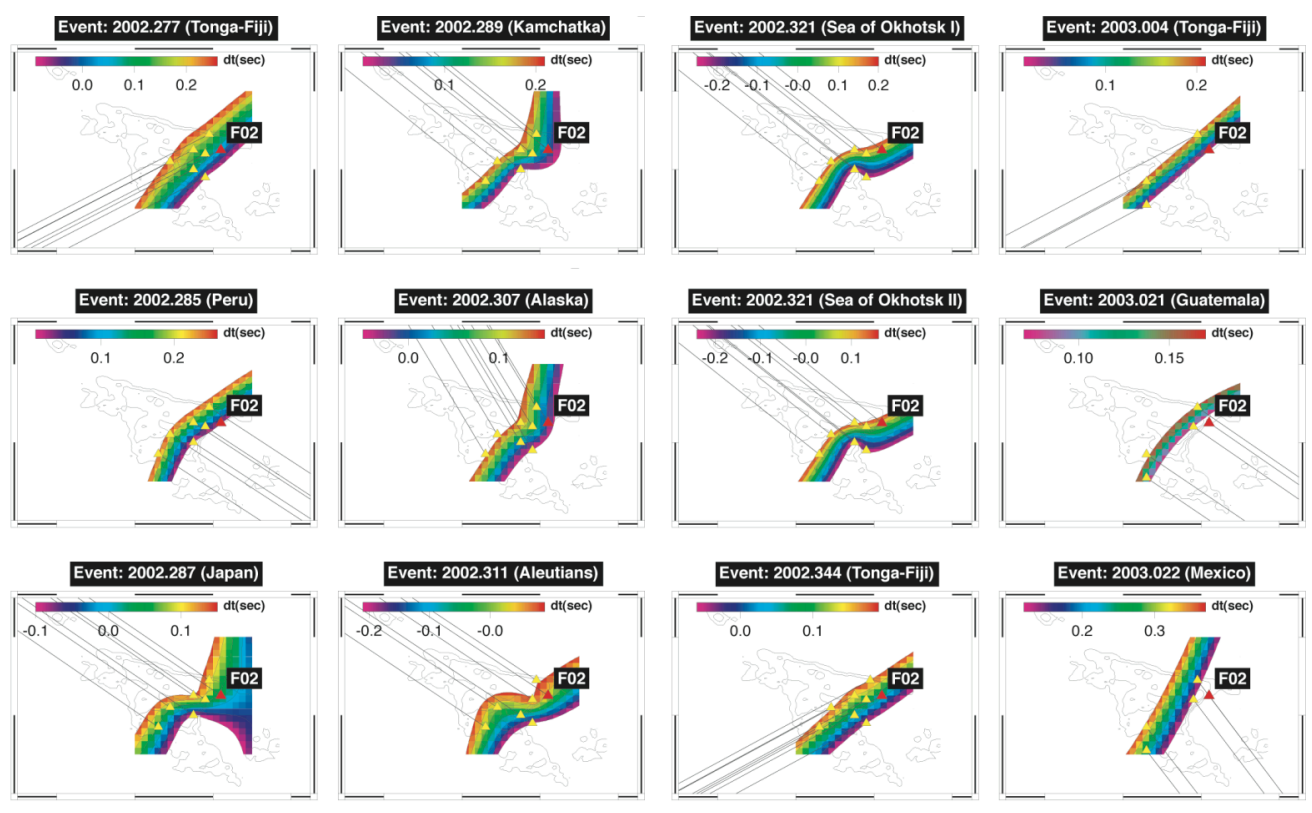

Figure 7.2. Differential $P$ travel time residuals for 12 teleseismic events recorded in the Las Vegas Valley. Color contours show the value of the differential travel time residuals (observed minus predicted travel time difference between the P waveforms of F02 (red triangle) and any given station (yellow triangles). Black contour lines are the basin depth estimate from Langenheim et al. (2001). The maximum variation in the residuals is about 0.5 seconds.

In order to analyze travel time residual measurements at each particular station, we constructed a "rose" of vectors, showing the direction, the size and the absolute sign of travel time residuals with respect to the F02 station (Figure 7.3). Negative residuals with respect to station F02 imply earlier arrivals, while positive residuals imply later arrivals of $\mathrm{P}$ energy than predicted by the radial ak135 model of Earth. There is general agreement between the sign of residuals and the reported basin position, whose lowvelocity sediments slow down seismic waves. As it can be seen from Figure 7.3, the most negative residuals are obtained for the rock site SGS and nearby stations situated in the eastern portion of the basin (F04 and F20), while the stations located toward the western and northern portion of the basin are characterized by positive residuals (SQP, 
CHY, VAH, LVM). Station F20, with large negative residuals is located above what is thought to be a basin edge, very close to its relatively steep eastern wall. Possibly, faster rocks below sediments drive the observed negative residuals.

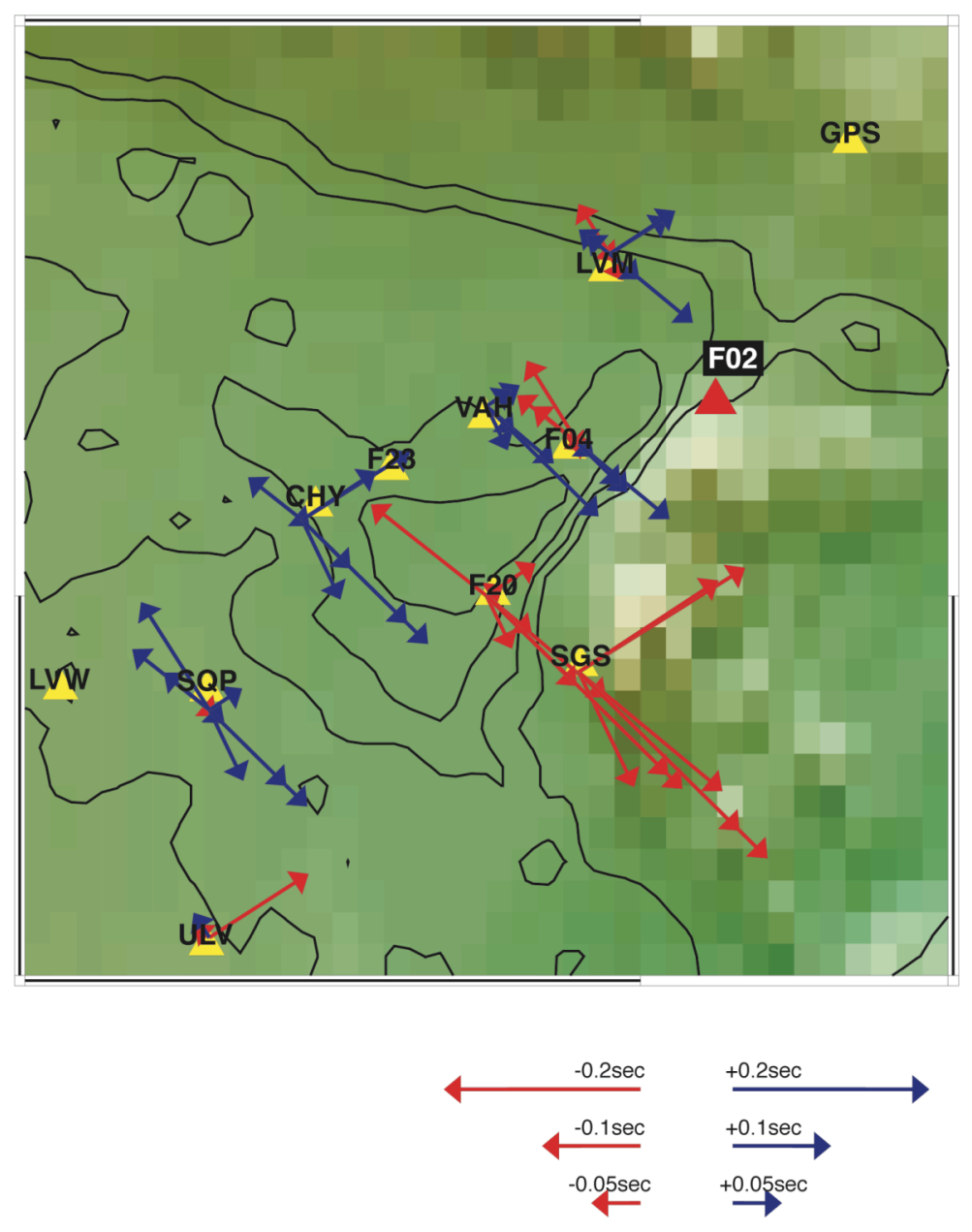

Figure 7.3. Differential travel time residuals plotted as vectors at each station, after the mean is taken out for each individual event. The size of the arrows shows the absolute value, while the color indicates the sign of residuals (see the legend). The arrows are oriented along the azimuth of the incoming waves. Contour lines are the basin depth estimate from Langenheim et al. (2001).

Figure 7.4 shows a generalized cartoon of the Las Vegas basin (Figure 12, Rodgers et al., 2004), a vertical cross-section along NW-SE direction constructed from gravity data (Langenheim et al., 2001a). According to the gravity model, the eastern wall of the basin is very steep. Figure 7.4 illustrates the character of the change in the sign of differential 
travel time residuals from negative in the east to positive in the west. Also noticeable is a bipolar character of residuals at station F04 and somewhat at LVM (Figure 7.3). The residuals are positive for the energy sampling the basin from the northwest, while they are negative for the energy sampling the hard rock from the southeast. Since the eastern wall of the basin is steep, a simple conceptual model of fast hard rock and slower sediments with a sharp boundary between them might sufficiently explain the observation of the travel time sensitivity to the direction of incoming energy. In addition, we repeated the travel time measurements using station LVM as a reference station. We found a similar coherent pattern (not shown here), with a clear demarcation line between two groups of stations: F02, F04, F20 and SGS on one side (negative residuals) and the rest of the stations on the other. It is remarkable that such level of coherence is observed in travel time residuals on a scale of tens of kilometers.

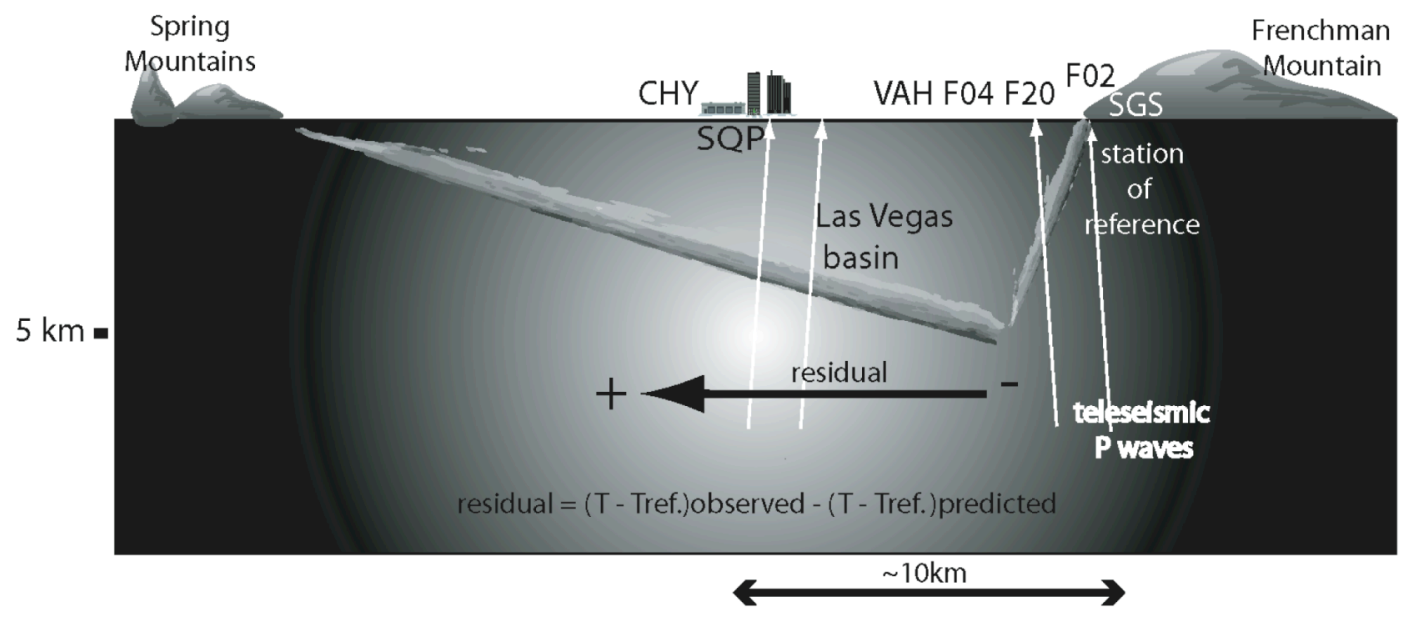

Figure 7.4. A cartoon of a vertical cross-section of the Las Vegas basin (indicated by a dash line in Figure 1) and near-vertical teleseismic waves. Stations from Figure 2 and Figure 3 are shown at the surface. The position of the city of Las Vegas is indicated by buildings. Change in the sign of the observed differential travel time residuals is illustrated by black arrow. The definition of differential travel time residuals used in this study is also given in the figure.

We demonstrated using $\mathrm{P}$ wave travel time observations that it is possible to detect and extract a coherent basin signal from teleseismic records. The observed variations in the travel time residuals across the basin reach 0.5 seconds. These observations confirm 
Langenheim et al. (2001a) and present a valuable source of constraints on velocity structure and shape of the basin, which can be used to construct initial structural models for 2 and 3-D finite difference modeling.

\subsection{Teleseismic Receiver Functions}

Teleseismic receiver functions (RF) are sensitive to the depths of discontinuities and are commonly used to estimate crustal structure (Langston, 1979; Owens et al., 1984; Ammon et al., 1990). RF's are computed by deconvolving the vertical component from the radial component of high signal-to-noise teleseismic P-waves. We computed teleseismic receiver functions from teleseismic P-waves using many of the same events shown in Figure 7.1a. We used the time domain deconvolution technique of Liggoria et al.. (1999), using a Gaussian filter of $5.0 \mathrm{~Hz}$ in order to resolve thin near-surface layers.
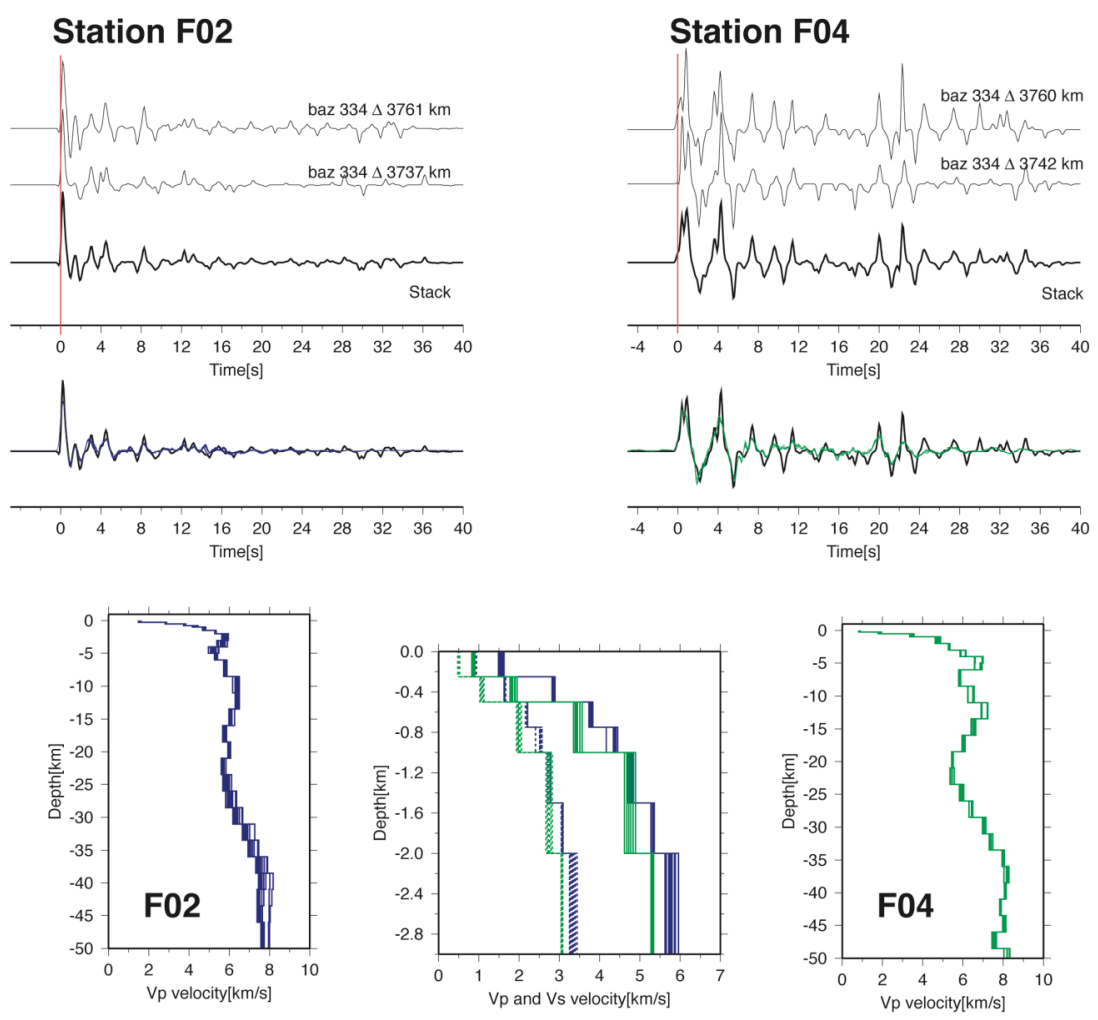

Figure 7.5. Receiver function results for the broadband stations F02 and F04 using the time-domain deconvolution (Gaussian filter $5.0 \mathrm{~Hz}$ ). Note the striking difference in the observed receiver functions of F02 and F04. We attribute this difference to thicker low velocity sediments beneath F04 site. 
These RF's reveal two main features, shown in Figure 7.5. Firstly, the crustal thickness in Las Vegas is consistent with previous estimates (30-35 km). Secondly, the near surface features are consistent with the Langenheim et al. (2001a) estimates of basin depth. Stations F02, outside of the basin, reveals higher velocities than station F04, in the deepest portion of the basin.

\subsection{Teleseismic S-Wave Site Response}

The LVVBB data allowed for us to investigate the excitation of Las Vegas basin by large teleseismic events. We measured Standard Spectral Ratio site response form horizontal component teleseismic S-waves, using station F02 as the reference site. Using broadband recordings of high signal-to-noise teleseismic S-waves allows us to resolve site amplification for lower frequencies than from lower magnitude regional earthquakes, such as those considered in Section 4.

The results, shown in Figure 7.6, indicate that many sites (CHY, F04, F20, LVM, SQP and $\mathrm{VAH}$ ) have the same peak at approximately $0.6 \mathrm{~Hz}$. This is consistent with the results from regional earthquakes (Figure 4.3). Note that the individual site response curves for any given station are very consistent. Finally, note that there are no additional peaks at frequencies lower than $0.5 \mathrm{~Hz}$ and that the curves taper to a site response of 1.0 at low frequencies $(0.1 \mathrm{~Hz})$. This indicates that the effects of low velocity basin sediments only impact amplification above $0.5 \mathrm{~Hz}$. 

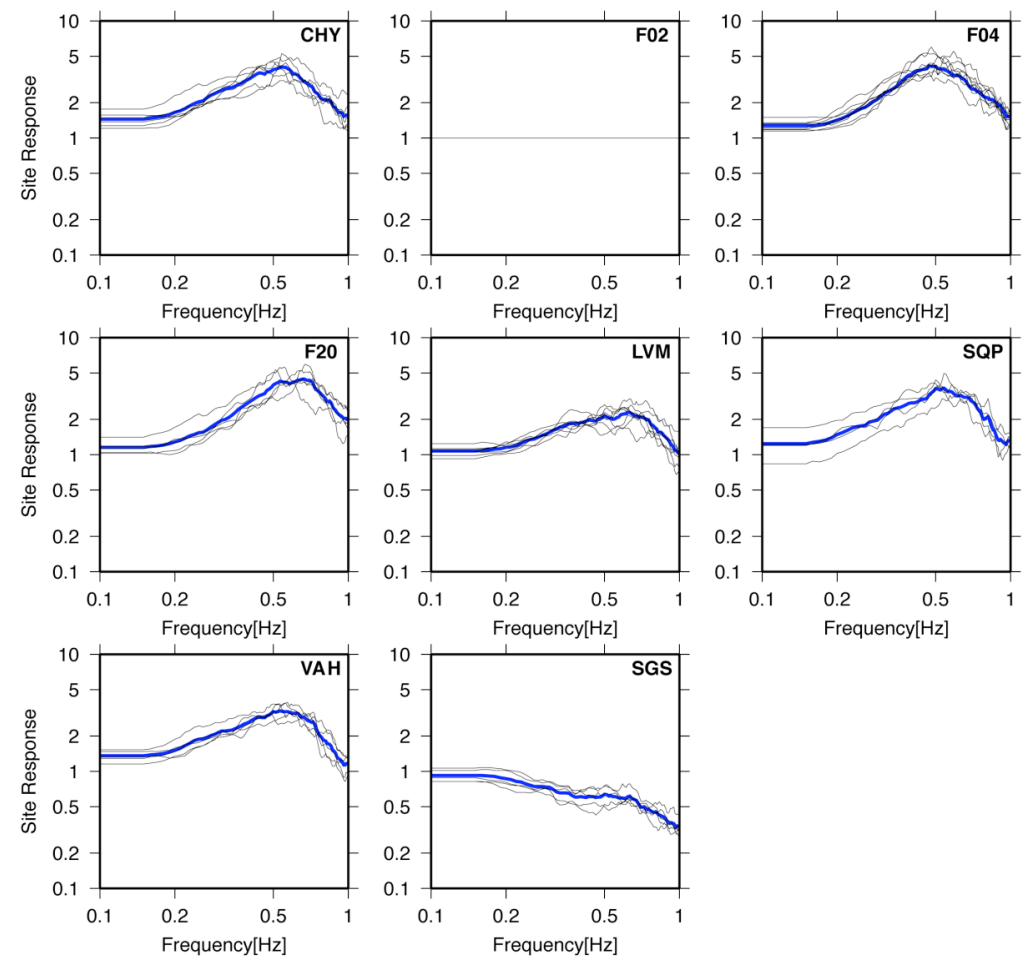

Figure 7.6. Site response from large teleseismic horizontal component S-waves using F02 as a reference site. Individual site response curves are shown in thin gray lines and the average curves are shown as thick blue lines.

\subsection{Microtremor Site Response}

We applied the Nakamura (1989) microtremor approach to estimate site response. This method takes the spectral ratio of horizontal to vertical $(\mathrm{H} / \mathrm{V})$ component motions for ambient (noise) recordings. This method tends to identify the resonant frequency of the near surface sedimentary column, but the amplifications are typically lower than other techniques (e.g. Field and Jacob, 1995; Lachet et al., 1996; Bonilla et al., 1997; Riepl et al., 1998). Figure 7.7 shows the H/V spectral ratios for the LVVBB sites for a 24-hour period. Note that the peak frequency of the $\mathrm{H} / \mathrm{V}$ ratios are consistent across the 24-hour period for each station. 
Station SGS

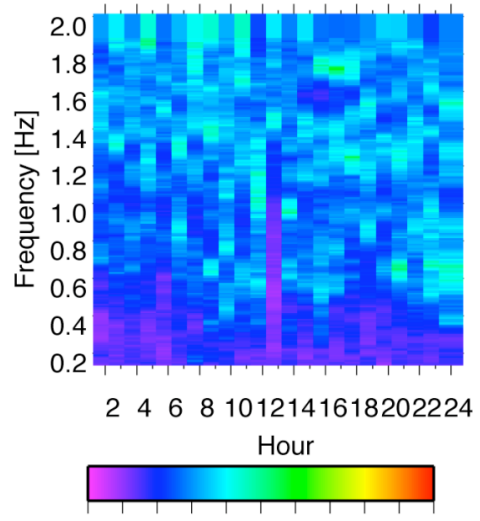

$\begin{array}{lllllllllll}0 & 1 & 2 & 3 & 4 & 5 & 6 & 7 & 8 & 9 & 10\end{array}$ $\mathrm{H} / \mathrm{V}$ ratio

\section{Station VAH}

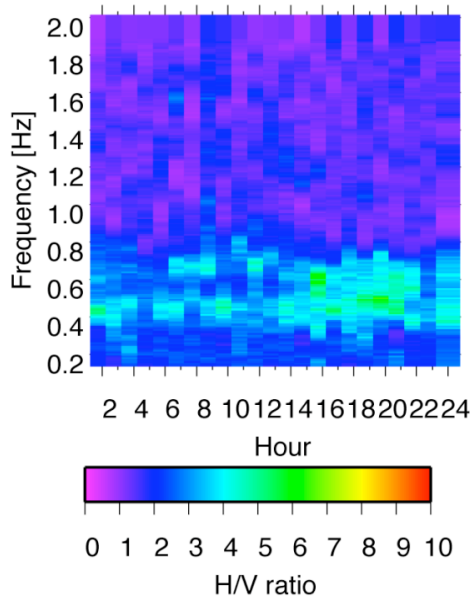

Station F02

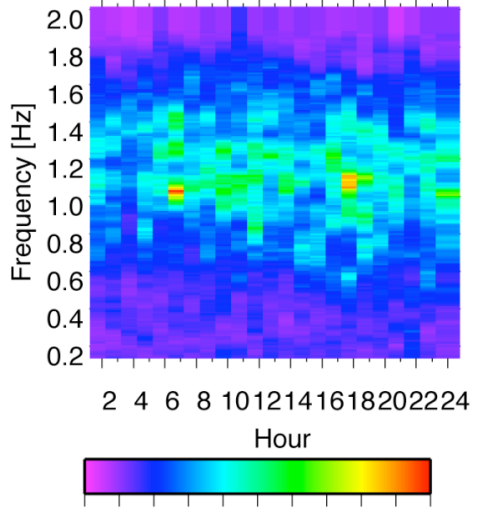

$\begin{array}{lllllllllll}0 & 1 & 2 & 3 & 4 & 5 & 6 & 7 & 8 & 9 & 10\end{array}$ $\mathrm{H} / \mathrm{N}$ ratio

Station F20

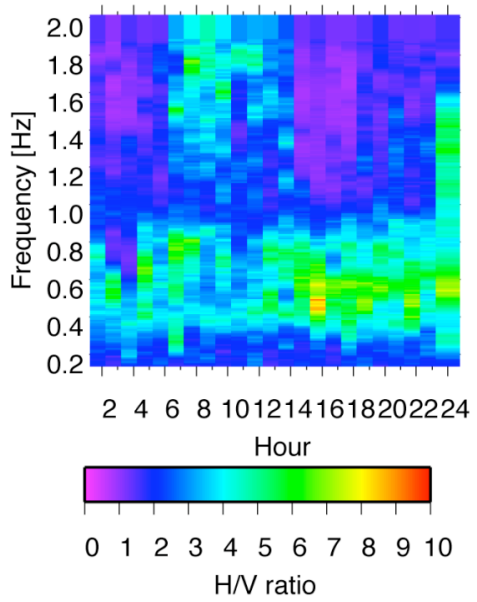

Station F04

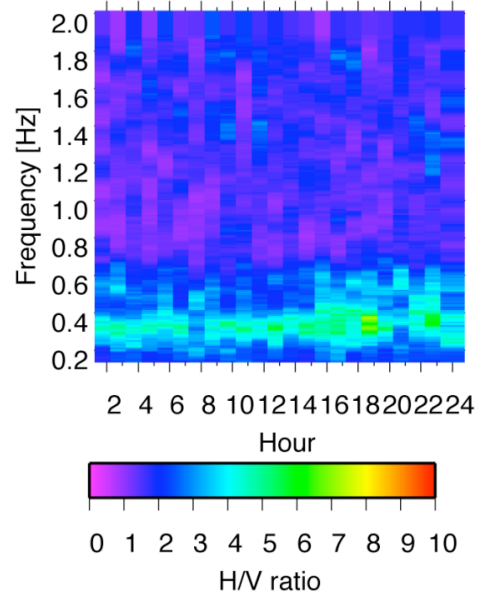

Station SQP

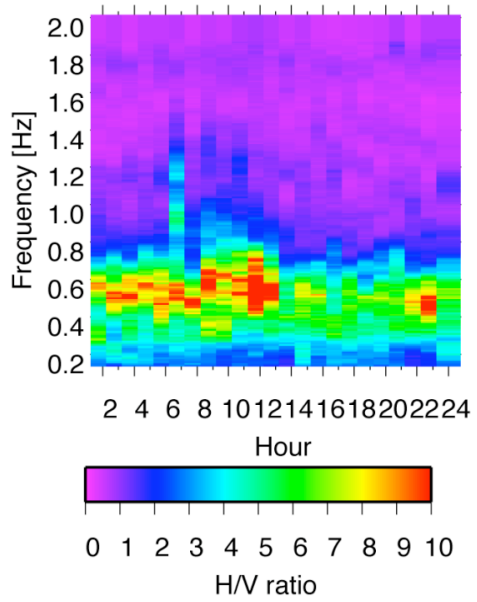

Figure 7.7. Microtremor $\mathrm{H} / \mathrm{V}$ spectral ratios for the LVVBB sites. These are plotted for a 24-hour period with the $\mathrm{H} / \mathrm{V}$ amplification color-coded and plotted as a function of frequency.

The frequency of peak amplification and the peak amplification value are plotted versus basin depth in Figure 7.8. These show that the peak frequency is inversely proportional to the basin depth, but the amplifications show no apparent trend with basin depth. The deeper portions of the basin have a resonant frequency of approximately $0.5 \mathrm{~Hz}$. Considering the resonant frequency, $\mathrm{f}_{0}$, of a layer of thickness $\mathrm{H}$ and shear velocity $\beta$, over a half space, $f_{0}=\beta / 4 \mathrm{H}$ and considering that the shear velocity of the shallow layers could be as low as $500 \mathrm{~m} / \mathrm{s}$, then the thickness of the resonating layer would be $250 \mathrm{~m}$. Thus the microtremor resonance results from shallow layers and not the overall 
sedimentary basin structure. In fact, the seismic refraction studies of Snelson et al (2004) indicate that the basin velocities increase to normal "hard rock" values (say, above 3.5 $\mathrm{km} / \mathrm{s}$ and $22.0 \mathrm{~km} / \mathrm{s}$ for compressional and shear velocities, respectively).

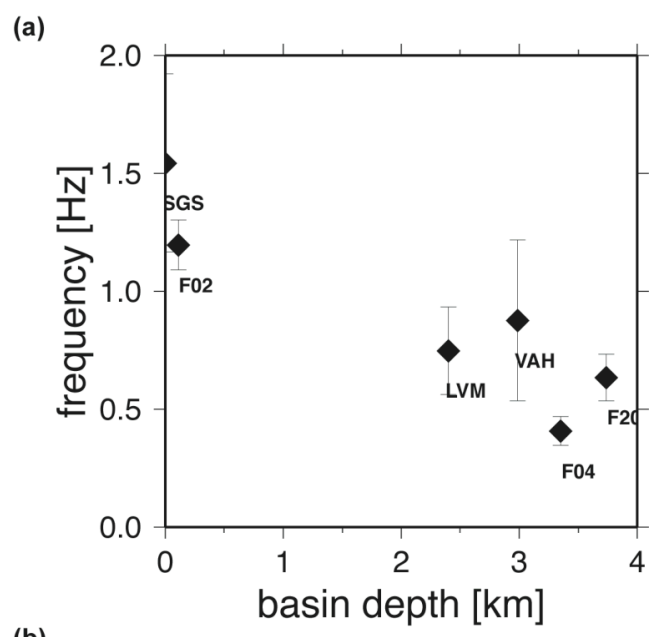

(b)

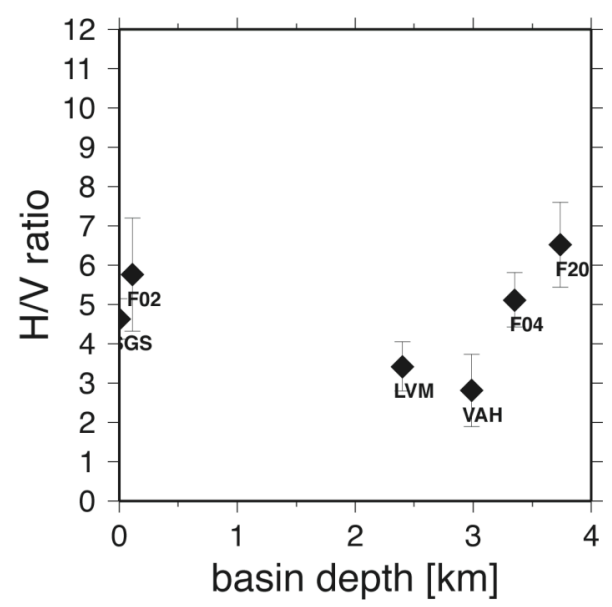

Figure 7.8. (a) Peak frequency and (b) amplification of microtremor $\mathrm{H} / \mathrm{V}$ spectral ratios versus basin depth (Langenheim et al., 2000) at LVVBB sites. 


\section{Summary of UNLV and UNR Sub-Contracts}

In a major component of our project, we collaborated closely with geophysicists, engineers and computer scientists at the University of Nevada, Las Vegas (UNLV) and the University of Nevada, Reno (UNR). These collaborations were supported by subcontracts starting approximately in the summer of 2002 and continuing through the summer of 2004. UNR has a contract for the Fiscal Year 2005. The objectives of these projects were to determine, assemble and integrate geophysical and geologic constraints of the sub-surface of Las Vegas Valley for understanding the physical features impacting amplification of seismic waves in Las Vegas as well as for full waveform modeling of the seismic response of the basin. Each project and investigator contributed a unique piece of the combined effort and worked closely with at least one other investigator. These efforts are briefly described below, providing summaries of the final reports submitted by the investigators in the Fall of 2004.

\subsection{Basin Structure - Prof. Snelson (UNLV)}

Langenheim et al. (2001a) estimated basin structure (depth to basin) from gravity and seismic reflection data. We wanted to investigate if this model was supported by other data as well as determine the velocity structure within the sedimentary structure of Las Vegas Basin. Under a sub-contract, Prof. Catherine Snelson performed a number of experiments and data analyses to address these issues (Snelson, 2004). These efforts involved basin-scale refraction experiments recording industrial (mining) explosions and controlled source explosions as well as analysis of legacy reflection data from oil and gas exploration in the basin. The results, described in detail in her report (Snelson 2004) provide a model of P-wave velocities in the basin as well as identify the major basin horizons.

8.2 Geotechnical Shear Wave Velocities - Prof. Luke (UNLV) and Prof. Louie (UNR) 
Shallow shear wave velocities are widely accepted to have a strong controlling influence on seismic ground motion (Anderson et al., 1996). Geotechincal studies typically concentrate on estimating the shear wave velocities of the upper 50-100 $\mathrm{m}$ of the surface. These studies are commonly performed for construction sites to determine vulnerability to earthquake ground motion amplification at a specific site. We were fortunate to work with two researcher teams employing different methods to estimate geotechnical shear velocity models for a large number of sets in Las Vegas. UNLV used a variety of methods for geotechnical characterization, including seismic surface waves, downhole and crosshole techniques (Luke and Liu, 2004). Refraction microtremor (ReMi) was developed at UNR (Louie, 2001; Louie et al., 2004). The UNLV effort includes investigations of numerical modeling of plane-layered structures to predict spectral acceleration with the algorithm SHAKE (Schnabel et al., 1972) and is described in report by Luke and Liu (2004). A joint UNLV-UNR study that combined the ReMi and SASW methods showed that the two methods are complimentary (Liu et al., 2004). The complete set of geotechinical seismic velocity profiles is archived by the UNLV and available online (over 70 measurements in total). All of these profiles are used to build three-dimensional geophysical models of Las Vegas Basin with the ModelAssembler software.

\subsection{Modeling Amplification by Geotechnical Layers - Prof. Sidharthanan}

A study comparing two widely used algorithms for computing the response of a horizontally polarized shear wave to a one-dimensional (plane-layered) seismic velocity profile was undertaken by Sidharthanan (2004). The two algorithms SHAKE (Schnabel et al., 1972) and DESRA (Yu et al., 1993; Ni et al., 1997) use slightly different approaches (frequency versus time domain, respectively) and handle the damping (anelastic) effects differently. This study showed that the results of SHAKE using reasonable assumptions yield conservative results for the seismic response at the surface of a soil column. The study supports the use of SHAKE for the conclusions reached by Luke and Liu (2004). 


\subsection{Geologic Modeling - Prof. Taylor (UNR)}

Characterization of subsurface lithology in Las Vegas Basin is important for providing geologic constraints on the seismic wave velocities from the geotechnical, seismic refraction and broadband studies. The effort by Taylor et al (2004) used over 1100 well logs in Las Vegas Valley to build a model of the subsurface. The lithologies fall into three categories: western, central/Las Vegas Wash and eastern. The lithologic records from well logs near geotechnical measurement sites were used establish correlations between lithology and shear wave velocities. It is well known that at the same depth, finer sediments have a lower seismic velocity than coarser sediments.

\subsection{ModelAssembler - Prof. Louie (UNR)}

One of the main objectives of the Las Vegas Valley Seismic Response Project was to develop a predictive capability of ground motion through first principles and simulation. The efforts described above to develop geophysical and geologic provide input into simulations of the ground motion response of Las Vegas Valley from seismic excitation. A computer software program was developed to assemble a geophysical model for simulations. The program, called ModelAssembler, takes a diverse set of inputs and uses a series of rules to build a model of the seismic velocities and density. The model is output into a format that can be directly read by the elastic finite difference code, $E 3 D$ (Larsen and Schultz, 1995).

\subsection{Two-Dimensional Sensitivity Tests}

A project to investigate seismic wave propagation in and around low-velocity basins and identify the characteristics that control ground motion amplification was undertaken by UNR and is described in a report by Pancha et al. (2004). The investigations employed two-dimensional elastic finite difference calculations using E3D (Larsen and Schultz, 1995). The 2D simulations allowed for frequencies slightly above $1 \mathrm{~Hz}$ and could be computed in a reasonable amount of time. The study found that a realistic crustal 
velocity, with velocity increasing with depth, is needed to correctly simulate basin effects. 


\section{References}

Ammon, C. J., G. E. Randall and G. Zandt, On the non-uniqueness of receiver function inversions, J. Geophys. Res., 95, 15303-15318, 1990.

Anderson, J., (2003). Strong motion seismology, in International Handbook of Earthquake and Engineering Seismology, Vol. 81B, International Association of Seismology and Physics of the Earth's Interior, 937-965.

Anderson, J., Y. Lee, Y. Zeng, and S. Day (1996). Control of strong motion by the upper 30 meters, Bull. Seism. Soc. Am., 86, 1749-1759.

Andrews, D. (1986). Objective determination of source parameters and similarity of earthquakes of differenr size, in Earthquake Source Mechanics, S. Das and C. Scholz (editors), American Geophysical Union, Washington D.C., 259-268.

Boatwright, J., J. Fletcher, and T. Fumal (1991). A general inversion scheme for source, site and propagation characteristics using multiple recorded sets of moderate-sized earthquakes, Bull. Seism. Soc. Am., 81, 1754-1782.

Bohannon, R. (1984). Nonmarine sedimentary rocks of Tertiary age in the Lake Mead region, southeastern Nevada and northwestern Arizona, U.S. Geological Survey Professional Paper 1259, 69 pp.

Bonilla, L., J.Steidl, G. Lindley, A. Tumarkin, and R. Archuleta (1997). Site amplification in the San Fernando Valley, California: Variability of site-effect estimation using the S-wave, coda and H/V methods, Bull. Seism. Soc. Am., 87, 710-730.

Boore, D. and W. Joyner (1997). Site amplification for generic rock sites. Bull. Seism. Soc. Am., 87, 327-341.

Borcherdt, R. (1970). Effects of local geology on ground motion near San Francisco Bay, Bull. Seism. Soc. Am., 60, 29-61.

Borcherdt, R., and J. Gibbs (1976). Effects of local geologic conditions in the region on ground motion and intensities of the 1906 earthquakes, Bull. Seism. Soc. Am., 66, 467500 .

Borcherdt, R. (1994). Estimates of site-dependent response spectra for design (methodology and justifcation), Earthquake Spectra, 10, 617-653.

Building Seismic Safety Council (BSSC) (1995). National Earthquake Hazard Reduction Program recommended provisions for seismic regulations for new buildings, 1994 edition, FEMA 222A/223A, developed for the Federal Emergency Management Agency, Washington, DC. 
Building Seismic Safety Council (BSSC) (1998). National Earthquake Hazard Reduction Program recommended provisions for seismic regulations for new buildings and other structures, 1997 Edition, FEMA 302/303, developed for the Federal Emergency Management Agency, Washington, DC.

Davis, L. and R. Lynch (1970). Seismic response characteristics at Las Vegas, Nevada, from underground nuclear detonations, NVO-1163-203, Environmental Research Corporation.

Dolenc D., D. Dreger, and S. Larsen, Basin Structure Influences on the Teleseismic Wave Propagation in the Santa Clara Valley, California, Bull. Seism. Soc. Am., in review.

Field, E., K. Jacob and S. Hough (1992). Earthquake site response estimation: a weak motion case study, Bull. Seism. Soc. Am., 82, 2283-2307.

Field, E. and K. Jacob (1995). A comparison and test of various site-response estimation techniques, including three that are not reference-site dependent, Bull. Seism. Soc. Am., $85,1127-1143$.

Field, E., and the SCEC Phase III Working Group (2000). Accounting for site effects in probabilistic seismic hazard analysis of Southern California: Overview of the SCEC Phase III Report, Bull. Seism. Soc. Am., 90, S1-S31.

Goldstein, P., D. Dodge, M. Firpo and L. Miner (2003). SAC2000: Signal processing and analysis tools for seismologists and engineers, in International Handbook of Earthquake and Engineering Seismology, Vol. 81B, International Association of Seismology and Physics of the Earth's Interior, 1613-1614.

Graves, R. (1996). Simulating Seismic Wave Propagation in 3D Elastic Media Using Staggered-Grid Finite Differences, Bull. Seism. Soc. Am., 86,

Harmsen, S. (1997). Determination of site amplification in the Los Angeles urban area from inversion of strong-motion records, Bull. Seism. Soc. Am., 87, 866-887.

Hartzell, S. (1992). Site response estimation from earthquake data, Bull. Seism. Soc. Am., 82, 2308-2327.

Kawase, H. (2003). Site effects on strong ground motion, in International Handbook of Earthquake and Engineering Seismology, Vol. 81B, International Association of Seismology and Physics of the Earth's Interior, 1013-1030.

Kennett, B. L. N., E. R. Engdahl \& R. Buland, Constraints on seismic velocities in the Earth from travel times, Geophys. J. Int., 122, 108-124, 1995.

King, J. and B. Tucker (1984). Observed variations of earthquake motion across a sediment-filled valley, Bull. Seism. Soc. Am., 74, 137-151. 
Kramer, S. (1996). Geotechnical earthquake engineering, Prentice Hall, Upper Saddle River, 653 p.

Lachet, C., D. Hatzfeld, P.-Y. Bard, N. Theodulidus, C. Papaioannuou and A. Savvaidis (1996). Site effects and microzonation in the city of Thessaloniki (Greece) comparison of different approaches, Bull. Seism. Soc. Am., 86, 1692-1703.

Langenheim, V., J. Grow, R. Jachens, G. Dixon, and J. Miller (2001a). Geophysical constraints on the location and geometry of the Las Vegas Valley Shear Zone, Nevada, Tectonics, 20, 189-209.

Langenheim, V., J. Grow, R. Jachens, G. Dixon, J. Miller, S. Lundstrom and W. Page (2001b). Basin configuration beneath Las Vegas Valley, Nevada: Implications for seismic hazard evaluation, Proceedings, $36^{\text {th }}$ annual Symposium on Engineering Geology and Geotechnical Engineering, 28-30 March, 2001, B. Luke, E. Jacobson and J. Werle eds., $755-764$.

Langston, C. (1979). Structure under Mount Rainer, Washington, inferred from teleseismic body waves, J. Geophys. Res., 84, 4749-4762.

Larsen, S. (2002). Las Vegas Basin Seismic Response Project: 3-D Finite-Difference Ground Motion Simulations, EOS trans. AGU, Fall Meet. Suppl., 83 (47), Abstract S12B-1188.

Larsen, S. and C. Schultz (1995). ELAS3D: 2D/3D elastic finite difference wave propagation code, Lawrence Livermore National Laboratory Report, UCRL-MA-121792.

Laske, G. and G. Masters, A global digital map of sediment Thickness, EOS Trans. AGU, 78, F483, 1997.

Lermo, J. and F. Chavez-Garcia (1993). Site effect evaluation using spectral ratios with only one station, Bull. Seism. Soc. Am., 83, 1574-1594.

Liggoria, J. and C. Ammon (1999). Iterative deconvolution and receiver function estimation, Bull. Seism. Soc. Am., 89, 1395-1400.

Liu, Y., and B. A. Luke (2004). Role of shallow soils in defining seismic response of a deep basin site subjected to high-energy explosive loading, Proceedings, 11th International Conference on Soil Dynamics and Earthquake Engineer and 3rd International Conference on Geotechnical Earthquake Engineering. University of California, Berkeley.

Liu, Y., Luke, B., Pullammanappallil, S., Louie, J., and Bay, J. (2005). Combining activeand passive-source measurements to profile shear wave velocities for seismic microzonation: accepted for the Geo-Frontiers 2005 Congress, Austin, Texas, Jan. 24-26. 
Louie, J. (2001). Faster, better: shear-wave velocity to 100 meters depth from refraction microtremor arrays: Bull. Seismol. Soc. Amer., 91, no. 2 (April), 347-364.

Louie, J. N., J. B. Scott, T. Rasmussen, W. Thelen, A. Pancha, M. Clark, H. Park,and C. T. Lopez (2004). Shallow shear-velocity transects of urban areas, and seismic-hazard mapping: presented at the Seismological Society of America Annual Meeting, Palm Springs, CA, April 14-16.

Luke, B., J, Louie, H. Beeston, V. Skidmore and A. Concha (2002). Las Vegas Seismic Response Project: Measured shallow soils velocities, EOS trans. AGU, Fall Meet. Suppl., 83 (47), Abstract S12B-1189.

Luke, B. and Y. Liu (2004). Las Vegas Seismic Response Project: Shallow sediment response, Final Report, University of Nevada Las Vegas

Martirosyan, A., U. Dutta, N. Biswas, A. Papageorgiou and R. Combellick (2003). Determination of site response in Anchorage, Alaska, on the basis of spectral ratio methods, Earthquake Spectra, 18, 85-104.

Mayeda, K., and W. Walter (1996). Moment, energy, stress drop and source spectra of western United States earthquakes form regional coda envelopes, J. Geophys. Res., 101, 11,195-11,208.

Murphy, J. and R. Hewlett (1975). Analysis of seismic response in the city of Las Vegas, Nevada: A preliminary microzonation, Bull. Seism. Soc. Am., 65, 1575-1597.

Nakamura, Y. (1989). A method for dynamic characteristics estimation of subsurface using microtremor on the ground surface, QR Railway Technical Research Institute, 30, 1 .

Ni, S.D., Siddharthan, R.V., and Anderson, J.G. (1997). "Characteristics of nonlinear response of deep saturated soil deposits," Bull. of the Seismological Soc. of America Vol. $87(2), 342-355$.

Olsen, K., R. Archuleta and J. Matarese (1995). Three-dimensional simulation of a magnitude 7.75 Earthquake on the San Andreas fault, Science, 270, 1628-1632.

Olsen, K. (2000). Site amplification in the Los Angeles Basin from three-dimensional model of ground motion, Bull. Seism. Soc. Am., 90, S77-S94.

Owens, T.J., G. Zandt and S.R. Taylor, Seismic evidence for an ancient rift beneath the Cumberland Plateau, Tennessee: A detailed analysis of broadband teleseismic $\mathrm{P}$ waveforms, J. Geophys. Res., 89, 7783-7795, 1984. 


\section{References}

Pancha, A., J. N. Louie and J. G. Anderson (2004). Las Vegas Basin 2D Sensitivity Tests: Response to explosive sources, University of Nevada Reno Report.

Patton, H. and S. Taylor (1984). Q structure of the Basin and Range from surface waves, J. Geophys. Res., 89, 6929-6940.

Phillips, W. S. and K. Aki (1986). Site amplification of coda waves from local earthquakes in central California, Bull. Seism. Soc. Am., 76, 627-648.

Riepl, J., P.-Y. Bard, D. Hartzfeld, C. Papaioannou and S. Nechschein (1998). Detailed evaluation of site-response estimation methods across and along the sedimentary valley of Volvi (EURO-SEISTEST), Bull. Seism. Soc. Am., 88, 488-502.

Rodgers, A., H. Tkalcic, D. McCallen, S. Larsen and C. Snelson (2004). Site response in Las Vegas Valley, Nevada from NTS explosions and earthquake data, submitted to Bull. Seism. Soc. Am.

Romanowicz, B., D. Dreger, M. Pasyanos and R. Uhrhammer (1993). Monitoring of strain release in central and northern California using broadband data, Geophys. Res. Lett., 20, 1643-1646.

Safak, E. (1997). Models and methods to characterize site amplification from a pair of records, Earthquake Spectra, 13, 97-129.

Schnabel., P.B., Lysmer, J., Seed. H.B. (1972). "SHAKE: A computer program for earthquake response analysis of horizontally layered sites," Report No. EERC 72-12 Earthquake Engineering Research Center, College of Engineering, University of California, Berkeley.

Scott, J., T. Rasmussen, B. Luke, W. Taylor, J. Wagoner, S. Smith and J. Louie (2005). Shallow shear velocity and seismic microzonation of the urban Las Vegas, Nevada basin, submitted to Bull. Seismo. Soc. Am. (Preprint at www.seismo.unr.edu/hazsurv)

Snelson, C. M., Sandru, J., McEwan, D. J., Hirsch, A., Zaragoza, S. A., Draa, A., Hanson, A. D., Kaip, G., Harder, S. H., Azevedo, S., McKibben, W., Rodgers, A., Lewis, J. P., Smith, D., Rock, D., and McCallen, D. (2003). Preliminary results from SILVVER '03 - Seismic Investigations of the Las Vegas Valley: Evaluating Risk, EOS Trans. AGU, 84(46), Fall Meet. Suppl., Abstract S11D-0325.

Snelson, C. M., D. J. McEwan, A. C. Hirsch, and S. A. Zaragoza, Imaging the Las Vegas Basin: Results From Recent Seismic Refractions Experiments, EOS Trans. AGU, 2004. 
Snelson, C. M. (2004). Las Vegas Valley Seismic Response Project: Controlled-source seismic refraction and broadband seismic experiments, Final Report for sub-contract B525097, University of Nevada Las Vegas.

Springer, D., G. Pawloski, J. Ricca, R. Roher and D. Smith (2002). Seismic source summary for all U.S. below-surface nuclear explosions, Bull. Seism. Soc. Am., 92, 18061840.

Steidl, J., A. Tumarkin and R. Archuleta (1996). What is a reference site?, Bull. Seism. Soc. Am., 86, 1733-1748.

Stidham, C., M. Antolik, D. Dreger, S. Larsen, and B. Romanowicz (1999). Threedimensional structure influences on the strong motion wavefield of the 1989 Loma Prieta Earthquake, Bull. Seism. Soc. Am., 89, 1184-1202.

Su, F., J. Anderson, S. Ni and Y. Zeng (1998). Effect of site amplification and basin response on strong motion in Las Vegas, Nevada, Earthquake Spectra, 14, 357-376.

Sweeney, J. and K. Mayeda (2004). Seismic determination of yield applied to the TTBT, Lawrence Livermore National Laboratory Technical Report, UCLR-TR-204591, Livermore, CA.

Tabor, L. (1982). Geology of the Las Vegas area, United States Department of Energy, Nevada Operations Office, Las Vegas, NV.

Taylor, W. J., B. Luke, C. Snelson, J. C. Evans, Y. Liu, J. Wagoner, A. Rodgers, D. McCallen and J. N. Louie (2004). Implications for ground shaking in Las Vegas basin, Nevada, based on relations among young faults, basin geometry, basin fill, and $\mathrm{V}_{\mathrm{s}}$,

Tkalcic, H., A. Rodgers, C. M. Snelson and D. McEwan, Comprehensive analysis of broadband seismic data in Las Vegas Valley, EOS Trans. AGU, 84(46), 2003.

Tucker, B., J. King, D. Hatzfeld and I. Nersesov (1984). Observations of hard-rock site effects, Bull. Seism. Soc. Am., 74, 121-136.

Wald, D., V. Quitoriano, T. Heaton and H. Kanamori (1999). Relationships between peak ground acceleration, peak ground velocity and Modified Mercalli Intensity in California, Earthquake Spectra, 15, 557-564.

Walter, W., K. Mayeda and H. Patton (1995). Phase and spectral ratio discrimination between NTS earthquakes and explosions. Part I: empirical observations, Bull. Seism. Soc. Am., 85, 1050-1067.

Wernicke, B., G. Axen and J. K. Snow (1988). Basin and Range extensional tectonics at the latitude of Las Vegas, Nevada, Geol. Soc. Am. Bull., 100, 1738-1757. 
Wessel, P. and W. H. Smith, Free software helps map and display data, EOS Trans. AGU, 72, 441, 1991.

Yu, G., Anderson, J., and Siddharthan, R.V. (1993). "On the characteristics of non-linear soil response," Bulletin of the Seismological Society of America, Vol. 83(1), Feb., 218244.

Yu, J., and J. Haines (2003). The choice of reference sites for seismic ground amplification analyses: Case study at Parkway, New Zealand, Bull. Seism. Soc. Am., 93, 713-723. 